LBL-10794

GSRMP-06

\title{
SIMULATION OF GEOTHERMAL SUBSIDENCE
}

I. Miller, W. Dershowitz, K. Jones, L. Myer, K. Roman, and M. Schauer Golder Associates, Inc.

Consulting Mining and Geotechnical Engineers

Kirkland. (Seattle), Washington 98033

March 1980

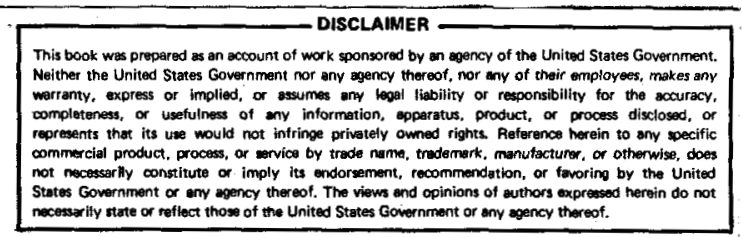

Prepared for Lawrence Berkeley Laboratory under LBL Purchase Order No. 3730302 and includes results of research done between June 1978 and March 1980, pursuant to the LBL contract with the U. S. Department of Energy, Division of Geothermal Energy for Geothermal Subsidence Research. 


\section{DISCLAIMER}

This report was prepared as an account of work sponsored by an agency of the United States Government. Neither the United States Government nor any agency Thereof, nor any of their employees, makes any warranty, express or implied, or assumes any legal liability or responsibility for the accuracy, completeness, or usefulness of any information, apparatus, product, or process disclosed, or represents that its use would not infringe privately owned rights. Reference herein to any specific commercial product, process, or service by trade name, trademark, manufacturer, or otherwise does not necessarily constitute or imply its endorsement, recommendation, or favoring by the United States Government or any agency thereof. The views and opinions of authors expressed herein do not necessarily state or reflect those of the United States Government or any agency thereof. 


\section{DISCLAIMER}

Portions of this document may be illegible in electronic image products. Images are produced from the best available original document. 







The authors have prepared three companion reports which present detalled results of this Investigation.

Report No. $\underline{\text { Title }}$

1 Physical Processes of Compaction (LBID 182)

2. Detailed Report on Tested Models (LBID 183)

3 Case Study Data Base (LBID 184)

An additional report on the subject of reservolr models was generated as part of the project. The report was produced in 1979 by Dr. George F. PInder under subcontract to Golder Assoclates and is titled "State-of-the-Art Review of Geothermal Reservoir Modelling" (LBL 9093).

Further information on Dr. Pinder's report and on the three companion reports is included in the bibllography.

\section{ACKNOWLEDGMENTS}

This report was prepared by Golder Associates, Kirkland (Seattle), Washington, under Lawrence Berkeley Laboratory (LBL) Purchase Order No. 3730302 and includes results of research done between June 1978 and March 1980. The subject research is pursuant to the LBL contract with the U. S. Department of Energy, Division of Geothermal Energy, for Geothermal Subsidence Research. It was administered under the technical direction of T. Simkin, J. Noble, and W. Schwarz of LBL. Mr. H. A. Todd was the contract administrator for LBL. 
The Lawrence Berkeley Laboratory of the University of California is conducting an ongoing research program almed at Improved understanding and control of ground movements caused by geothermal power production. As part of this research program, Golder Associates, acting under subcontract to the University, performed an assessment of existing mathematical models for subsidence simulation and prediction. This report summarizes the results of that study. 



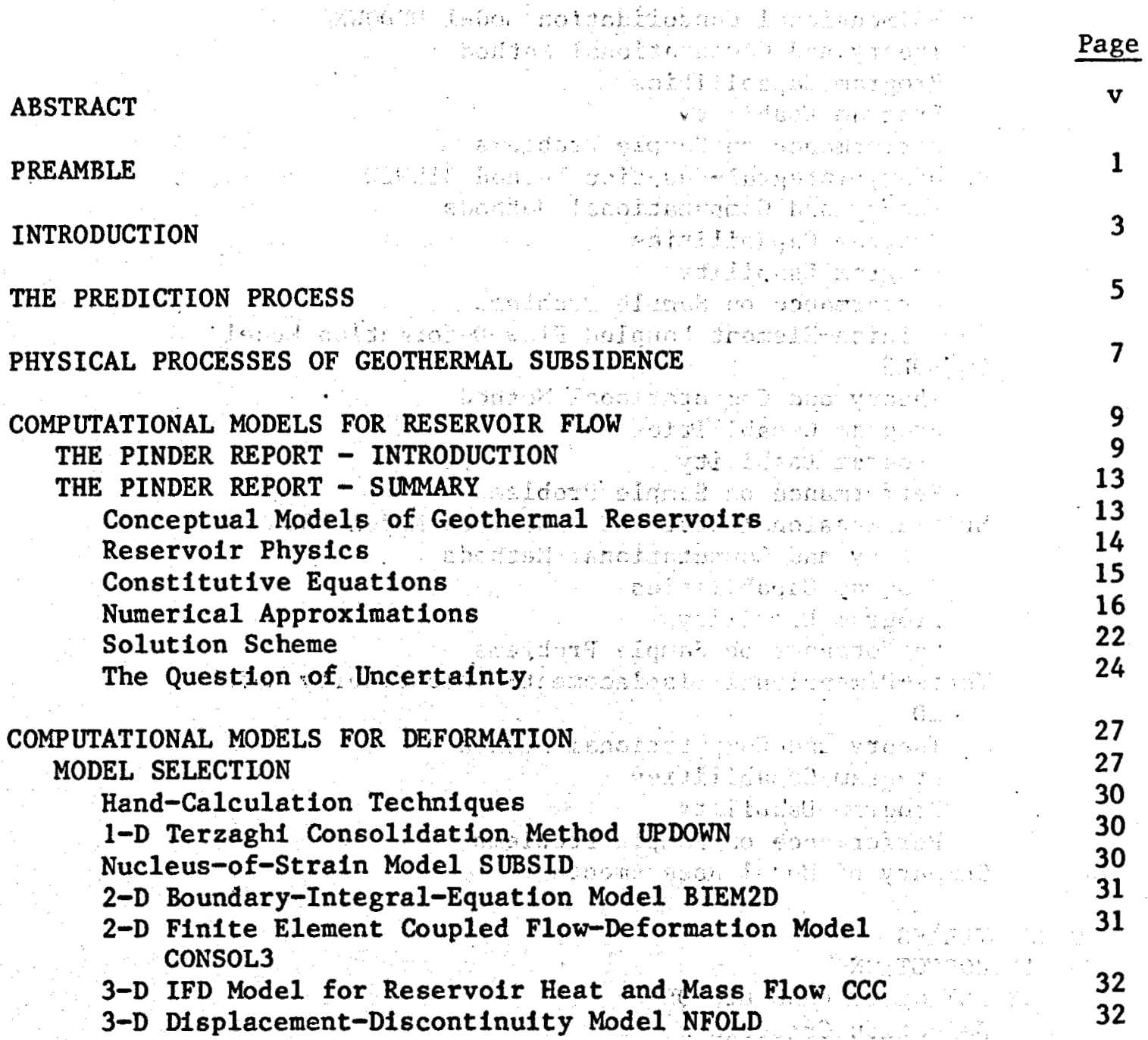

PROFICIENCY ASSESSMENT $\quad 33$

INTRODUCTION

SAMPLE PROBLEM DESCRIPTIONS $\quad 33$

MODEL ASSESSMENTS 42

Hand-Calculation Methods $\quad 42$

Theory and Computational Method 42

Capabilities $\quad 42$

Usability $\quad 44$

Performance on Sample Problems 44

Nucleus-of-Strain Model SUBSID , , 44

Theory and Computational Methods 44

Program Capabllities $\quad 45$

Program Usability $\quad 45$

Performance on Sample Problems $\quad 45$ 
$\begin{array}{lr} & \text { Page } \\ \text { One-Dimensional Consolidation Model UPDOWN } & 46 \\ \text { Theory and Computational Method } & 46 \\ \text { Program Capabilities } & 46 \\ \text { Program Usability } & 47 \\ \text { Performance on Sample Problems } & 47 \\ \text { Boundary-Integral-Equation Method BIEM2D } & 48 \\ \text { Theory and Computational Methods } & 48 \\ \text { Program Capabilities } & 48 \\ \text { Program Usability } & 48 \\ \text { Performance on Sample Problems } & 49 \\ \text { 2-D Finite-Element Coupled Flow-Deformation Model } & 49 \\ \text { CoNSol3 } & 49 \\ \text { Theory and Computational Methods } & 50 \\ \text { Program Capabilities } & 50 \\ \text { Program Usability } & 50 \\ \text { Performance on Sample Problems } & 50 \\ \text { Multidimensional Heat and Mass Flow Model CCC } & 50 \\ \text { Theory and Computational Methods } & 51 \\ \text { Program Capabilities } & 52 \\ \text { Program Usability } & 52 \\ \text { Performance on Sample Problems } & 53 \\ \text { Three-Dimensional Displacement-Discontinuity Model } & \end{array}$ NFOLD

Theory and Computational Method 53

Program Capabilities $\quad 53$

Program Usability $\quad 54$

Performance on Sample Problems $\quad 55$

Summary of Model Assessments $\quad 55$

CASE STUDIES $\quad 57$

INTRODUCTION $\quad 57$

SELECTION OF CASE HISTORY $\quad 57$

Selection Criteria $\quad 58$

Similarity of Environment $\quad 58$

Data Availability $\quad 58$

Diversity of Environment $\quad 59$

Discussion of Selected Sites 61

REAL-CASE STUDIES $\quad 67$

INTRODUCTION $\because \cdots 67$

THE GEYSERS $\quad{ }^{6} 68$

Brief Site Description _. 68

Models Used in Simulation $\quad 69$

Development of Required Information 70

Pressure Changes $\quad 70$

Temperature Changes $\quad 71$ 
Resume of Mode1s $\quad \ldots \quad 77$

Hand Calculations $\quad \cdots \quad 77$

Two-Dimensional Boundary Integral Equation 78 Mode1 BIEM2D

Three-Dimensional Nucleus-of-Strain Model SUBSID 78

The Geysers Summary $\quad \mathbf{8 0}$

WAIRAKEI $\quad 80$

Brief Site Description $\quad \cdots \quad 80$

Models Used In Simulation $\quad$. 84

Resume of Model Simulations $\quad 85$

One-Dimensional Hand Calculations $\quad 85$

Two-Dimensional CONSOL3 Finite-Element Model 89

Three-Dimensional Nucleus-of-Strain Model SUBSID . 91

Wairakel Summary $\quad \cdot \quad 92$

DISCUSSION OF REAL-CASE STUDIES

Accuracy of Model Predictions 96

Relationship Between Real Case and Choice of Model 96

Model and Real-Case Dimensionality 97

Model Information Requirements and Avallable 97

Information

Model Constitutive Relations and Behavior 97

Information Requirements of Model 1ng Approaches 98

Applicabllity. of Model Assumptions 99

$\begin{array}{ll}\text { IDEALIZED-CASE STUDY } & 101\end{array}$

INTRODUCTION $\quad 101$

AUSTIN BAYOU PROSPECT $\quad 101$

Brief Site Description $\quad 101$

$\begin{array}{ll}\text { Conceptual Model } & 102\end{array}$

$\begin{array}{ll}\text { Investigation Plan } & 107\end{array}$

Resume of Model Simulations 108

Hand Calculations 108

CCC, NFOLD, BIEM2D $\quad 109$

CONSOL3 112

DISCUSSION OF IDEALIZED-CASE STUDY $\quad 115$

Flow Modeling $\quad 115$

Flow-Deformation Coupling 119

Constitutive Relationships $\quad 121$

$\begin{array}{ll}\text { Dimensionality } & 121\end{array}$

Modeling Portions of a System 126

Faults 130

Elastic Parameter Study $\quad 132$

Reinjection of Geothermal Fluid Wastes ， 135

CASE STUDY - CONCLUSIONS 142 
REVIEW AND RECOMMENDATIONS

OVERALL SUBSIDENCE PREDICTION PROCESS

Page

RECOMMENDATIONS :

Overa11 Approach

Reservolr Flow Models

Deformation Models

145

145

147

147

148

149

REFERENCES

155 


\section{LIST OF TABLES}

Table

Title

Page

1a Comparison of the Mult1phase D1stributed-Parameter Geothermal Reservoir Models

$1 \mathrm{~b}$ Nomenclature for Table la

Dimensionality of Models

Material Properties for Sample Problems

Sample Problem Summary

Results of Proficiency Assessment

Desired Data for Case-History Studies

Data Avallability for Case-History Candidate Sites

Austin Bayou Case Study - Overburden Material

Properties

Austin Bayou Case Study - Reservolr Sandstone and Shale Material Properties 


\section{LIST OF FIGURES}

Geothermal Subsidence Prediction Process

Reservolr Models: Sources of Uncertainty

Sample Problem 1, Infinite Confined Reservoir

Sample Problem 2, Infinite Leaky Reservoir

Sample Problem 3, Finite Confined Reservoir

Sample Problem 4, Finite Leaky Reservoir

Sample Problem 5, Thick Finite Confined Reservoir

Sample Problem 6, Fintte-Confined, Wedge-Shaped Reservoir

The Geysers Case Study - Steam Pressures in Deep

The Geysers Case Study - Assumed 1-D Pressure Profile

The Geysers Case Study - Simplifled Plan of

Pressure Contours

The Geysers Case Study - Assumed 2-D Pressure Profile

The Geysers Case Study - Hand Calculation Model Using 12 Discs

The Geysers Case Study - Nucleus-of-Strain Model Using Two Spheres

The Geysers Case Study - Nucleus-of-Strain Model Using 72 Spheres

The Geysers Case Study - Observed and Predicted Subsidence Profiles

Wairake1 Case Study - Plan of Geothermal Field

Wairake1 Case Study - Cross Section of Geothermal Field

Wairakel Case Study - 1-D Model Assumed PressureTemperature Change

Walrakel Case Study - Cross Section Used in 2-D Finite-Element Model

Wairakel Case Study - Plan of Grid for Nucleus-ofStrain Model

Wairakei Case Study - Observed and Predicted Subsidence Contours Section Parallel to Boundary Faults Showing Geology at Depth of 15,045 Feet 
Austin Bayou Case Study, Subsidence Contour From

Hand Calculations and NFOLD

Bayou Reservolr in One, Two, and Three Dimensions Reservoir Interval With "Limited" Model Interval Shown by Dashed Line in Aquifer with Distance from Well (Axisymetric Case)

Austin Bayou Case Study, One-Dimensional Flow in Aquitard due to Rapld Equalization of Pore Pressures in Sandstone

Austin Bayou Case Study, Surface Displacement Predicted by BIEM2D

Austin Bayour Case Study, Pore Pressure Proflle for CCC Models of Various Portions of Austin Bayou System at 1000 Weeks

Austin Bayou Case Study, Pore Pressure Change With Time, CCC Models of Various Portions of Austin. Bayou System at 1000 Weeks, Center of Sand Nearest Edge Geothermal Production and Compaction from CCC and Hand Calculations CCC at 1000 Weeks, Axisymmetric and 3-D Geometries Austin Bayou Case Study, DDJ2D Two-Dimensional Displacement-Discontinuity Model for Austin Bayou Subsidence Obtalned by CONSOL3 with Different Values of Elastic Parameters, Constant $G / K=0.75$ 
xiv

Figure

Title

Page

45

Austin Bayou Case Study, Reinjection Schemes

138

for Control of Geothermal Subsidence

46

Austin Bayou Case Study, Nonlinear, Inelastic

140

Stress Curves for Reinjection Into Shallow

Layers

47

Austin Bayou Case Study, Reinjection Into

141

48 Production Layer

143

49

Austin Bayou Case Study, Reinjection Into Layers Surrounding Production Layer

Contributions to Uncertainty of Geothermal

146

Subsidence Predictions 
PREAMBLE

It is possible for substantial movements to be caused by the extraction of geothermal fluids for power production. These movements can have adverse environmental impacts in a number of ways, Including damaging surface structures, reversing natural dralnage directions, compromising irrigation channels, inducing fault movement, flooding lowlying areas, and damaging subterraneous structures and we1ls. Thus, it is important that acceptable methods of predicting subsidence and its impact be avallable to assist both energy developers and the public in planning geothermal developments.

This report presents an assessment of methods for predicting geothermal subsidence. The toplc is not new and has been addressed in two fairly recent studies.

- THE ANALYSIS OF SUBSIDENCE ASSOCIATED WITH GEOTHERMAL DEVELOPMENT, Vols. 1-3, by R. W. Atherton et al., Systems Control, Inc. (1801 Page M1ll Road, Palo Alto, Cal1f.), September 1976.

- EVALUATION OF GEOTHERMAL ENERGY EXPLORATION AND RESOURCE ASSESSMENT - FINAL REPORT, Vo1. 1: A Review of Geothermal Subsidence Modeling, by M. K. Grover et al., R \& D Assoclates (P.0. Box 9695, Marina De1 Rey, Cal1f.).

It is not the intention of this report to duplicate the work of the above studies. We would recommend that the reader who is not already familiar in general terms with geothermics and geomechanics review the above reports, which provide an Introduction and a broad perspective. This report is to some extent a specialist's report. Its purpose is to compare the usefulness of different numerical models and to make recommendations for developing new or improved ones. 
This report addresses a series of aspects of the geothermal subsidence prediction process.

- The nature of the subsidence prediction process

- The physical processes which are involved in subsidence

- Computational models for reservolr flow

- Computational models for deformation

- Case histories of subsidence

As noted on the first page of this report, a number of companion reports have been prepared which present in detail different aspects of the work summarized herein. By and large, these reports will not be of interest to the casual reader. Readers interested in actual1y using one of the subsidence models reviewed herein may want to read the detalled report on those models, and readers interested in reservoir modeling will want to read the Pinder (1979) report. (See "Computational Models for Reservolr Flow" in this report for a summary of the Pinder report.) 


\section{INTRODUCTION}

The objective of this research is to assess the adequacy of existing mathematical models for estimating land subsidence and lateral ground deformation. The most obvious approach is to simply apply a number of models to known field situations (case historles) and see how successfully they predict the known responses. However, such an approach might not expose the true strengths and weaknesses of the ind $1-$ vidual models or of models as a whole.

Due to the complex nature of the systems (geological, thermal, mechanical, fluid flow, etc.) Involved in geothermal subsidence, it is not possible to define a site which is representative of all other sites; each site has unique features. Thus, the fact that a given mathematical model does or does not accurately simulate the observed response of a specific site says little about the model's true capabliltles; a good match may simply be fortultous, and the model might perform poorly at the next site.

On the other hand, a bad simulation might be merely due to bad data. It is problematic whether, even with a full exploration program, it is possible to fully delineate a particular geothermal subsidence system. Thus, the amount of data avallable in any case history will probably be only a fraction of what is needed to fully define the system. It is quite unreasonable to test a mathematical subsidence model on such a case. The uncertainties in the system could entirely obscure the capabilities of the model.

The alternative approach of modeling a purely hypothetlcal system would obviate the above difficulties, since the system would be completely understood. The drawback is that such analyses would not enable us to assess the validity of our fundamental theorles. For Instance, successfully predicting the response of a hypothetical linear 
poroelastic half-space would not mean that real systems will always behave as linear poroelastic half-spaces.

In order to avold these problems with case histories, the research program divided the problem into two component parts.

- The first component assessed the individual attributes of particular mathematical models in their own right (i.e., does the model do what it is supposed to do and how well does it do 1t?).

- The second component determined, through studies of both real and hypothetical subsidence case histories, the significance of different mathematical model attributes. (For instance, when could a model which did not couple flows with deformations perform as well as a coupled model? When was an elastic material model Inadequate? Was the use of sophisticated models a waste of time due to the unavalability of suitable input data?) 
THE PREDICTION PROCESS

It is not appropriate to attempt to assess the utility of a computational model for geothermal subsidence prediction without considering the place of the model within the overall prediction process.

- The geothermal subsidence prediction process is a logical chain, whereby a physical system is successively represented by fleld data, a conceptual model, and a computational model. There is no sense in using an overly sophisticated computational model to simulate the behavior of an incompletely understood physical system. On the other hand, when good data are avallable, the computational model should be capable of doing them justice.

Figure I presents diagrammatically the structure of the prediction process and points out the sources of error in each stage. One of the purposes of the present report is, by reviewing and modeling actual case studies, to assess the magnitude of these errors and thus to attempt to establish an appropriate degree of model sophistication. 


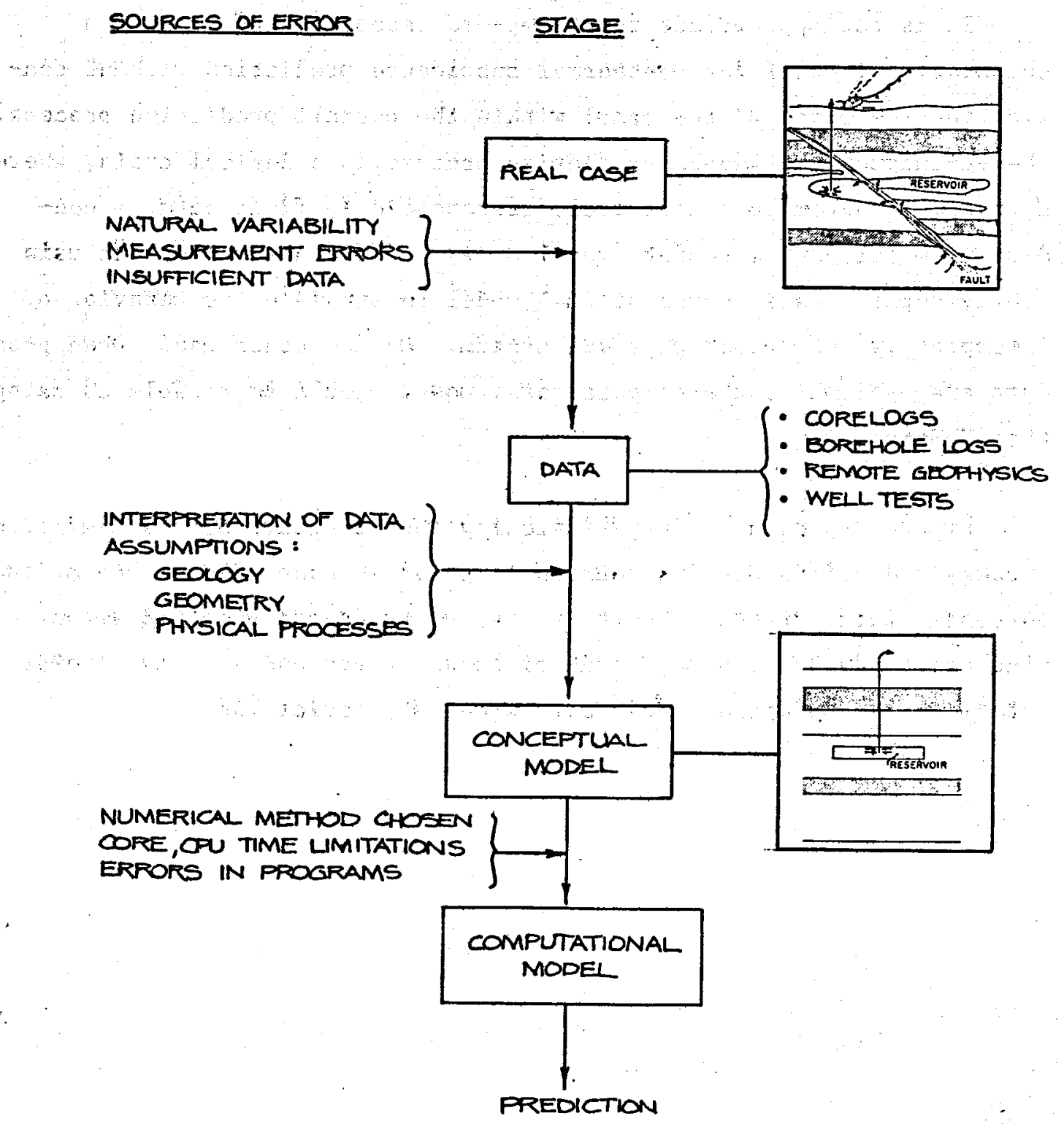

FIGURE 1

GEOTHERMAL SUBSIDENCE PREDICTION PROCESS 


\section{PHYSICAL PROCESSES OF GEOTHERMAL SUBSIDENCE}

A large number of different physical processes. can be involved in geothermal subsidence. They include all the processes occurring in multiphase fluld and heat flow plus the processes of deformation. A review of the physical processes involved can be found in Atherton et al. (1976, Vol. II).

From the point of view of subsidence modelers, the processes are much simpler. Large numbers of physical processes are lumped together and described by phenomenological parameters such as "permeabllity," "compaction coefficlent," and "plastic yleld surface." The variables that are usually treated are relatively few, comprising:

- Fluid pressure and composition

- Fluid flow

- Temperature

- Stress

- Deformation

- Time.

These varlables are described and interrelated by equations which elther express balance or conservation principles (e.g., conservation of mass) or else define phenomenological relations (e.g., stress-strain relationships). It is these latter relations that describe the physical processes of subsidence as they relate to the modeler.

Subsidence modeling is usually the domain of two different types of speclalist: reservoir flow modelers (who may be more interested in the production of the reservolr than in Its deformation) and deformation modelers. The reservoir flow modelers generally consider the relationships between the following variables: 
- Fluid pressure and composition

- Fluid flow

- Temperature

- Time.

Stress and deformation are of secondary interest to the reservoir modelers.

The reservolr modeler's output (fluid pressure and composition; temperature) is the deformation modeler's input. The deformation modeler then predicts stresses and deformations as a function of time. The physical processes considered by the deformation modeler relate temperature, fluid pressure, stress, strain, and time. They are reviewed in Companion Report 1 (Miller et al. 1980a). 
COMPUTATIONAL MODELS FOR RESERVOIR FLOW

\section{INTRODUCTION}

The deformations which cause subsidence are due to changes in reservoir temperature and fluid pressure and, as a result, it is not possible to model subsidence without modeling the reservolr. on the other hand, it is usually possible to adequately model the reservolr without considering deformations (by assuming that the total vertical stress at any point is constant, or even that the reservoir is rigid). Thus, it is common practice to first model the reservolr of a system and then use the computed pressure and temperature drops as input to a deformation model. This division is not made because of a lack of adequate theory to simulate a fully-coupled system, but rather it is made in order to render the numerical solution practical. A fullycoupled, multidimensional model is almost beyond the capabilities of today's computers; even when separated, the Individual reservoir and deformation models can be enormously expensive.

The state-of-the-art of geothermal reservoir flow modeling is not a sultable toptc for nonexperts, and accordingly Golder Associates retained Dr. George Pinder (1979) of Princeton University to prepare a critical review of existing reservoir models. This section is essentlally an abstraction of the Introduction and sumary of Dr. Pinder's report.

\section{THE PINDER REPORT - INTRODUCTION}

The objective of Pinder's (1979) report is to summarize and, to the degree possible, evaluate the state of the art in geothermal reservoir modeling - As used in the report, the term "geothermal reservolr model" refers to the representation of the dynamics and thermodynamics of a geothermal reservofr, without skeletal deformation, using the concepts 
of porous flow physics and the subsequent solution of the resulting assemblage of differential and partial differential equations. Only those models which have been developed exclusively for geothermal simulation are considered within the scope of the report. Thus, models prepared for the simulation of steam-injection processes in o11 recovery (e.g., Coats 1974; Weinstein et al. 1974) were excluded from the report. Two- and three-dimensional distributed-parameter models were primarily considered. It should be pointed out, however, that considerable success has been achieved in predicting the performance of the Wairakel geothermal fleld using zero dimensional or lumped parameter formulations (e.g., Whiting and Ramey 1969; Brigham and Morrow 1974).

There are several distinct but interrelated elements of geothermal reservoir modeling. The most fundamental element is the conceptual model of the reservolr. While fleld data are relatively scarce and, at least in part, are not freely avallable to the sclentific community, there is nevertheless a general concensus of oplnion on the fundamental aspects of the reservolr. It is belleved, and in some reservofrs clearly demonstrated, that the primary condults of energy transport are fractures. The porous medium blocks, delineated by these fractures, act as the long-term energy suppliers feeding the fracture system.

Geothermal reservolrs can be classified on the basis of their fluid composition. The most common type of field is characterized by reservoir fluid which is predominantly water. This type of fleld, often referred to as a hot-water system, is found at Wairakei, New Zealand, Cerro Prieto, Mexico, and many other locatlons around the world. Reservoirs which primarily produce steam are called "vapor-dominated." The major reservolrs of this class are found at The Geysers in California, at Lardere11o in Italy, and at the Matsukawa fleld in Japan. Hot-water systems characteristically produce from 70 to 90 percent of their total mass as water at the surface, while vapor-dominated systems produce dry to superheated steam (Toronyi and Farouq-Al1 1977). The pressures of 
vapor-dominated systems are below hydrostatic. Moreover, the initial temperatures and pressures are very near those corresponding to the maximum enthalpy of saturated steam: $236^{\circ} \mathrm{C}$ and $31.8 \mathrm{~kg} / \mathrm{sq} \mathrm{cm}$. The regional distribution of fluids within a reservoir is essentially unknown.

The assumptions inherent in the conceptual model of the reservolr should dictate the framework of its mathematical description. In the case of geothermal reservolrs, however, the physical and mathematical foundations for multiphase mass-and-energy transport through fractured porous media do not exist. Consequent1y, all of the existing multiphase models assume the reservolr to be a porous medium. When fractures are Included, they are highly Idealized geometrically and, al though the parameter values may differ (Coats 1977), they employ the same governing equations as the porous medlum. Fractured reservolr mass-and-energy transport has been considered in a formal way for hot-water systems (0'Ne111 1977), but this has not yet been extended to a steam-water reservolr.

Given the theoretical constraint clted above, the governing flow and transport equations for geothermal reservolr simulation are obtalned through one of three ways.

- The simplest approach is essentially a macroscopic mass balance. In other words, one assumes that the balance laws observed at the microscoplc level are, with minor modification, valid for the porous medium as well. This approach does not provide insight into the microphysics of energy transfer at the pore level, but does provide a set of governing equations not unlike those obtalned using more sophisticated techniques.

- A second approach Involves the use of mixture theory as developed in continum mechanics. This approach is more 
rigorous but, while recognizing the existence of pore-level interaction, it does not provide adequate insight into the nature of this interaction.

- The most promising approach is through formal integration of the microscopic balance equations over the porous medium, possibly augmented through constitutive theory.

Having generated an appropriate set of governing equations, one is faced with the task of solving a set of highly nonlinear, partialdifferential equations. In nearly all cases, this is approached numerically. There are several difficulties encountered in the numerical solution of the geothermal reservoir equations. The first task is to select a set of dependent variables, since several possibilities exist. One must then decide upon a method of approximation. Current1y, finite-difference and finite-element schemes are employed. one is now confronted with the problems assoclated with the simulation of convection-dominated transport: numerical dispersion (oscillations) and diffusion (smearing of a sharp front). Possibly the most difficult task-the efficient and accurate treatment of the highly nonlinear coefficlents-still remains, however. Virtually every geothermal model handles this problem differently.

From the reservoir engineering point of view, there are two additional factors to consider. The fleld application of a geothermal code requires a proper representation of the well-bore dynamics. This is particularly important in the case of simulations in the immediate vicinity of the well. A second practical problem involves the reduction of the general three-dimensional system to an areal two-dimensional representation. This requires formal integration over the vertical. This integration should be carried out carefully so that essential elements of the reservoir physics are salvaged. 
THE PINDER REPORT - SUMMARY

Conceptual Models of Geothermal Reservolrs

Geothermal. reservoirs are difficult to catalogue physically. They are relatively scarce and tend to be unique in their respective settings. Moreover, they are difficult to instrument because of the adverse nature of the geothermal environment. Fortunately, a few fields are monitored, particularly those at Wairakei in New Zealand, The Geysers in California, Larderello in Italy, and, more recently, Cerro Prieto in Mexico. With the exception of The Geysers, these installations are publicly administered; thus, the field data are generally antritite available.

While there is still a great deal to learn about geothermal reservoirs, a knowledge of the physics of the system 1s gradually emerging. Interaction between mathematical modelers and reservolr engineers has shed light on many aspects of the problem. By and large, this information tends to corroborate concepts formulated by earlier scientists and engineers working in the field. Nevertheless, fundamental questions remain. At the megascopic level, there is still speculation on the role of recharge in the overall system and the source of energy at depth is incompletely understood. At the macroscoplc scale, the role of fractures in mass and energy transport is not well understood and the interaction between fractures and porous blocks is virtually unknown.

The conceptual model of the reservolr is particularly important in fabricating the initial and boundary conditions on the system and the source terms. In the short term, the flux terms are probably of the greatest concern. As the pressure decilne approaches the boundarles of the reservolr, boundary conditions obviously begln to play an important role. Fortunately, or perhaps unfortunately in the case of newly 
developed fields, long-term records in conjunction with geohydrologic information can provide important insight into boundary type and locations. To achieve reliable forecasts of productivity in an undeveloped geothermal reservoir, new or improved geophysical techniques for the definition of reservoir geometry and properties will be required.

\section{Reservolr Physics}

Reservoir physics are those physical phenomena that involve the transport of energy, mass, and momentum within a geothermal reservoir. The mathematical realization of these phenomena gives rise to the governing equations of the reservoir simulator. Until very recently, the procedure for establishing these equations was based on analogy, with point equations derived using the concepts of continuum mechanics. In the case of porous media, this approach was extended using mixture theory. Another methodology which appears to be gaining favor is based on the concepts of mass and volume averaging. This approach appears to provide enhanced physical insight into the interaction between the various phases encountered in the reservoir. Pinder believes that a rigorous development of the equations governing multiphase mass and energy transport in a porous medium reservolr is possible. The next challenge will be to establish techniques for measuring, the parameters arising in these new and more comprehensive equations. While these developments will provide a better understanding of the physical processes encountered in the reservoir, they will probably not materially Influence the accuracy of long-term reservolr performance predictions.

The role of fractures in geothermal reservolr performance, however, Is quite a different matter. Wairakel and The Geysers depend upon fracture permeability to achieve satisfactory mass flows. To date, little is known about modeling fractured reservoir systems and even less is known about how to accurately determine important properties such as fracture permeability, porosity, orientation, and extent. Two schools of thought exist on how fractured reservolrs should be modeled. 
- The discrete fracture approach is a conceptual model which requires information on discrete fractures. The discrete. fractures are subsequently modeled in combination with their nelghboring porous medium blocks. Unless there are major advances in field measurement methodology, it is unlikely such data w11l even occasionally be avallable.

- The second approach is based on the concept of overlapping continua-one for the fractures and the other for the porous blocks. In this approach, several new sets of field parameters would be necessary. These would be volume-averaged parameters similar to permeability. Although this may provide a viable tool for modeling fractured reservolis, it is a rather recent concept and probably belongs within the realm of research at this time.

Unlike porous-flow physics, advances in fracture-flow physics could result in important changes in our ideas about geothermal reservoir simulation.

\section{Constitutive Equations}

Constitutive theory, though a very important area, is recelving only token attention. The Stanford Geothermal program is responsible for the majority of research relevant to this topic. While it is possible to determine a great deal about the functional form of constitutive equations arising in reservolr physics, experiments are essential to verify hypotheses and measure parameters. Fundamental relationships such as relative permeability curves are not available; the existence or nonexistence of Important cap1llary effects has yet to be established; the thermodynamic relationshlps for curved steamwater Interfaces are not avallable; elasticity-plasticity models require additional investigation. Needless to say, the introduction of fracture 
flow, chemical precipitation, and dissolution further aggravates the problem of an inadequate experimental program in this area.

of more pressing importance to the reservolr engineer is the measurement of constitutive parameters at the field level. Given various, rather reasonable assumptions, some of the constitutive knowledge gaps outlined above can be set aside, at least momentarily. One cannot, however, disregard problems in the measurement of important parameters such as permeability, porosity, and thermal conductivity. Accurate forecasts which reflect accurate parameter estimates are exceedingly difficult to come by in the geothermal environment.

\section{Numerical Approximations}

The numerical schemes employed in existing geothermal models are summarized in tables $1 \mathrm{a}$ and $1 \mathrm{~b}$. The important elements of the discussion can be brlefly stated as follows:

- Dependent variables: those variables solved for explicitly in the governing equations

- Variables are defined in the 11st of variables

- Well approximation: the utilization of a model of the well bore

- Equation approximation: the mathematical formalism employed in obtaining the governing porous medium equations

- MACRO designates a macroscopic balance

- MIX designates mixture theory methodology of continuum mechanics

- VINT denotes volume integration from the microscopic level to the macroscopic level 
TABLE 1a

COMPARISON OF MULTIPHASE DISTRIBUTED-PARAMETER

GEOTHERMAL RESERVOIR MODELS

(from Pinder 1979)

\begin{tabular}{|c|c|c|c|c|c|c|c|c|c|c|c|c|c|c|c|c|c|}
\hline 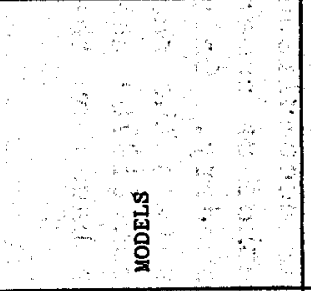 & 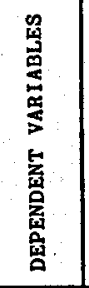 &  & 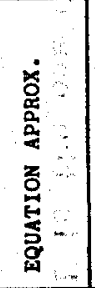 & 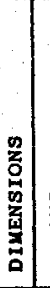 & 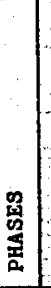 & 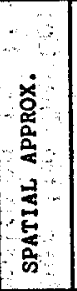 & 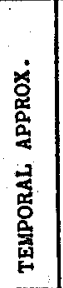 & 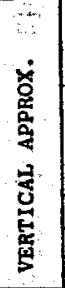 & 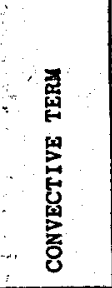 & 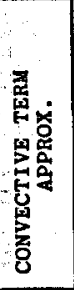 &  & 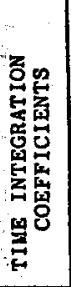 & 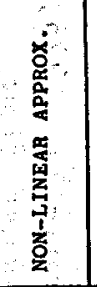 &  & 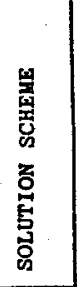 & 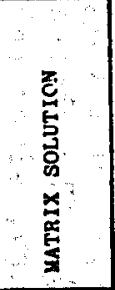 & 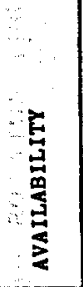 \\
\hline $\begin{array}{l}\text { Torony } 1 \text { and } \\
\text { Faroug } A 11 \text { (1975) }\end{array}$ & $\begin{array}{l}p_{p} \\
s_{w}\end{array}$ & nEs & MACRO & 2 & 2 & ro & FD & No & $v \cdot v_{f} b_{f}$ & UFD & IMP & IMP & NRA & $\ldots$ & $\begin{array}{r}\text { sik } \\
\vdots \\
\vdots \\
\end{array}$ & & PRIV \\
\hline $\begin{array}{l}\text { Lasse ter, witherspoon } \\
\text { and Lippmang (1975) }\end{array}$ & $\begin{array}{l}p_{1} \\
v_{1}\end{array}$ & vo & MACRÓ & $\begin{array}{l}1 \\
2 \\
3\end{array}$ & $\begin{array}{l}1 \\
2\end{array}$ & IFO & FD & No & $\nabla \cdot v_{p} v_{p}$ & UFD & $\theta$ & EXP & NONE & NoNE & SEQ & $y^{\text {ITR }}$ & PUB \\
\hline $\begin{array}{l}\text { Browneil, Garg } \\
\text { and Pritchett (1975) }\end{array}$ & & YES & MIX & \begin{tabular}{l|l}
1 & \\
2 & \\
3 &
\end{tabular} & 1 & FD & FD & $\begin{array}{r}\text { so } \\
\vdots \\
\vdots\end{array}$ & $\nabla \cdot v_{f} u_{f}$ & UFD & CENT & IMP & NRA & LEX & sIM & ADI & $\begin{array}{l}\text { PRIV } \\
-\end{array}$ \\
\hline $\begin{array}{l}\text { Faust and } \\
\text { Mercer (1975) }\end{array}$ & $\begin{array}{l}p_{p} \\
h_{p}\end{array}$ & No & VINT & $\begin{array}{l}1 \\
2 \\
3\end{array}$ & 12 & $\begin{array}{c}\mathrm{FD} \\
(\mathrm{FE})\end{array}$ & FD & YES & $\nabla \cdot v_{f} h_{s}$ & OFD & $\theta$ & $\begin{array}{l}\text { IMP } \\
\text { EXP }\end{array}$ & NHA & $\operatorname{TAN} \frac{2 \mathrm{D}}{3 \mathrm{D}}$ & $\frac{\operatorname{SEQ}}{\operatorname{SIX}}$ & $\frac{D}{\text { SSOR }}$ & PUB \\
\hline Coats (1977) & $\begin{array}{l}p_{w}, T \\
p_{s}, s_{s}\end{array}$ & YES & UACRO & 2 & 2 & Fo & To & $\begin{array}{c}\text { No } \\
\vdots \\
-\end{array}$ & $\nabla \cdot v_{\alpha}^{h_{a}}$ & UFD & IUP & IMP & KRA & $?$ & sim & \begin{tabular}{cccc} 
& $\mathbf{D}$ & $\vdots$ \\
$\ddots$ & & & 1 \\
\hdashline & & 4
\end{tabular} & PRIV \\
\hline $\begin{array}{l}\text { Huyakorn and } \\
\text { Pinder (1972) }\end{array}$ & $\begin{array}{l}p_{p} \\
n_{f}\end{array}$ & no & MACro & 1 & 1 & FE & $F D$ & No & $\nabla \cdot v_{f}^{h_{l}}$ & UFE & \begin{tabular}{cc} 
IMP \\
\hdashline \\
\hdashline & $\ddots$
\end{tabular} & IMP & NRA & TAN & sin & D & PUB \\
\hline $\begin{array}{l}\text { Thomas and } \\
\text { Pierson (1976) }\end{array}$ & $\begin{array}{l}p_{w}, T \\
s_{w}, T \\
p_{s}, T\end{array}$ & YES & \begin{tabular}{cc} 
YACRÖ \\
\hdashline & 0 \\
& \\
\end{tabular} & $\begin{array}{l}1 \\
2 \\
3 \\
3\end{array}$ & $\frac{1}{2}$ & $\therefore$ & FD & No & $\nabla \cdot v_{p} h_{p}$ & $?$ & $\begin{array}{c}\text { INP } \\
\vdots \\
\vdots\end{array}$ & EXP & IMPES & IMP & sIM & IUPES & $\begin{array}{c}\text { PRIV } \\
\vdots \\
\vdots\end{array}$ \\
\hline $\begin{array}{l}\text { Voss and Pinder } \\
\text { (Voss, 1978) }\end{array}$ & $\begin{array}{l}p_{p} \\
h_{p}\end{array}$ & no & VINT & $\begin{array}{l}2 \\
3\end{array}$ & $\begin{array}{l}1 \\
2\end{array}$ & FE & $5 D$ & พo & $v \cdot \nabla h_{f}$ & UFE & $\theta$ & $\theta$ & TIM & SLA & $\sin$ & BIFEPS & PUB \\
\hline
\end{tabular}


TABLE 1b:

NOMENCLATURE FOR TABLE la

1. The sets of dependent variables employed in solving the flow and energy transport equations are $\left(\rho_{f}, U_{f}\right),\left(p_{f}, h_{f}\right),\left(p_{f}, S_{W}\right)$, $\left(p_{W}, T: p_{s}, s_{s}\right)$, and $\left(p_{w}, T ; s_{W}, T: p_{s}, T\right)$. The choice between $\left(\rho_{f}, U_{f}\right)$ and $\left(p_{f}, h_{f}\right)$ seems rather arbitrary, since one is readily derived from the other for presentation.

2. The majority of models will accommodate one-, two-, and three-space dimensions. The notable exceptions are Toronyi and Farouq-Ali (1975) and Huyakorn and Pinder (1977).

3. With the exception of the Toronyl and Farouq-Al1 (1975) model, all simulators can handle efther one- or two-phase flow.

4. Finite-difference methods, finite-element methods, and integrated finite-difference methods have been used in spatial approximations. The majority of models employ finite-difference methods.

5. All models approximate the time dimension using finite-difference methods.

6. Explicit, implicit, and mixed explicit-implicit schemes are employed in the representation of the nonlinear coefficients; the majority of algorithms employ an implicit formulation.

7. Where an implicit formultion is used, either the Newton-Raphson method or the total increment method is employed to linearize the approximating equations.

8. The only vertically integrated areal model is the one developed by Faust and Mercer (1977a).

9. All methods employ some form of upstream welghting for the convective term.

10. The transition across the phase boundary is accomplished in a number of ways. Most schemes involve some method of numerical damping which stops the oscillation across this boundary. Only the model of Voss and Pinder (Voss 1978) completely resolves the phase-change problem. The approach of Thomas and Pierson (1976) deserves additional study; it was difficult to evaluate based on the available literature.

11. A we11-bore model is included in the models of Toronyi and Farouq-Al1 (1975), Coats (1977), Thomas and Plerson (1976), and Brownell et al. (1975). 
- Dimensions: the number of space dimensions employed in example problems

- Phases: the number of phases that can coexist at any given point in space and time

- Spatial approximation: the numerical scheme used to approximate space derivatives

- IFD denotes integrated finite difference

- FD denotes finite difference

- FE denotes finite element

- Temporal approximation: the numerical scheme used to approximate the time derivative

- FD denotes finite different

- Vertical integration: the formal procedure of Integrating the three-dimensional equations vertically when generating a two-dimensional areal model.

- Convection term: the form in which the convective term appears In the model

- Convective term approximation: the numerical scheme employed in approximating the convective term

- UFD denotes upstream-welghted finite difference

- UFE denotes upstream-welghted finite element

- Time integration of unknowns: the type of time-derivative approximation employed 
- $\emptyset$ denotes a general formulation $0.5 \leq \emptyset \leq 1$

- CENT denotes a Crank-Nicolson scheme (i.e., $\emptyset=0.5$ )

- IMP denotes a backward difference approximation

- Time integration coefficients: the location in the time domain where the nonlinear coefficients are evaluated (nomenclature the same as previous case)

- Nonlinear approximation: the method used to linearize nonlinear equations

- NRA denotes Newton-Raphson iteration

- IMPES denotes implicit pressure, explicit saturation

- TIM denotes the total increment method

- Phase change method: the technique used to move numerically across the phase-change boundary

- LEX denotes 1imited excursion technique

- $\Delta t$ ADJ denotes a modification of $\Delta t$ as the phase boundary is approached

- TAN denotes a modification of Newton-Raphson to allow the tangent to be taken in a direction away from the phase boundary

- IMP denotes a formulation accounting for the phase change with the equations

- SLA denotes saturation line adjustment

- Solution scheme: the method used to solve the two coupled governing equations

- SEQ denotes the sequentlal solution of each (1.e., $\mathrm{N}$ equations are solved twice per iteration) 
- SIM denotes the simultaneous solution of $2 \mathrm{~N}$ equations at each iteration

Matrix solution: the technique used to solve linear algebraic equations

- ITR denotes an iterative method

- ADI denotes alternating-direction implicit procedure

- D denotes a direct solution scheme

- SSOR denotes slice successive over relaxation

- IMPES denotes implicit-pressure, explicit-saturation method

- BIFEPS denotes block-iterative, finite-element preprocessed scheme

- Avallability: the designation of avallability of model to the public

- PUB designates models funded through public monies and therefore avallable to the public

- PRIV designates models developed with private funds which are thus probably proprietary

The formulation of the approximating equations is relatively straightforward. The linerization of the resulting nonlinear equations is rather challenging. The Achilles' heel of the methodology is the treatment of the phase change. For some problems, probably the majority

$\gamma$ of those encountered in the field, the problem can be treated rather crudely. For those which are dominated by the phase-change phenomenon, an accurate formulation is essential. Because there 18 no test which is sufficlent to demonstrate the accuracy of geothermal reservolr simulators, Pinder could only speculate on the adequacy of this element of the development. 


\section{Solution Scheme}

The flow and energy equations can be solved either sequentially or simultaneously. The sequential solution employs estimates of the energy varlable when solving the flow equation and estimates of the flow variable when solving the energy equation. This uncoupling is desirable because it is more efficient to solve $N$ equations twice than to solve $2 \mathrm{~N}$ equations once. The disadvantage is that it is generally necessary to iterate between the equations, and convergence is not, in general, guaranteed. The majority of existing models solve the two equations simultaneously and employ Newton-Raphson type schemes to accommodate the nonlinearity wich arises. The two-dimensional model of Faust and Mercer (1979b) and the formulation of Lasseter et al. (1975) are exceptions to this general rule.

The matrix equations which arise in either approach may be solved efther directly or iteratively. Direct methods are based on Gaussian elimination and are reliable when applied to a well-behaved system of equations. Iterative methods tend to be more efficient for large problems (e.g., more than 500 equations) but generally require a higher level of numerical ingenuity to program and apply effectively. The majority of iterative schemes are block-iterative and thus incorporate a direct solution module in the iterative algorithm. This is true for the models considered, with the exception of Lasseter et al. (1975).

The primary factors to consider in the selection of a solution scheme are accuracy and efficlency. Ease of programing will probably play a secondary role because of the considerable computer costs involved in geothermal reservoir simulation. Because a comparison of the accuracy and efficiency of the models outlined in Table 2 has never been undertaken, one cannot select an optimal approach directly. 
TABLE 2

DIMENSIONALITY OF MODELS

\begin{tabular}{cll}
\hline DIMENSIONALITY & FLOW MODEL & DEFORMATION MODEL \\
\hline $1-D$ & $\begin{array}{l}\text { UPDOWN } \\
\text { CCC } \\
\text { CONSOL3 }\end{array}$ & $\begin{array}{l}\text { Hand CalCs } \\
\text { CCC }\end{array}$ \\
2-D & CCC & $\begin{array}{l}\text { BIEM2D } \\
\text { CONSOL3 }\end{array}$ \\
& CONSOL3 & \\
AxIsymmetric & CCC & Hand Ca1cs \\
& CONSOL3 & CONSOL3 \\
3-D & CCC & SUBSID \\
& NFOLD \\
\hline
\end{tabular}


The complexity of geothermal reservolr physics essentially precludes the verification of existing codes using analytical solutions. One can, however, compare solutions generated by a model against other numerical solutions or experimental data.

The Question of Uncertainty

In this section we attempt to address the question of simulation uncertainty. In fact, each of the preceding sections has addressed this problem indirectly. Because the history of geothermal reservoir simulation is very short, we have little experience with which to estimate the accuracy of our forecasts. Thus, this discussion must draw on personal experience and studies in related areas. In Figure 2, we present a completely subjective estimate of the distribution of uncertainty in the reservoir simulation process. We wish to emphasize that uncertainty does not reside within the technology of equation solving but rather resides in the formulation of the equations and the measurements of fleld parameters.

With respect to geothermal reservoir simulation, we are led to conclude that uncertain input data generates solution uncertainty of about the same magnitude (using the coefficient of variation as the uncertainty measurement). The greatest uncertainty in the solution occurs during the period of maximum change in the system. As the system approaches steady-state, the solution uncertainty decreases. The problem that remains to be considered is the estimation of the input uncertainty. 




FIGURE 2

RESERVOIR MODELS: SOURCES OF UNCERTAINTY 
26 
COMPUTATIONAL MODELS FOR DEFORMATION

There are a number of techniques which can be used to numerically model geothermal subsidence. These include nucleus-of-strain techniques, boundary-integral techniques, the finite-element method, the finite-difference method, and analytical solutions. For each technique there are usually a number of different types of implementation in terms of dimenstonality (one-dimensional; two-dimensional, axisymetric, and three-dimensional), material properties (11near/nonlinear, homogeneous/ Inhomogeneous), and so on. In addition, for each technique and each type of implementation there are often a number of computer programs, developed at different institutions, with greater or less sophistication in terms of debugging, documentation, generality, usability, etc. The first task performed In this study was to attempt to ldentify all of the major models and then to select a number of representative models for detalled evaluation.

Sophisticated reservoir models (reviewed in P1nder 1979) were not included in the survey of existing models described below. Nor were any - of the reservoir models tested due to the anticipated difficulty in acquiring the models, defining test problems, and conducting successful analyses. This is not to understate the importance of reservolr models In the overall subsidence modeling process-they are just as important as deformation models. Three of the tested mode1s do treat coupled flow, but all of them are limited to single-phase flow and only one treats heat flow and thermal effects:

\section{MODEL SELECTION}

A questionnalie was prepared and distributed to a list of model owners. The list was based partly on personal knowledge and partly on models Identified from publications (Including Atherton et al. 1976 [27 models] and Grover et al. 1977 (10 models]). Each rec1pient was in turn 
asked to Identify any model owners who had not been contacted. In all, 25 questionnaires were sent out and 11 responses were recelved. Figure 2 is a schema which was included with the questionnaire and which was intended to help elucidate the different types of modeling technique and implementation.

In addition to the models identified by the survey, a number of techniques for subsidence modeling were identified which were not assoclated with a particular author or computer program. These included boundary-integral techniques, methods of hand calculation, and nucleusof-strain techniques.

The selection of models for detalled review was relatively straightforward. A majority of the models reported in the literature - were not developed with the intent of being used by others. As a result, they were not avallable, not documented, or were otherwise unusable. In the end, seven models were selected for detalled review:

- Hand-calculation techniques

- The nucleus-of-strain method (SUBSID)

- The one-dimensional Terzaghi-consolidation method (UPDOWN)

- The two-dimensional boundary-integral-equation method (BIEM2D)

- A two-dimensional nonlinear finite-element model for deformation with coupled isothermal fluid flow (CONSOL 3 )

- A three-dimensional integrated-finite-difference model for single phase nonisothermal flow, with one-dimensional Terzaghi deformation (CCC) 
- A three-dimensional displacement-discontinuity method (NFOLD).

Each of these models is discussed in some detall in the following sections.

It was decided that a three-dimensional finite-element method program would not be included in the detalled review process. Although such models have the theoretical capacity to produce better results than any of the models we selected, that capability is probably not real1zable In practice due to the enormous cost of running the models. We found that (1) it would be a major expense to acquire a suitable program, (2) it would be somewhat expensive to modify the program to accept specified pore pressures and temperatures as input, and (3) it would be a further major expense to run the program. It was decided that it was not appropriate to Incur such expenses simply to demonstrate what is already known--that three-dimensional finite-element deformation models are forced to use grossly simplistic meshes in order to prevent unacceptably high costs. Had there been a freely avallable, fully documented, and tested code with the capacity to handle specified pore pressures and temperatures, we would probably have elected to test it.

One disappointment of the model selection process was that we were unable to find a functioning model which coupled state-of-the-art reservoir flow physics with the full equations of deformation mechanics. Such a code (AGRESS) was at one time developed at Systems, Science and Software, Inc., but it was not successful due to numerical difficulties and high cost. A two-dimenstonal single-fluld phase version of such a code has been developed by Dr. Alberto Peano (Istituto Sperimentale Mode111 e Strutture S.P.A., Viale Glulio Cesare, 29-24100 Bergamo, Italy) but was not available in time for this study (see Borsetto 1979a, 1979b). 
A brief description of each of the selected models follows. The models are described in more detail in Companion Report 2 (Miller et a1. 1980b). Table 2 summarizes the dimensionality of the models.

\section{Hand-Calculation Techniques}

It is possible to use a number of techniques to compute the one-dimensional compaction of the reservoir materials. Three techniques were selected for testing: a one-dimensional poroelastic theory using specified temperature and fluid pressure changes, a one-dimensional poroelasticity theory using specified temperature and volume of fluid removed, and the Terzaghi e-log p consolidation equation. The propagation of the reservoir compaction to the ground surface uses a technique developed by Geertsma (1973) for a disk-shaped poroelastic reservoir.

1-D Terzagh1 Consolidation Method UPDOWN

The model selected in this case is that developed by Helm (1975) while with the U.S. Geological Survey. The model is intended for use in a horizontally layered system and computes the time-dependent compaction of an aquitard (clay or shale layer) due to water-pressure drops in the adjacent aquifers. The program assumes one-dimensional compaction with Terzaghi-type e-log $p$ behavior and with Darcy flow of constant-density water. Due to aquifer production, the program was designed for modeling subsidence rather than for geothermal subsidence.

Nucleus-of-Strain Mode1 SUBSID

Variants of the nucleus-of-strain method have been developed by a number of Investigators (e.g., Geertsma 1973; Gambolati 1972). Essentially, all the models rely on an exact solution to the problem of a uniform pressure or temperature drop within a spherical region in an 
isotropic, homogeneous elastic half-space. In SUBSID, Irregularlyshaped reservoirs are modeled by superimposing the effects of a number of spheres.

The computer program used was developed by Golder Assoclates for the purpose of the study and is reproduced and documented in Companion Report 2 (Miller et al. 1980b). The solution was based on the Mindlin and Chen (1971) adaptation of the Goodler (1937) solution for a point temperature change in an infintte space.?

\section{2-D Boundary-Integra1-Equation Method BIEM2D}

The program selected in this case was originally developed by 'John W. Bray at the University of London. The version used in the study was taken from the book, Underground Excavation Englneering, by Hoek and Brown (1980?) and was modifled to incorporate fluid pressure and temperature effects. The method models a two-dimensional, homogeneous elastic 1sotroplc space In plane strain and is defined by linear boundary elements along'the ground surface, around contours of pressure and temperature drop, and around any underground excavations.

\section{2-D Finlte-Element Coupled Flow-Deformation Model CoNsol3}

This is a fully-coupled two-dimensional (planar or axisymmetric) model for Darcy flow of water and nonlinear deformation. The program was developed by Roland $w$. Lewis at the University of Wales at Swansea and has been used in several simulations of subsidence Induced by groundwater extraction (Schrefler et al. 1977; Lewis and Schrefler 1978). For problems where the fluid pressures were known (from field observations or from a reservoir model), it was intended to specify the fluid pressures as boundary conditions and use fust the deformation aspects of the model. 
3-D IFD Model for Reservor Heat and Mass Flow CCC

This code was developed at Lawrence Berkeley Laboratory (L1ppmann et al. 1977). It consists of an IFD (Integrated finite difference) model for flow in systems of any dimensionality (one-dimensional, two-dimensional, axisymmetric, or three-dimensional). The vertical strain in each element is computed based on the Terzaghi assumptions of constant total vertical stress, no lateral strain, and e-log $p$ or e-p behavior. The flow model incorporates single-phase fluid and heat flow.

3-D Displacement-Discontinuity Model NFOLD

This model was developed by Krishna Sinha while at the University of Minnesota (Sinha 1979). It is designed for analyzing the threedimensional stress and displacement fields induced by mining activities in thin seams in an isotropic homogeneous elastic medium. It can also model Induced movement of faults. It was modified for this project to incorporate the effects of pressure and temperature drops. 
PROFICIENCY ASSESSMENT

INTRODUCTION

When seven models had been selected for detailed review, the next step was to make proficlency assessments of the mode1s. This involved reviewing the usability of each model and testing its ability to perform its calculations "as advertised." Usability included such items as the quality of documentation, the programing style, the ease of input, and the comprehensibility of output.

Testing of the models ability to perform their calculations was done by using a series of standard test problems. Not all models were suitable. for all of the test problems, which, although simple, were designed to exercise a number of modeling aspects. A brief review of the six test problems follows.

\section{SAMPLE PROBLEM DESCRIPTIONS}

For simplicity, a constant pressure drop in the reservolr was assumed in each problem. Materlal properties are also consistent between problems. The reservolr materlal was assumed to be linear elastic, described by constant bulk modulus $K$ and Poisson's ratio $U$. For problems in which flow to the reservolr from confining layers was permitted, the confining layer materlal properties were represented by a nonlinear e-log p compressibility relation. Unless specified (as in the case of the e-log $p$ material), the material surrounding the reservolr is assumed to have the same material properties as the reservoir interval. Material properties are specified in Table 3.

The six problems are discussed in general below. A summary of pertinent factors for problem definition is given in Table 4. 
TABLE 3

MATERIAL PROPERTIES

\begin{tabular}{|c|c|}
\hline LINEAR ELASTIC & E-LOG P COMPRESSIBILITY \\
\hline $\mathrm{K}=\begin{array}{l}1.44 \times 10^{6} \\
\text { (bulk modulus) }\end{array}$ & $\begin{aligned} c_{c} & =0.15 \text { (compaction coefficient) } \\
e & =0.3 \text { (vold ratio) }\end{aligned}$ \\
\hline $\begin{aligned} v= & 0.25 \\
& \text { (Poisson's ratio) }\end{aligned}$ & $\begin{aligned} \mathrm{m}_{\mathrm{v}}= & 1.111 \times 10^{-6} \mathrm{psf} \\
\mathrm{c}_{\mathrm{v}}= & 1.736 \times 10^{-6} \mathrm{ft} 2 / \mathrm{sec} \\
& \text { (coefficient of consolidation) } \\
\mathrm{k}= & 1.208 \times 10^{-10 \mathrm{ft} / \mathrm{sec}} \\
& \text { (hydraulic conductivity) }\end{aligned}$ \\
\hline
\end{tabular}


TABLE 4

SAMPLE PROBLEM SUMMARY

\begin{tabular}{|c|c|}
\hline $\begin{array}{l}\text { ROBLEM } \\
\text { NO. }\end{array}$ & DESCRIPTION \\
\hline 1 & $\begin{array}{l}\text { Uniform linear elastic material properties throughout } \\
\text { half-space. } \\
\text { Rock mass saturated from surface downward. } \\
\text { Reservolr interval bounded above and below by impermeable } \\
\text { boundaries. } \\
\text { Initial pore pressure distribution as shown in Figure } 3 \text {. } \\
\text { Uniform pressure drop of } 5.04 \times 10^{4} \text { psf in reservolr. }\end{array}$ \\
\hline 2 & $\begin{array}{l}\text { Linear elastic reservolr and elsewhere except shale layer; } \\
\text { Infinite reservoir. } \\
\text { Shale layer e- } \log \text { p compressibility. } \\
\text { Impermeable boundary below reservolr. } \\
\text { Constant head boundary at top of shale layer. } \\
\text { Untform pressure drop of } 5.04 \times 10^{4} \text { psf maintalned in } \\
\text { reservoir. } \\
\text { Initial and final pore pressure distribution as shown. }\end{array}$ \\
\hline 3 & $\begin{array}{l}\text { Finite, thin reservolr of disk shape. } \\
\text { Impermeable boundaries around reservoir. } \\
\text { Uniform linear elastic material properties throughout. } \\
\text { Inttial pore pressure distribution as shown. } \\
\text { Uniform pressure drop of } 5.04 \times 10^{4} \text { in reservolr. }\end{array}$ \\
\hline
\end{tabular}


TABLE 4 (Cont.)

SAMPLE PROBLEM SUMMARY

\begin{tabular}{|c|c|}
\hline $\begin{array}{l}\text { PROBLEM } \\
\text { NO. }\end{array}$ & DESCRIPTION \\
\hline 4 & $\begin{array}{l}\text { Same geometry as Problem } 3 . \\
\text { Properties of shale layer above reservoir: e-log p } \\
\text { compressibility. } \\
\text { Impermeable boundary below reservoir. } \\
\text { Constant head boundary at top of shale. } \\
\text { Besides shale layer, material linear elastic. } \\
\text { Uniform pressure drop of } 5.04 \times 10^{4} \text { psf maintained in } \\
\text { reservoir. } \\
\text { Initial and final pore pressure as shown. }\end{array}$ \\
\hline 5 & $\begin{array}{l}\text { Thick, cylindrically shaped reservoir. } \\
\text { Uniform elastic material properties throughout. } \\
\text { Uniform pressure drop of } 2.16 \times 10^{4} \text { psf in reservoir. } \\
\text { Impermeable boundaries surrounding reservoir. } \\
\text { Constant initial pore pressure gradient of } 61.92 \mathrm{psf} / \mathrm{ft} \text { from } \\
\text { surface downward. }\end{array}$ \\
\hline 6 & $\begin{array}{l}\text { Wedge-shaped reservoir. } \\
\text { Uniform elastic material properties throughout. } \\
\text { Uniform pressure drop of } 2.88 \times 10^{4} \text { psf in reservoir. } \\
\text { Impermeable boundaries surround reservoir. } \\
\text { Constant initial pore pressure gradient of } 61.92 \mathrm{psf} / \mathrm{ft} \text {. }\end{array}$ \\
\hline
\end{tabular}


For problems 1 to 4 the assumed hydrostatic gradient from surface to a depth of 500 feet was $61.92 \mathrm{psf} / \mathrm{ft}$. From 500-foot to 570-foot depth the head is assumed to increase linearly from 61.9 to $100.8 \mathrm{psf} /$ $\mathrm{ft}$. Below 570 feet, the gradient is constant at $100.8 \mathrm{psf} / \mathrm{ft}$. In problems 5 and 6 , a hydrostatic gradient of 61.92 psf is assumed for the entire depth represented in the problems.

In problems 1 and 2 (figures 3 and 4 ) the reservoir interval is infinite in lateral extent and thin relative to its depth. A uniform, instantaneous pressure drop is assumed over the entire reservoir. No fluid-flow calculations need be done for problem 1 . Problem 2 is onedimensional in fluid flow because vertical flow to the sand from the overlying clay is allowed. After the initial pressure reduction, the pressure is held constant in the reservoft.

Either problem 1 or problem 2 can be solved by all of the candidate programs except NFOLD and SUBSID. Exact analytic solutions can be obtained for these problems to provide checks on program solution accuracy.

The finite reservoir problems 3 and 4 (figures 5 and 6 ) represent the next step in geometric complexity in that both are two-dimensional. Depending on the program, these problems were run in either planar twodimensional or axisymmetric mode. (For example, program ccc could accommodate either axisymmetric or planar geometry, and so both geometrles were run.) The BIEM2D program, on the other hand, could accommodate only planar two-dimensional geometry. Problem 3 is similar to problem 1 in that the reservoir is confined. Flow into the reservoir from the confining layer is allowed in problems 2 and 4 . Surface displacements for the finte-confined axisymmetric-reservoir problem can be compared for accuracy with analytic solutions obtalned by Geertsma (1973). 


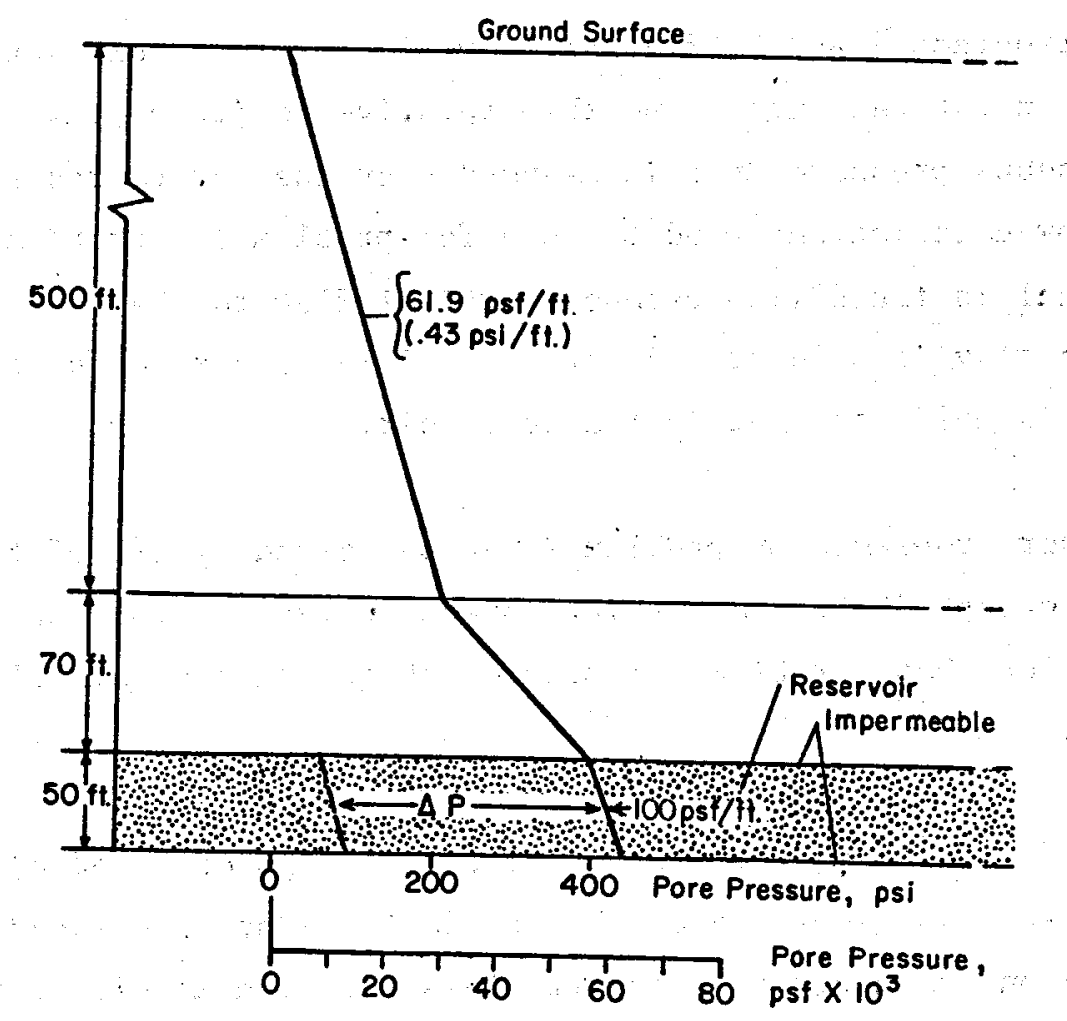

FIGURE 3

SAMPLE PROBLEM 1

INFINITE CONFINED RESERVOIR 
Ground Surfoce

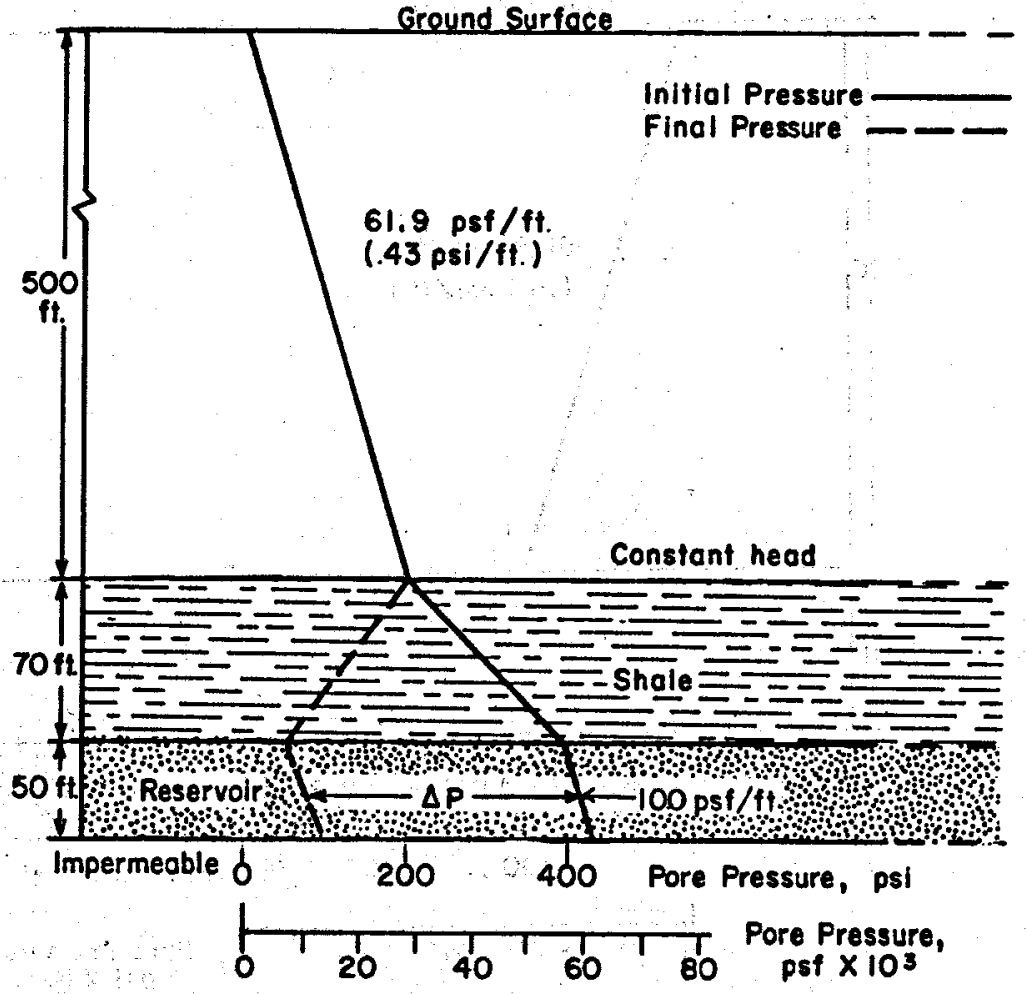

FIGURE 4

SAMPLE PROBLEM 2

INFINITE LEAKY RESERVOIR 


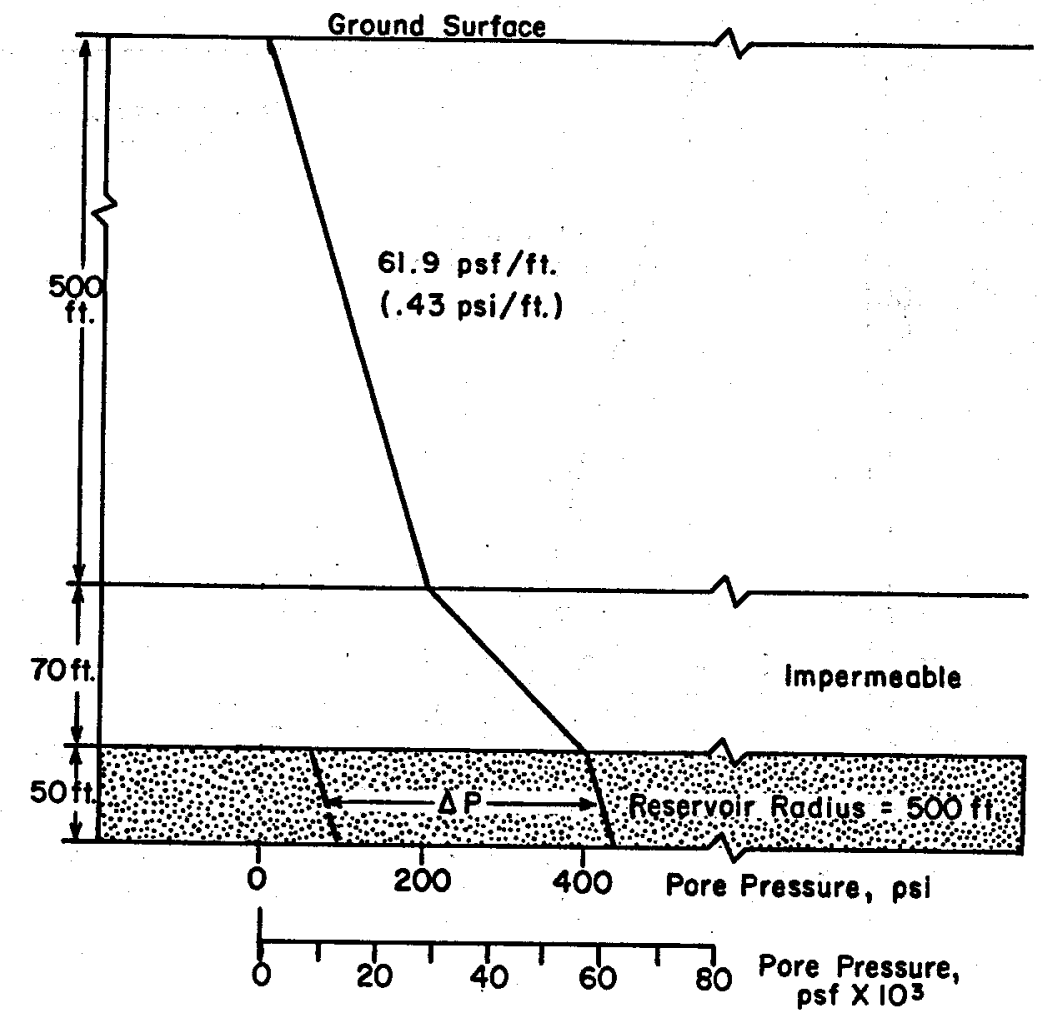

FIGURE : 5

SAMPLE PROBLEM 3

FINITE CONFINED RESERVOIR 


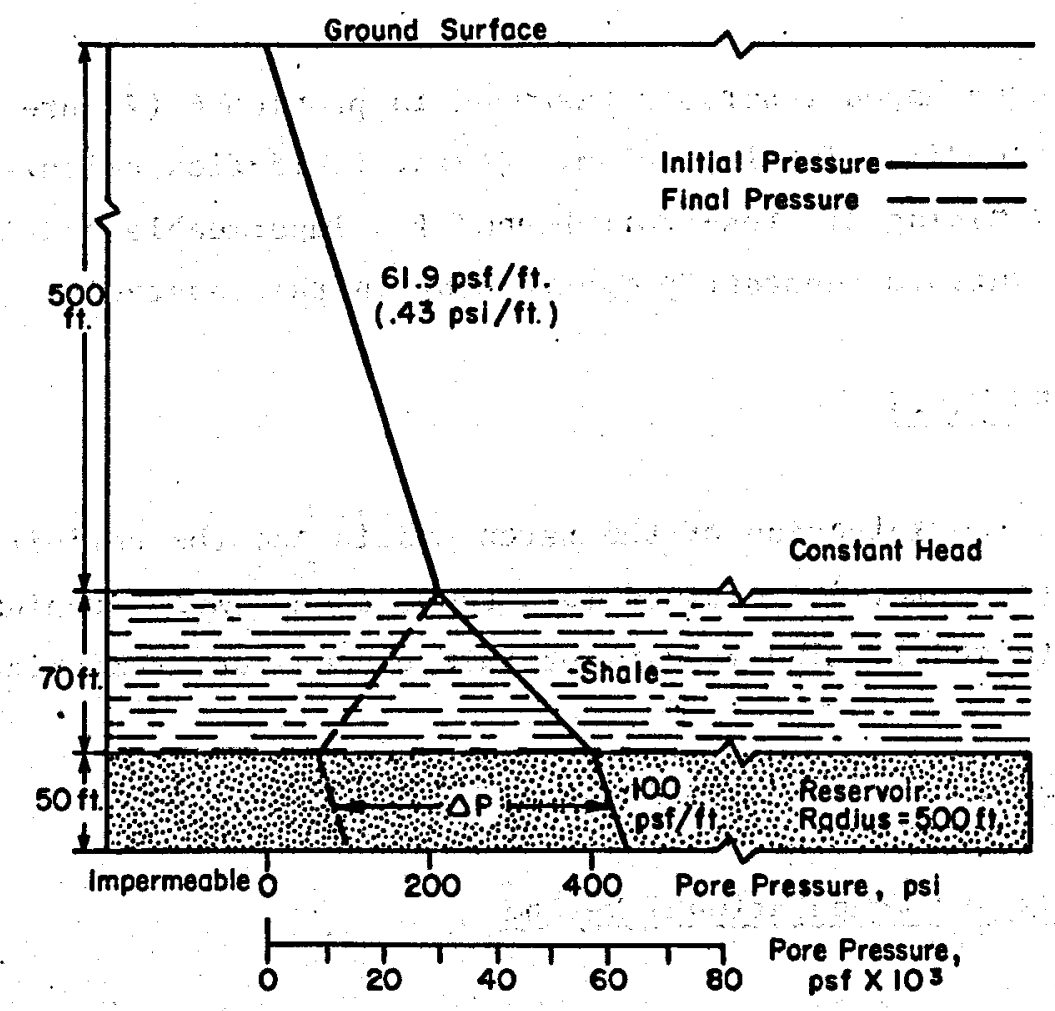

FIGURE 6

SAMPLE PROBLEM 4

FINITE LEAKY RESERVOIR 
Problem 5 (Figure 7) represents a thick reservoir surrounded by impermeable boundaries. It was run in both the axisymmetric and planar mode. The problem is identical to problem 3 except in the ratio of depth to reservoir thickness. In problem 3 this ratio is 11.9, whereas in problem 5 the ratio is 1 . This problem permitted evaluation of program capabilities for solution of problems. In which horizontal displacements and stress changes in the reservoir become significant.

A wedge-shaped reservoir was used in problem 6 (Figure 8) to represent a three-dimensional problem. Again, fluld-flow calculations were avoided by making all reservolr boundaries impermeable and by maintaining a uniform constant pressure drop in the reservolr.

\section{MODEL ASSESSMENTS}

After the selection of the seven models and the definition of the six test problems, it remained to attempt each sample problem with its appropriate model. The results of this process are summarized below.

\section{Hand Calculation Methods}

\section{Theory and Computational Method}

One-dimensional compaction of aquifers and aquitards may be calculated by hand. The temperature change and either the volume of fluid produced or the pressure change in the of interest must be specified. Surface subsidence is determined using the Geertsma thin-disk solution, superposing a number of disks if necessary.

\section{Capabilities}

Either linear-elastic or e-log p constitutive relationships can be assumed. As the reservoir is assumed to be one-dimensional, the 


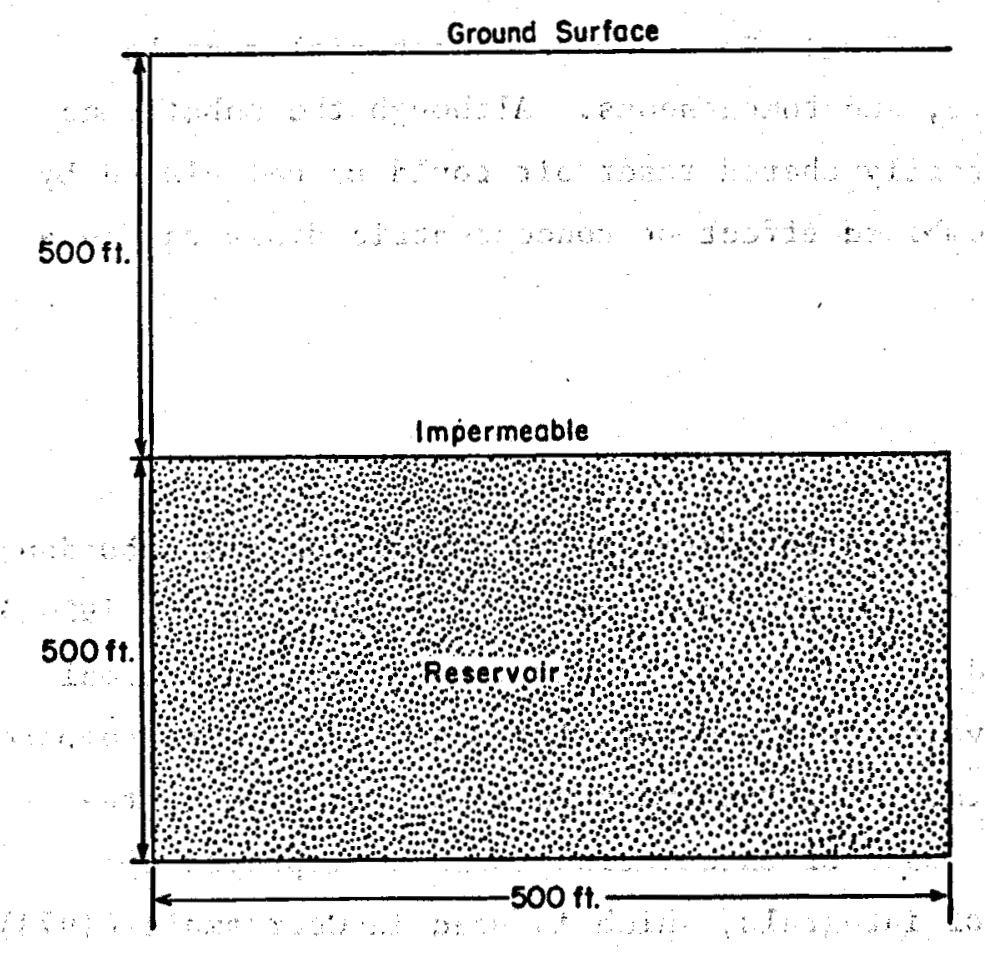

FIGURE 7

SAMPLE PROBLEM 5

THICK FINITE CONFINED RESERVOIR

\section{IHICR FINITE CONFINE RESERVOIR}


compaction is laterally uniform. The overburden material must be linear-elastic, 1sotropic, and homogeneous. Although the subsidence profile due to an arbitrarily shaped reservoir could be calculated by hand, determining the combined effect on nonconcentric disks can be a tedious job.

\section{Usability}

A hand-calculation method for determining compaction and subsidence is described in Section 2.0 of Companion Report 2 (Miller et al. 1980b). The information required is rather rudimentary. Elastic and thermal properties of the reservoir fluid and material must be known to compute compaction. Polsson's ratio for the overburden is specified in the subsidence computation. Ease of calculation could be improved by extension of the table of integrals, which is used in Geertsma's (1973) disk solution.

\section{Performance On Sample Problems}

All sample problems were solved by hand. Where necessary, simplifying assumptions were made. The aquitard in problem 3 was assumed to have the same lateral extent as the aquifer. The prismatoidal reservoir in problem 6 was modeled into a cylinder of equal volume to approximately determine surface subsidence. In all cases, the calculation of compaction and subsidence was straightforward and the answers compared well to those found by using the six computer programs.

Nucleus-of-Strain Model SUBSID

Theory and computational method

SUBSID models the propogation of stress and displacement Induced in a homogeneous, 1sotropic 11near half-space by pressure changes at spherlcal nuclei of strain within the half-space. 
The solution to the case of pressure changes in spherical inclusfons is quite general, since it allows modeling in three dimensions and since any shape of pressure change zone can be modeled by superposition of spheres.

\section{Program Capabilites}

SUBSID does not model geothermal reservolrs themselves but rather models the propogation of stress and strain from the reservoirs. A reservoir is represented as a pressure-change region made up of an array of spheres. The pressure change chosen for the spheres must represent both thermal and pore-pressure effects within the reservoir due to the extraction of geothermal fluid. The reservoir and the surrounding material are assumed to be made of the same homogeneous, isotropic Inear elastic material described by Young's modulus $E$ and Poisson's ratio $U$.

\section{Program Usability}

SUBSID is an easy program to use. Documentation for the program, which is Included in Companion Report 2 (M11ler et al. 1980b), is thorough and stralghtforward. Input to the program Includes only material properties $E$ and $U$ and sphere rad11, location, and pressure drops. Output of Induced stresses and displacements is avallable at any user-specified observation point. The program, though threedimensional, is inexpensive; it requires less than 9 CPU seconds on a CDC Cyber 75 computer for 208 source spheres and 484 observation points.

\section{Performance on Sample Problems}

SUBSID could be Implemented on sample problems which: 
- Are reasonably three-dimensional

- Could be represented by regions of known pressure drop in a body with no pressure change.

SUBSID was used to solve sample problems 3,5 , and 6 . Sample problems 1 and 2 are essentially one-dimensional and are therefore inappropriate for SUBSID. Sample problem 4 includes a shale aquitard of unknown pressure drop.

Coding of sample problems was straightforward, and threedimensional results were obtained at moderate cost ( 1 to 9 CPU seconds). Results from the axisymmetric problems 3 and 5 were compared with Geertsma's (1973) analytic solution for a unfform pressure drop within an infinitely thin disk. The surface vertical and horizontal displacements are generally within 2 percent of analytic solutions.

One-Dimensional Consolidation Mode1 UPDOWN

Theory and Computational Method

UPDOWN calculates one-dimensional consolidation according to Terzaghi theory. Solution is achieved by application of the finite difference method in space and time.

\section{Program Capabilities}

UPDOWN performs only one-dimensional flow and deformation calculations. Its strength lies in its ability to handle material properties which are weakly nonlinear and inhomogeneous and boundary conditions which vary with time.

Terzaghi consolidation can be described in terms of effective stress $p$, hydraulic conductivity $k$, and specific storage s. Both $k$ and 
8 can be specified as functions of stress or location. Boundary conditions are expressed in terms of effective stresses above and below the zone of flow. Effective stresses on the boundaries can be specified at any desired time.

\section{Program Usability}

The theory of UPDOWN is straightforward and is explained well in the 1iterature. Application of the program could be hampered by inadequate explanations in the avallable input manual and by bugs in the program.

The preparation of Input for UPDOWN requires 1ittle effort. Only a small number of parameters are required, and input is organized in a logical, concise manner. Compaction is output at any user-specified time Interval, and effective stresses are output at every grid point within the aquitard. If nonlinear modeling is required, profiles of virgin and elastic specific storage and of hydraulic conductivity are also output.

The solution cost of UPDOWN is very low-under $6 \mathrm{CPU}$ seconds for the sample problem run to test the program.

\section{Performance on Sample Problems}

Only one-dimensional problems with flow-through porous media can be modeled by UPDOWN. Use of UPDOWN was therefore restricted to sample problem 2. All other sample problems except sample problem 1 are either two- or three-dimensional. Problem 1 does not allow flow.

Flow results from UPDOWN agreed with those obtained by the more sophisticated flow program CCC, with steady-state reached at approximately 30 years. Ultimate consolidation agrees with the analytic solution obtained using hand calculations and the Terzaghi theory. 
Boundary Integral-Equation Method BIEM2D

Theory and Computational Methods

The boundary integral-equation method is a low-cost technique for modeling the effect of regions of stress or temperature change within a homogeneous, isotropic linear elastic space. The particular method used is based upon a solution by John W. Bray of Imperial College, with modification by Golder. Associates. The solution uses superposition of closed-form solutions of stress and displacement fields for strip loads within elastic media. Pore-pressure and temperature-change effects are both modeled by applying strip loads around contours of pressure or temperature drop.

\section{Program Capabilities}

Only two-dimensional plane strain propogation of stress and displacement are modeled by BIEM2D. Mass flow, heat flow, and timedependent phenomena are ignored. All calculations are performed at equilibrium.

Anisotropic or inhomogeneous spaces cannot be modeled. Pressure and temperature change contours may occur at any location within the elastic space, at any orientation, and with any magnitude. The presence of the ground surface is incorporated.

\section{Program Usability}

A new users' manual, including recent program enhancements and an Improved discussion of input parameters, is given as Appendix B of Companion Report 2 (Miller et al. 1980b). W1th the users' manual and a rudimentary understanding of the program, complex models for geothermal reservolrs can be coded in approximately 1 hour. Geometries and 
material property assumptions are simple and can be coded in a stralghtforward manner. Specification of stress or temperature change boundary elements is alded by automatic element generation.

Program output includes stress and displacement at each boundary element and at any user-specified grid points. Output is selfexplanatory.

Due to the efficiency of the code, the cost of modeling for wellformed, straightforward problems is generally under 1 CPU second.

\section{Performance on Sample Problems}

BIEM2D is one of the most factle models studied and was used to model every sample problem in which pressure-change contours were known (sample problems $1,3,5$, and 6 ).

A11 sample problems except sample problem 6 were solved in less than 1 CPU second. Sample problem 6, in which a three-dimensional geometry was approximated in two dimensions, required $1.2 \mathrm{CPU}$ seconds.

The ground surface subsidence in sample problem 1 was within 3 percent of the analytic solution.

\section{2-D Fintte Element Coupled Flow-Deformation Model CoNsol3}

\section{Theory and Computational Methods}

CONSOL 3 has the most soph1sticated deformation theory of the models tested. It uses the finite element method with 1soparametric elements to model the coupled flow and deformation of heterogeneous, isotropic, elastic-plastic materials. Problems can be two-dimensional (plane strain, plane stress) or axisymetric. In the time domain, an 
adjustable impliclt finte-difference scheme is used. A full set of matrix equations is formed and solved using a Gaussian solver at each time step.

\section{Program Capabilities}

Up to 200 elements and 300 nodes can be used and up to 100 time steps can be taken (these limits depend on computer menory size). A number of stress-strain models are avallable. Single-phase, isothermal flow of an elastic fluid is considered.

\section{Program Usability}

The documentation for CoNsol 3 is poor. Explanations are limited and there are erroneous and misleading statements. Input to the program has some convenience features but could be greatly improved. Output includes effective stresses, displacements, reactions, and flow rates. The program is not particularly efficient and is expensive for large problems.

\section{Performance on Sample Problems}

Sample problem 2 was modeled using two quadratic finite elements, and the steady-state solution matched the exact solution. Problem 4 was modeled with 42 quadratic elements and produced very believable results.

Mult1dimensional Heat and Mass Flow Model CCC

\section{Theory and Computational Methods:}

According to equations developed by Lippmann et al. (1977) and other researchers, CCC models the flow of heat and fluids through porous 
media on the basis of conservation of mass, momentum, and energy. The solution is achleved by application of an integrated finite-difference technique. The integrated finite-difference technique allows solution to be achieved in elther one, two, or three dimensions. Coupled stress/ heat-flow/massflow calculations are achleved by an 1terative technique which alternates heat-flow and fluid-flow calculations over time.

CCC models deformation as elther a linear or a nonlinear onedimensional consolidation. Even where flow calculations are threedimensional, deformation calculations are one-dimensional.

CCC performs effective stress calculations and assumes constant total vertical stress at the upper boundary.

\section{Program Capabilit1es}

CCC is an extremely flexible program. It can handle any dimensionality of flow (but only one-dimensional deformation). Material properties can be inhomogeneous but not anisotroplc. Both fluid and rock properties can be temperature dependent. Fluid viscosity, density, thermal expansivity, and heat capacity can be temperature dependent. Intrinsic permeability, specific heat, and thermal conductivity may be temperature dependent. Permeability may also be a function of vold ratio for nonlinear materials.

Boundary conditions can be spectfled as mass or heat flow or as constant pressure or temperature. Boundary conditions can be imposed at any point within the space, as well as to the edges of the region being modeled.

All of the capabilitles of CCC have been tested by Golder Associates, and all perform adequately. 
Program Usability

The flexibility of CCC makes it difficult for the user to understand and code input parameters. Although the input manual is fairly comprehensive, there are many parameters which cannot be determined without the expenditure of considerable time and effort.

In addition, the iteration scheme used by CCC depends on several empirical factors. These factors are difficult for an inexperienced user to deduce and yet control the efficiency of calculations. With properly selected factors, efficlency can be an order of magnitude greater than with default values.

Output from the program, including stresses, temperatures, and changes at all nodal points and boundaries, is comprehensive. Control of printout time intervals is inexact because the program chooses its own time steps.

The cost of the program is dependent on three factors:

- Size and detall of modeled region

- Time frame

- Iteration input parameters (discussed above).

For simple, one-dimensional problems, solution can be achieved in a few CPU seconds, while three-dimensional, nonlinear models may require hundreds or thousands of CPU seconds.

\section{Performance on Sample Problems}

CCC could be implemented for any problem in which flow occurred. It was used for sample problem 2 (one-dimenstonal) and for sample problem 4 (two-dimensional). 
Coding of sample problems was moderately difficult... Even though simple material properties were assumed and thermal effects were Ignored, iteration parameters took considerable effort to determine.

The efficlency of CCC for the sample problems was reduced conslderably by the fact that even though thermal effects were Ignored, CCC still performed coupled heat-flow calculations. Sample problem 2 took $3.5 \mathrm{CPU}$ seconds, while sample problem 4 took $18.3 \mathrm{CPU}$ seconds. - Pore-pressure changes predicted for sample problem 2 agree with - results obtalned with hand calculations and one-dimensional consolidation program UPDOWN. Pore-pressure changes predicted for sample problem 4 are identical to one-dimensional results over the reservolr and decrease rapidly at distance. This conforms with expectations.

Three-Dimensional Displacement-Discontinuity Mode1 NFOLD

Theory and Computational Method

NFOLD models the propogation of stress and displacement from thin rectangular elements within an elastic space. NFOLD uses a threedimensional displacement-discontinuity approach developed by Sinha and

- Crouch (Crouch 1976). This approach allows considerable savings in time and expense, since only the discontinuity elements themselves must be modeled:

NFOLD accepts as Input prescribed values of reservolr compaction and cannot model flow or boundary condition changes with time. Reservolr compaction has to be computed by a model such as CCC.

\section{Program Capab1litles}

NFOLD does all calculations in three dimensions and therefore is not efficient for one- or two-dimensional analyses. One- or 
two-dimensional analyses can be performed using NFOLD by approximating their conditions in three dimensions.

NFOLD models the rock mass as a homogeneous, isotropic linear elastic whole space or half-space. It cannot handle multiple materials. It can, however, model nonlinear and stress-free discontinuities and is therefore 1deal for modeling fault zones.

Geothermal reservoirs are modeled by vertical displacements (compaction) only. This limits applicabllity where substantial horizontal movement occurs or where reservolr displacements cannot be calculated. NFOLD can be used in conjunction with multidimensional flow programs such as CCC.

In its present form, NFOLD cannnot compute deformations other than at elements, although the equations for this calculation are known. As a result, we were forced to use elements to model the ground surface (rather than using the half-space option in the program), which greatly increased the cost of analysis.

\section{Program Usability}

NFOLD is designed for ease of use. Input is simplifled by a clever automatic element generation scheme. Output is avallable in clearly labeled tables and on printer plots. Documentation of the program theory is avallable in published papers. (Crouch 1973; Crouch and Fairhurst 1976) and in a thesis (Sinha 1979).. The program users' manual is adequate.

NFOLD is considerably more efficient than other three-dimensional models based on finite elements or finite differences. Extensive threedimenstonal models can be run for under $300 \mathrm{CPU}$ seconds, including nonlinear fault elements. 


\section{Performance on Sample Problems}

As a three-dimensional model, NFOLD is inapproprlate for most of the case studies, which are one- or two-dimensional. NFOLD was used to model sample problem 3, which is two-dimensional, by use of a large width to approximate a two-dimensional condition. The model produced results within 25 percent of the Geertsma analytic solution at a cost of $130 \mathrm{CPU}$ seconds and accurate results at a cost of about 300 CPU seconds. The high cost is due to the necessity of modeling in three dimensfons.

When used for a simple three-dimensional case study, the cost was only $20 \mathrm{CPU}$ seconds.

\section{SUMMARY OF MODEL ASSESSMENTS}

All of the selected models were able to accurately perform their calculations. There were, however, mafor differences in the usability of the models. The two largest mode1s, CCC and CONSOL3, were Inadequately documented for novice users and consumed a large amounts of time in trial-and-error experimentation to understand input parameters. None of the models had programmers documentation (11sts of varlables, flow charts). None of the programs produced plotted output (except NFOLD, which produced printer-plots of stresses and displacement). Table 5 presents a qualitative summary of the results of the proficlency: assessment.

It would be Inappropriate to suggest that the deficlencies in model usability were the fault of the model developers. Most of the models were developed. with the intention that they would be used only by their creators. Also, the cost of making a program highly usable and fully documenting it usually exceeds the cost of developing the program in the first place. 
TABLE 5

RESULTS OF PROFICIENCY ASSESSMENT

\begin{tabular}{|c|c|c|c|c|c|}
\hline \multirow[b]{2}{*}{ MODEL } & \multirow[b]{2}{*}{ EFFICIENCY } & \multicolumn{3}{|c|}{$\begin{array}{r}\text { USABILITY } \\
\end{array}$} & \multirow[b]{2}{*}{ PROGRAMMING } \\
\hline & & DOCUMENTATION & INPUT & OUTPUT & \\
\hline Hand Calcs & UG & G & $\mathrm{NA}$ & NA & NA \\
\hline $\begin{array}{l}\text { Nucleus-of- } \\
\text { Strain SUBSID }\end{array}$ & UG & G(2) & G & G & $\mathbf{F}$ \\
\hline $\begin{array}{l}\text { Terzagh1 } \\
\text { Consol. UPDOWN }\end{array}$ & ug & $\mathbf{F}$ & G & G & $\mathbf{F}$ \\
\hline $\begin{array}{l}\text { 2-D Boundary- } \\
\text { Integral- } \\
\text { Equation Method } \\
\text { BIEM2D }\end{array}$ & UG & G(2) & VG & G & $F-G$ \\
\hline $\begin{array}{l}\text { 2-D Coupled } \\
\text { FEM CONSOL3 }\end{array}$ & $\mathbf{P}$ & $\mathbf{P}$ & $\mathbf{F}$ & F & $\mathbf{P}$ \\
\hline $\begin{array}{l}\text { 3-D IFD } \\
\text { Flow Model CCC }\end{array}$ & $P-G(1)$ & P-F (2) & $\mathbf{F}$ & $F-G$ & $\mathbf{P}$ \\
\hline $\begin{array}{l}\text { 3-D Displace- } \\
\text { ment Discon- } \\
\text { tinuity NFoLd }\end{array}$ & F & G & G & G & $\mathbf{F}$ \\
\hline
\end{tabular}

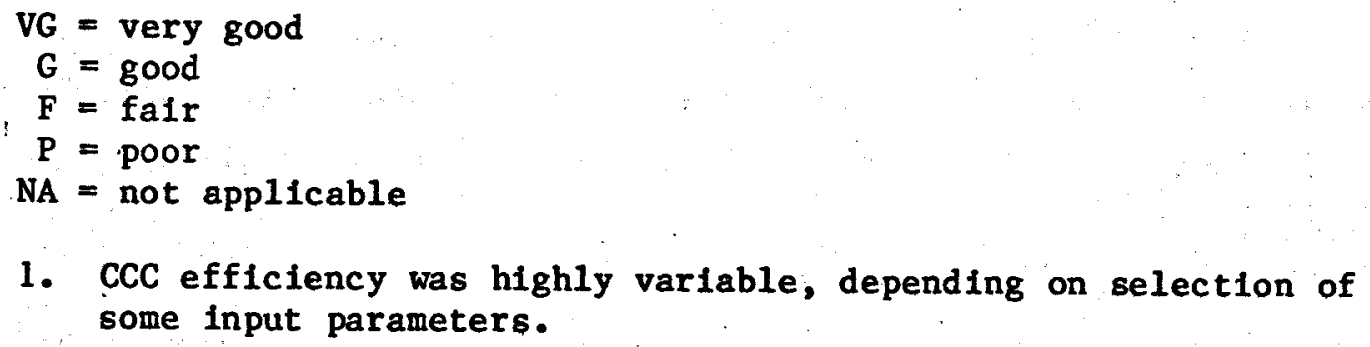

1. CCC efficiency was highly variable, depending on selection of some input parameters.

2. The original documentation was upgraded by Golder Associates. Users' manuals for BIEM2D and SUBSID are included in Companion Report 2 (Miller et al. 1979b). The improved manual for CCC is available from Golder Associates. 


\section{CASE STUDIES}

\section{INTRODUCTION}

The objective of the case study phase of this research was to assess subsidence prediction capabilities through simulation of selected case histories. Selection of the mathematical models used in these simulations was described earlier. In this section, the selection of three acceptable case histories 18 described and the results of the various simulations are discussed.

\section{SELECTION OF CASE HISTORY}

Two "real" subsidence case historles and an "Ideallzed" case history were selected. The two real-case histories were to be modeled as accurately as possible with avallable data. Candidate sites were Wairake1, Chocolate Bayou, and The Geysers. From these, Wa1rakel and The Geysers were selected. The idealized-case study, though based on a real site, was to be more generalized and hypothetical in nature than the real-case studies. Candidate sites were Austin Bayou Prospect, East Mesa, and Raft River. Austin Bayou Prospect was selected as the Idealized-case study.

These case historles were selected based on three criterla :

1. Relevance or similarity to other geothermal systems

2. Quality and quantity of avallable data

3. Diversity of geohydrologic environment represented.

Each criterion is discussed further in the following section. 
Selection Criteria

\section{Similarity of Environment}

The most relevant of the avallable subsidence case histories are obviously those for geothermal sites. Unfortunately, there are very few such sites worldwide. Therefore, other subsidence sites having geohydrologic characteristics analogous or simflar to geothermal environments were also considered. One example is the Chocolate Bayou ofl and gas field in Texas (part of which is geopressured), which is analogous to Gulf Coast geopressured geothermal sites.

In selecting a case to use as a model for the idealized case history, additional sites currently being explored and tested for potential geothermal power development were considered. Some of these sites have the potential to develop subsidence problems.

\section{Data Availability}

Availability of detalled, accurate data was a critical criterion for case history selection. Defining input data for simulation of a case using the more sophisticated models would require extensive knowledge of the geothermal system, Including 1ts geometry, fluid and solid properties, and history of development. Both input data and data on reservoir and overburden response to production were required as a check of the models.

To assist in comparing candidate sites, desired data were subdivided into the following categories:

- System definition

- Reservoir development 
- Reservolr response

- Overburden response

- Physical-mechenlcal parameters

Typical data requirements corresponding to each of these categories are summarlzed in Table 6 .

Considering the amount of data and detall required, it is not surprising that none of the case historles reviewed ylelded a satisfactory data set.

\section{Diversity of Environment}

An effort has been made to select case histories representing the spectrum of geohydrological environments. There is obviously a limit to the diversity which can be incorporated Into three case studies. Nevertheless, an attempt was made to select cases exhibiting variations in the following factors:

- Reservolir fluid type (one ór two phases)

- Reservolr and overburden geology

- Fluid pressures (e,g., geopressured or normally pressured).

Diversity is also important as a check on the range of applicability of the models. Models which accurately predict subsidence in one environment may be poor simulators of physical processes in another environment. For example, the assumption of a linear relation between volume change and pressure may be valid in one case but inaccurate in a case which involves larger pressure changes. Thus, a goal of our program was to determine the limitations of models with respect ta simulation of the various different aspects of reservolr and overburden behavior. A parallel goal was that of developing an understanding of 
TABLE 6

DESIRED DATA FOR CASE HISTORY STUDIES

\section{CATEGORY}

System Definition

Reservoir Development

Reservoir Response

Overburden Response

Physical-Mechanical

Parameters

\section{TYP ICAL DATA REQUIREMENTS}

Geology of reservoir and overburden, geohydrologic boundaries, faulting, inftial conditions (temperature, pressure, stress), heat-flow conditions (convective, conductive)

Number and location of wells, chronology of well placement, depth of completion, production rates and magnitudes, reinjection

Changes in temperature, pressure, flow rates; pressure changes in interburden, compaction of reservoir

Pressure changes, deformations below and on surface (subsidence measurements)

Permeability, porosity, compressibility of interburden and adjacent overburden, material constants (moduli, etc.) 
the relationship between accuracy of modeling of certain physical processes and accuracy of subsidence prediction.

\section{Discussion of Selected Sites}

The process of case history selection was made significantly easier by a previously completed study, "Case Historles of Subsidence Areas" (Grimsrud et al. 1978). In the Grimsrud study, 34 subsidence sites worldwide were evaluated and four were selected for detailed review. The criteria for selection of these four sites were essentially the same as the criteria discussed above. Thus, it was not necessary to re-evaluate the same Initially large number of candidate sites. The four subsidence case historles presented in detail in the Grimsrud report were reviewed with respect to the specific requirements of this study, and two additional sites were evaluated for possible use as base cases for the 1dealized-case study. As a result of this review process, three candidate sites for real-case historles were selected (Wairake1, The Geysers, and Chocolate Bayou) and three candidate sites for the Idealized-case study were selected (Austin Bayou Prospect, Raft River Basin, and East Mesa). These six sites are reviewed in Companion Report 3 (Miller et al. 1980c).

Table 7 is a summary of data avallability and presents a qual1tative ranking of the data avallability for each candidate case history. Included in the rating is an evaluation of how well the data represent In situ conditions. For example, permeabilities determined from well tests are much more representative of in situ permeabilities than permeabilities measured from intact rock core. This is particularly true in cases where flow is fracture-influenced or fracture-controlled (e.g., The Geysers and Wairake1). From Table 7 it is immedlately clear that there is no avallable case where all required data are available. 
TABLE 7

DATA AVAILABILITY OF CANDIDATE SITES

\begin{tabular}{|c|c|c|c|c|c|c|c|}
\hline & & Walrake1 & Geysers & $\begin{array}{l}\text { Chocolate } \\
\text { Bayou }\end{array}$ & $\begin{array}{l}\text { Austin } \\
\text { Bayou }\end{array}$ & $\begin{array}{l}\text { East } \\
\text { Mesa }\end{array}$ & $\begin{array}{r}\text { Raft } \\
\text { River }\end{array}$ \\
\hline $\begin{array}{l}\text { Systew } \\
\text { Definition }\end{array}$ & $\begin{array}{l}\text { Stratigraphy } \\
\text { Geologic Structure } \\
\text { Hydrologic Boundaries } \\
\text { Initial Conditions } \\
\text { Heat Flow }\end{array}$ & $\begin{array}{l}\text { Good } \\
\text { Good } \\
\text { Fair } \\
\text { Good } \\
\text { Poor }\end{array}$ & $\begin{array}{l}\text { Fair-Poor } \\
\text { Fair-Poor } \\
\text { Fair } \\
\text { Good } \\
\text { Poor }\end{array}$ & $\begin{array}{l}\text { Good-Excellent } \\
\text { Good-Excellent } \\
\text { Good } \\
\text { Good } \\
\text { Poor }\end{array}$ & $\begin{array}{l}\text { Good-Excellent } \\
\text { Good-Excellent } \\
\text { Good } \\
\text { Good } \\
\text { Poor }\end{array}$ & $\begin{array}{l}\text { Fatr } \\
\text { to } \\
\text { Poor }\end{array}$ & $\begin{array}{l}\text { Fa1r } \\
\text { to } \\
\text { Poor }\end{array}$ \\
\hline $\begin{array}{l}\text { Reservolr } \\
\text { Development }\end{array}$ & $\begin{array}{l}\text { Drilling History } \\
\text { Fluld Production } \\
\text { History } \\
\text { Reinfection/ } \\
\text { Recharge }\end{array}$ & $\begin{array}{l}\text { Excellent } \\
\text { Good } \\
\text { Poor }\end{array}$ & Fair & $\begin{array}{l}\text { Excellent* } \\
\text { Good* } \\
\text { Falr }\end{array}$ & NA & NA & NA \\
\hline $\begin{array}{l}\text { Reservolr } \\
\text { Response }\end{array}$ & $\begin{array}{l}\text { Pressure } \\
\text { Temperature } \\
\text { Interburden } \\
\quad \text { Changes } \\
\text { Reservoir } \\
\quad \text { Compaction }\end{array}$ & $\begin{array}{l}\text { Excellent } \\
\text { Fair } \\
\text { None } \\
\text { None }\end{array}$ & Pair & $\begin{array}{l}\text { Good* } \\
\text { None } \\
\text { None }\end{array}$ & NA & NA & NA \\
\hline $\begin{array}{l}\text { Overburden } \\
\text { Response }\end{array}$ & $\begin{array}{l}\text { Surface } \\
\text { Subsidence } \\
\text { Subsurface Movement }\end{array}$ & $\begin{array}{l}\text { Excellent } \\
\text { None }\end{array}$ & $\begin{array}{l}\text { Good } \\
\text { None }\end{array}$ & $\begin{array}{l}\text { Fair } \\
\vdots \\
\text { None }\end{array}$ & NA & NA & $\mathrm{NA}$ \\
\hline $\begin{array}{l}\text { Physical } \\
\text { Mechanical } \\
\text { Parameters }\end{array}$ & $\begin{array}{l}\text { Permeability } \\
\text { Porosity } \\
\text { Compressibility } \\
\text { Deformation Moduli } \\
\text { Thermal Properties }\end{array}$ & $\begin{array}{l}\text { Fair } \\
\text { to } \\
\text { Poor }\end{array}$ & $\begin{array}{l}\text { Poor } \\
\text { to } \\
\text { None }\end{array}$ & $\begin{array}{l}\text { Good for } \\
\text { Reservoir, } \\
\text { Poor } \\
\text { Otherwise }\end{array}$ & $\begin{array}{l}\text { Good for } \\
\text { Reservoir, } \\
\text { Poor } \\
\text { Otherwise }\end{array}$ & $\begin{array}{l}\text { Fair for } \\
\text { Reservolr, } \\
\text { None } \\
\text { Otherwise }\end{array}$ & $\begin{array}{l}\text { Poor } \\
\text { to } \\
\text { None }\end{array}$ \\
\hline
\end{tabular}

*Assumed available at Texas Railroad Commission

NA - Not Applicable 
There are three reasons for incomplete or unsatisfactory data.

- Usually, data are gathered to meet objectives other than subsidence prediction. (For instance, in the oll flelds there is detalled information on the reservolr rocks but little information on interburden and overburden.)

- The complexity of many systems precludes obtaining a precise understanding of their characterlstics. The Influence of intricate fault networks on reservolr flow patterns is an example of the type of system complexity commonly found and incompletely understood.

- It is difficult to obtain realistic physical-mechanical parameters and design laboratory or field experiments which will yield parameters truly indicative of mass behavior. This is often a problem of scale; the size of the sample tested is too small to be representative of the entire mass. This problem of realistic parameters is not restricted to the cases selected in this study; it will be met whenever subsidence prediction is attempted.

The problems of unreliable parameters or system complexity are partially circumvented by models which require little detall for system definition and few input parameters. Generally, such models are considered to be less accurate theoretically, though they may in fact provide results as accurate as those of more complex models. Thus, there are tradeoffs between data completeness, model complexity, and accuracy of predictions. One of the objectives of this study has been to assess these tradeoffs.

From the three candidate sites, Wairakel and The Geysers were selected for real-subsidence case histories. 
There were two primary reasons for these selections.

- Wairakei represents the most complete subsidence case history. In addition, it is a case in which the withdrawal of geothermal fluids has definitely been related to surface subsidence.

- The Geysers is an Important case to study because it is the only one of the six candidate cases with a vapor-dominated geothermal reservolr.

Chocolate Bayou had the second most complete data set and is also located on the Gulf coast, a region from which a case study was desired. However, rather than use Chocolate Bayou as a real-subsidence case history, much of the data from Chocolate Bayou was incorporated into the data base for the idealized-case study described below.

The primary reasons for selecting Austin Bayou Prospect for the Idealized-case study are listed below.

- Austin Bayou Prospect is representative of a region (Gulf Coast) where there is potential for geothermal development.

- Due to abnormal pressures, there is a potential for significant subsidence.

- The sedimentary geology of sands and shales is different from the geologic units of Wairakel and The Geysers.

- The sediments are more nearly representative of a homogeneous porous medium than other sites and thus may be more amenable to modeling by continuum methods. 
- With the addition of data from Chocolate Bayou, Austin Bayou has a more complete data basé than the other candidate idealized cases. 


\section{REAL-CASE STUDIES}

\section{INTRODUCTION}

The two real-case studies afforded the opportunity to use avallable modeling techniques and information to simulate the behavior of real geothermal systems. The first real-case study was The Geysers geothermal field in Northern California, which has been in production for almost 20 years. The second, which is perhaps the best-documented case of geothermal subsidence, was the Walrakel geothermal field in New Zealand.

Real-case studies provided answers to several important questions.

- How well do current models and avallable information approximate real behavior?

- How can the appropriate modeling approach be determined for a given case?

- What type of Information is necessary for different modeling approaches?

- How applicable are the varlous models and their underlying assumptions?

In each case study, we will first present a brief description of the site which has been abstracted from Companion Report 3 (Miller et a1. 1980c). We w11l then describe the development of various models for the case from the point of view of the information requirements of the model. Finally, we will discuss the results of the modeling. 
$\underline{\text { THE GEYSERS }}$

\section{Brief Site Description}

The Geysers geothermal field is located in the Coast Range of Northern California. The reservoir rock is Franciscan Graywacke, and reservoir overburden includes solls, volcanics, shales and sandstones, and assorted igneous rocks.

Structura1ly, The Geysers' area is extremely complex and incompletely understood, with a series of fault blocks and thrust plates. The area is tectonically active.

The Geysers' geothermal resource is primarily in the form of steam. A hydrogeologic boundary to the northwest is provided by a fault, but other boundaries, including vertical boundaries, are unclear. The lateral extent of The Geysers' field has been estimated at 15,000 feet by 15,000 feet. The Geysers is relatively deep; steam has been recovered from wells to 10,040 feet and the bottom of the reservoir has not been established. The Geysers' depth is therefore of a magnitude similar to its extent. Thermal gradients and temperature changes due to pumping at The Geysers appear to play an important role in behavior.

The Geysers has two reservolrs: a relatively thin, shallow reservoir and an extensive deeper reservoir which was discovered later. The two reservoirs are partially connected. The nature of the hydrothermal flow system at The Geysers does not appear to be definitively understood. The reservoir is steam-dominated, but water appears to be present at all depths. One hypothesis is that steam rises from a deep boiling pool (at a depth of perhaps 15,000 to 20,000 feet), migrates upward, condenses in the upper part of the reservoir, and then trickles back down to the pool. 
Although a large amount of data may have been collected at The Geysers, most information is proprletary and was not avallable to us. Reservoir deformation information is completely unavailable. Surface subsidence from 1973 to 1977 is known to be 0.45 feet, however.

A more detailed description of The Geysers can be found in Companion Report 3 (Miller et al. 1980c).

\section{Models Used in Simulation}

Simulations of The Geysers were conducted using axisymmetric hand calculations, the two-dimensional boundary-element method, and the three-dimensional nucleus-of-strain method. Only deformation models were developed, as insufficient Information exists for development of flow models. Since temperature effects appear to be important, special attention was given to thermally-induced deformations.

Two-dimensional modeling of The Geysers was performed using the boundary-element method rather than the displacement-discontinuity method because the thickness of The Geysers' field made the use of displacement-discontinuity elements impractical. The boundary-element method can handle thick reservolrs. It is limited, however, to a homogeneous Ilnear elastic mass. Two-dimensional modeling could have been done equally well, if somewhat more expensively, with the consol 3 finiteelement model.

Three-dimensional modeling of The Geysers was performed with the nucleus-of-strain method. The nucleus-of-strain method can be used to represent complex, three-dimensional geometries such as that at the Geysers. 
Development of Required Information

Information required for calculations includes the following:

- Material properties

- Pressure changes

- Temperature changes.

Material properties were difficult to determine. No measured values for elastic or thermal deformation properties are available for The Geysers. The rock type of the reservoir region is Franciscan Greywacke, which exhibits elastic moduli in the range $E=2.1$ to $2.8 \mathrm{x}$ $10^{8} \mathrm{psf}, U=0.1$ to 0.6 (Wuerker 1963). A value of $2.6 \times 10^{8} \mathrm{psf}$ was selected as a representative value for $E$, and .. 2 was selected as a representative value for $U$. These represent Lame parameters $G=1.1 \mathrm{x}$ $10^{8} \mathrm{psf}$ and $\lambda=7.3 \times 10^{7} \mathrm{psf}$. For the sake of simplicity, the interaction coefficient was chosen as 1 , although a value of $0.8 \mathrm{might}$ be more reasonable. Thermal deformation properties vary little between geological materials and are generally in the range $5 \times 10^{-6}$ to $1.1 \times$ $10^{-5} \mathrm{C}^{-5}$ (Clark 1966). A value of $1 \times 10^{-5 \circ} \mathrm{C}^{-1}$ was assumed as a conservative value.

Subsidence information is available only for the period 1973-1977, and accordingly the simulations only covered that period. Historically, development of The Geysers occurred in two stages: prior to 1968, production was only from the shallow reservolrs, while subsequently it was primarily from the deep reservoirs. In the time period modeled, deformation from production of the shallow reservolr is assumed to have stopped.

\section{Pressure Changes}

The pressure changes were developed by extrapolation of values presented by Lipman et al. (1977), who determined that the initial 
pressure field for the hydrothermal system is an almost uniform pressure of $514 \mathrm{psi}\left(7.4 \times 10^{4} \mathrm{psf}\right)$. They also presented pressure contours in the deep reservolr as of 1977 for a sea-level datum (Figure 9).

Lipman et al. (1977) presented a pressure history at one location in the geothermal system (Cobb Mounta1n) which showed that about 75 percent of the total reduction in pore pressures from inftial conditions to 1977 occurred prior to 1973. The assumed pressure change profile with depth (Figure 10) was developed from Lipman's result as follows. Initial pressures were taken directly from Lipman's observation of initial pressures for the system. The pressure profile as of 1977 was then developed by projecting Lipman's sea-level pressures to the level of the well bottom at 8000 feet below sea level (neglecting the weight of the steam) and then assuming a Inear gradient to 12,000 feet below sea level, where pressures are again assumed to have their initial values. The pressure change from 1973 to 1977 is assumed to equal 25 percent of the total pressure change from inttial conditions to 1977.

The two-dimensional variation in the pressure change was developed by combining a simplified version of the one-dimensional pore-pressure profile (F1gure 10) and Lipman's (1977) contours at sea level (Figure 11). The resulting two-dimensional pore-pressure change profile for Initial conditions to 1977 is shown In Figure 12. Again, pore-pressure change from 1973 to 1977 is assumed to be 25 percent of that from initial conditions to 1977 .

\section{Temperature Changes}

Estimates of temperature changes at depth due to geothermal production are not avallable. Most of the avallable information on thermal behavior at The Geysers is summarized In Garrison (1972).

Garrison (1972) presents six pairs of data on pressure and temperature for some shallow wells. This relationship might be construed as 


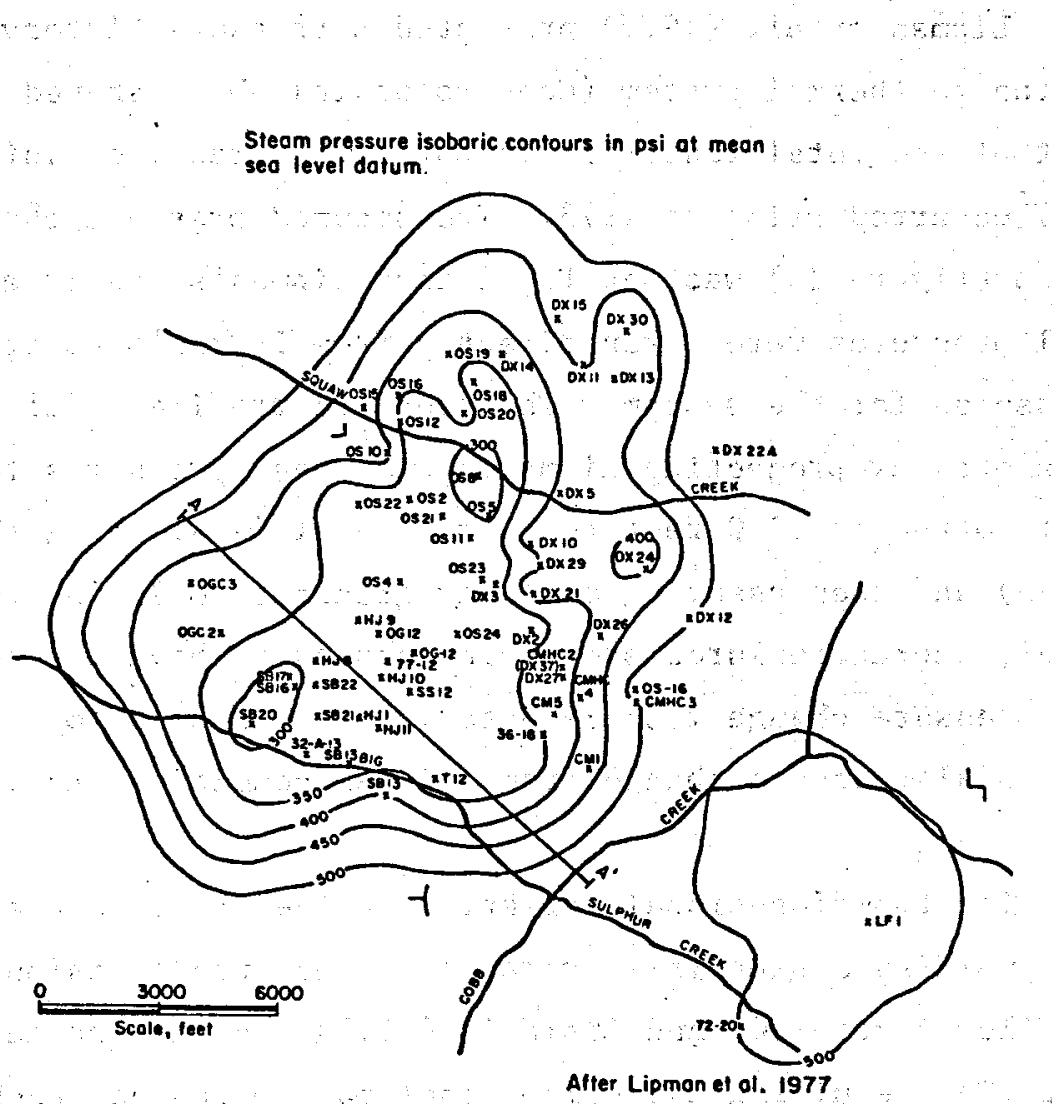

\section{FIGURE 9}

THE GEYSERS CASE STUDY

STEAM PRESSURES IN DEEP RESERVOIR, 1977

Reproduced with permission from Union

oil Company of California. 
Ground Surface

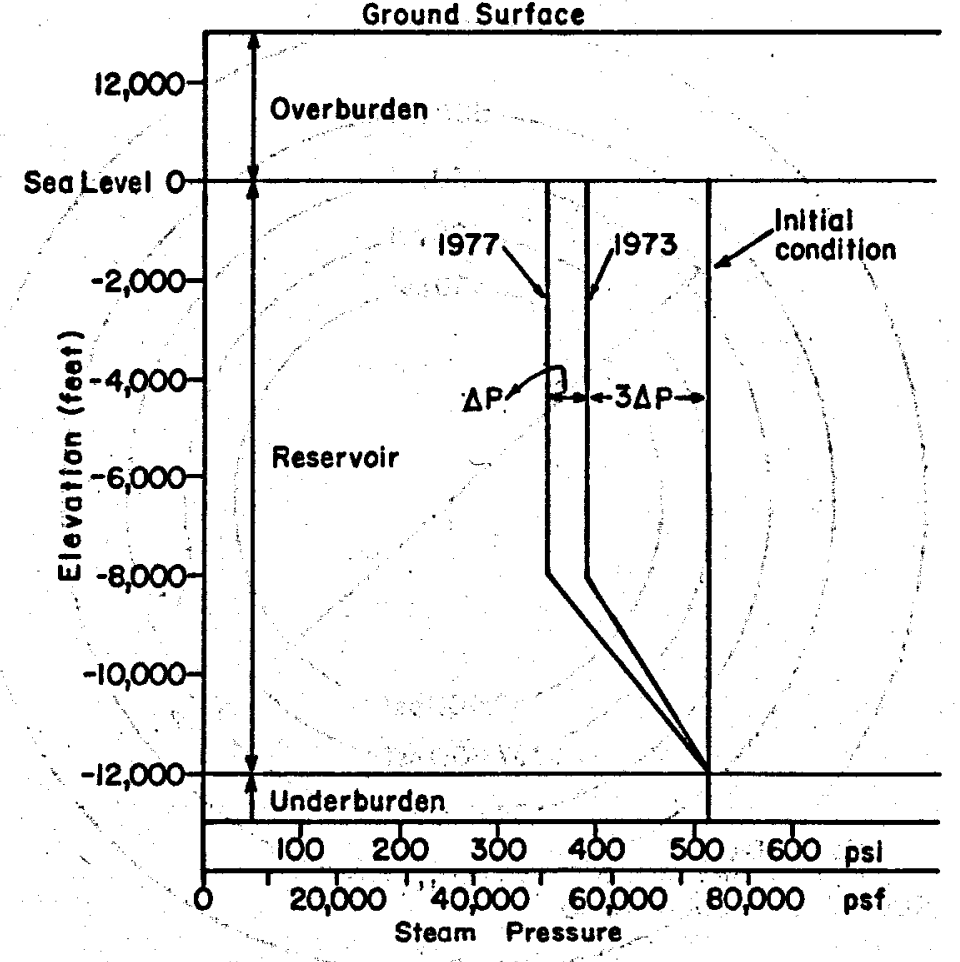

FIGURE 10

THE GEYSERS CASE STUDY

ASSUMED 1-D PRESSURE PROFILE 




FIGURE 11

THE GEYSERS CASE STUDY

SIMPLIFIED PLAN OF PRESSURE CONTOURS 



FIGURE 12

THE GEYSERS CASE STUDY ASSUMED 2-D PRESSURE PROFILE 
indicating that temperature is dependent on pressure. If, in its initial state, the reservoir is essentially uniform in pressure and temperature, these observations may all represent points on a single pressure-temperature curve. The data, which form an approximately straight line when plotted, result in the equation:

$$
\Delta T=9.31 \times 10^{-4} \Delta P
$$

where $\Delta T=$ temperature change in degrees centigrade $\Delta P=$ pressure change in psf.

An alternative method for predicting the temperature-change profile is from thermodynamic considerations. Assuming a constant enthalpy expansion of the steam from the point of maximum enthalpy produces a $\Delta \mathrm{T}-\Delta \mathrm{P}$ relation very close to that given above.

Truesdale and White (1973) propose a model for vapor-dominated reservolirs where there is a temperature drop as pressures decrease and pore water bolls, draining heat from the rock. (Eventually, however, the pore water boils away and the underlying pool starts to boll. As it boils down its salinity increases, and so does the temperature of the steam it produces.)

Even if the above expression for steam temperature drop is essentially correct, there is no way to know whether the rock will remain at the same temperature as the steam. Assuming that it does, it is possible to compute the effects of thermal contraction based on the pressure drop. As set out in Companion Report 1 (Miller et al. 1980a), the effect of a temperature change of $\Delta T$ for an isotropic material is equivalent to a pore-pressure change of $3 \alpha \mathrm{K} \Delta \mathrm{T}$ divided by the pore-pressure interaction coefficient (unity in this case). In the above expression, $\alpha$ is the coeffictent of linear thermal expansion and $K$ is the bulk modulus. Combining the effects of pressure and temperature drop into an equivalent pressure drop $\Delta \mathrm{P}^{*}$ gives: 


$$
\begin{aligned}
\Delta P^{*} & =\Delta P\left(1+3 \times 10^{-5} \times 1.44 \times 10^{8} \times 9.31 \times 10^{-4}\right) \\
& =5.03 \Delta P
\end{aligned}
$$

Thus it appears that temperature effects at The Geysers are over four times as important as pressure effects.

Resume of Mode1s

\section{Hand Calculations}

Hand calculations for The Geysers case study used the thermo-poroelastic theory developed in Companion Report 1 (M11ler et al, 1980a) and in Companion Report 2 (Miller et al. 1980b).

For a pore pressure drop of $5904 \mathrm{psf}$ and $c_{\mathrm{m}}=3.462 \times 10^{-9}$, psf $^{-1}$, the compaction of the approximately 10,000 -foot-th1ck reservoir interval is

$$
C=\left(3.462 \times 10^{-9}\right)(5.03 \times 5904)(10,000)=1.03 \text { feet }
$$

In a one-dimensional system this would result in a uniform subsidence of 1.03 feet at the surface.

Modeling the reservolr interval as a single disc at a depth below the surface of 8000 feet and a radius of 6150 feet gives a surface subsidence profile (equation [8] in Companion Report 2).

$$
U_{z}=2(1.03)(.8) A \cdot(p, 1.30)
$$

Substituting values of A from Table 1 of Companion Report 2 (Miller et a1. $1980 \mathrm{~b}$ ), the subsidence profile shown in Figure 6 was computed. The maximum subsidence is 0.344 feet. 
Considering the great vertical extent of the reservoir and the horizontal and vertical variation of pressure and associated temperature change, a more accurate 12-disk model of the reservolr was developed (Figure 13). The pressure drop on each disk was 2452 psf; thus, where two coaxial disks overlapped, the total pressure drop was 5904 psf. Disks 1 through 5 had 8600-foot diameters and disks 6 through 12 had 16,000-foot diameters. Disks 1, 2, 6, and 7 were 1000 feet thick while the remaining disks were 2000 feet thick. The surface subsidence due to this stack of disks can be calculated by adding the effects of the 12 disks. The maximum subsidence for the 12-disk mode1-0.410 feet-is 19 percent greater than that for the single-disk model. Figure 16 compares the predicted surface subsidence profile.

\section{Two-Dimensiona1 Boundary-Integra1-Equation Mode1 BIEM2D}

- Two-dimensional (plane strain) modeling was performed with BIEM2D, a two-dimensional boundary-integral-equation method (boundary element) model. BIEM2D is an inexpensive, easy-to-use model. Although the conceptual model of The Geysers is axisymetric, BIEM2D was forced to treat it as a planar problem.

Figure 16 shows the subidence computed by BIEM2D. The maximum displacement is 2.68 feet from initial conditions to 1977 , or 0.67 feet from 1973 to 1977 .

\section{Three-Dimensional Nucleus-of-Strain Mode1 SUBSID}

Nucleus-of-strain model SUBSID was used for three-dimensional (axisymmetric) modeling of The Geysers. Pressure-change values were assumed based upon simplified versions of the pressure contours shown in Figure 12. Temperature-change effects were handled as they were in the other models. 


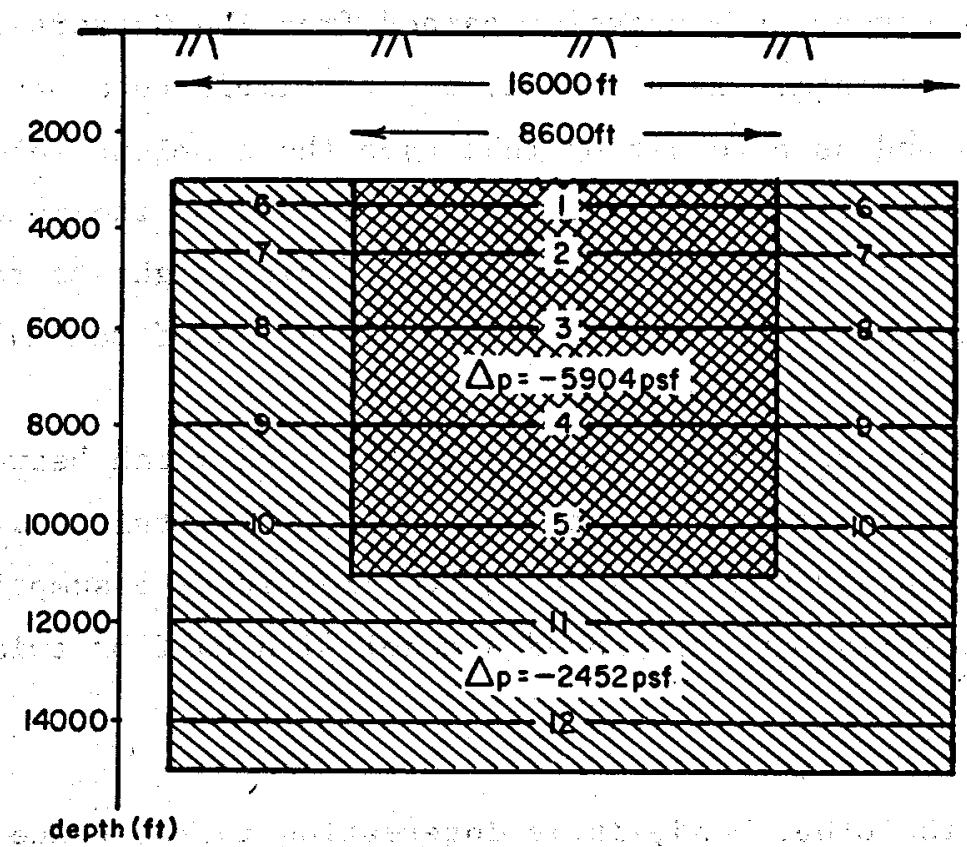

FIGURE 13

THE GEYSERS CASE STUDY

HAND-CALCULATION MODEL USING 12 DISKS 
Two nucleus-of-strain models were developed. The first used two spheres to model the pressure drop and the second used 72 spheres. The nucleus-of-strain models are illustrated in figures 14 and 15 . The maximum computed surface subsidence was 0.54 and 0.42 feet, respectively, from 1973 to 1977 .

The Geyers Summary

The strongest impression gained from The Geysers case study is of the lack of data. As a result, a very simple conceptual model was developed, and as a result of that even the simplest subsidence models were reasonably appropriate. However, none of the models predicted the east-west tilting shown in Figure 16 (which might be tectonic) and none predicted the localized nature of the region of maximal subsidence.

It is our opinion that the rather good match between predicted and observed subsidence (Figure 16) is largely fortultous. Our model of The Geysers contained a number of quite gratuitous assumptions, and we could just as easily have developed a model with half or twice the subsidence.

On the other hand, it is interesting to speculate on the amount of additional data that would be required if one wanted to significantly decrease the uncertainty in the model. It appears to us that it would take a major investigative program to achieve this end.

\section{WAIRAKEI}

\section{Brief Site Description}

The Wairakel geothermal field is located on the North Island of New Zealand in the island's central volcanic district. This region is heavily faulted with highly variable stratigraphy, including sandstone, 
81

1

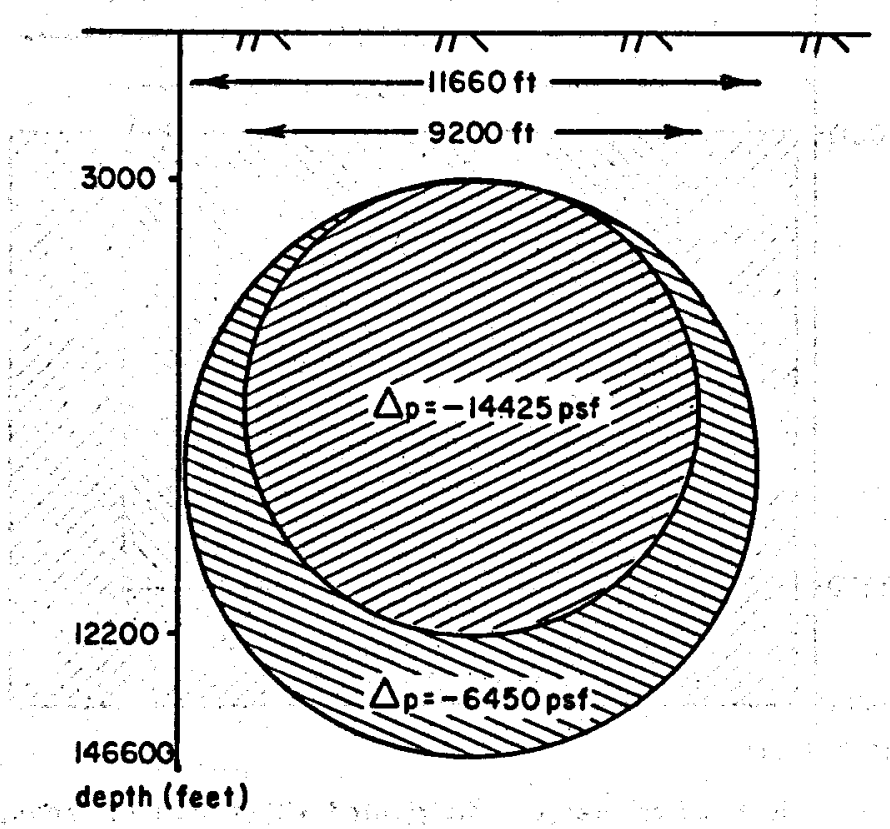

FIGURE 14

THE GEYSERS CASE STUDY

NUCLEUS-OF-STRAIN MODEL USING TWO SPHERES 


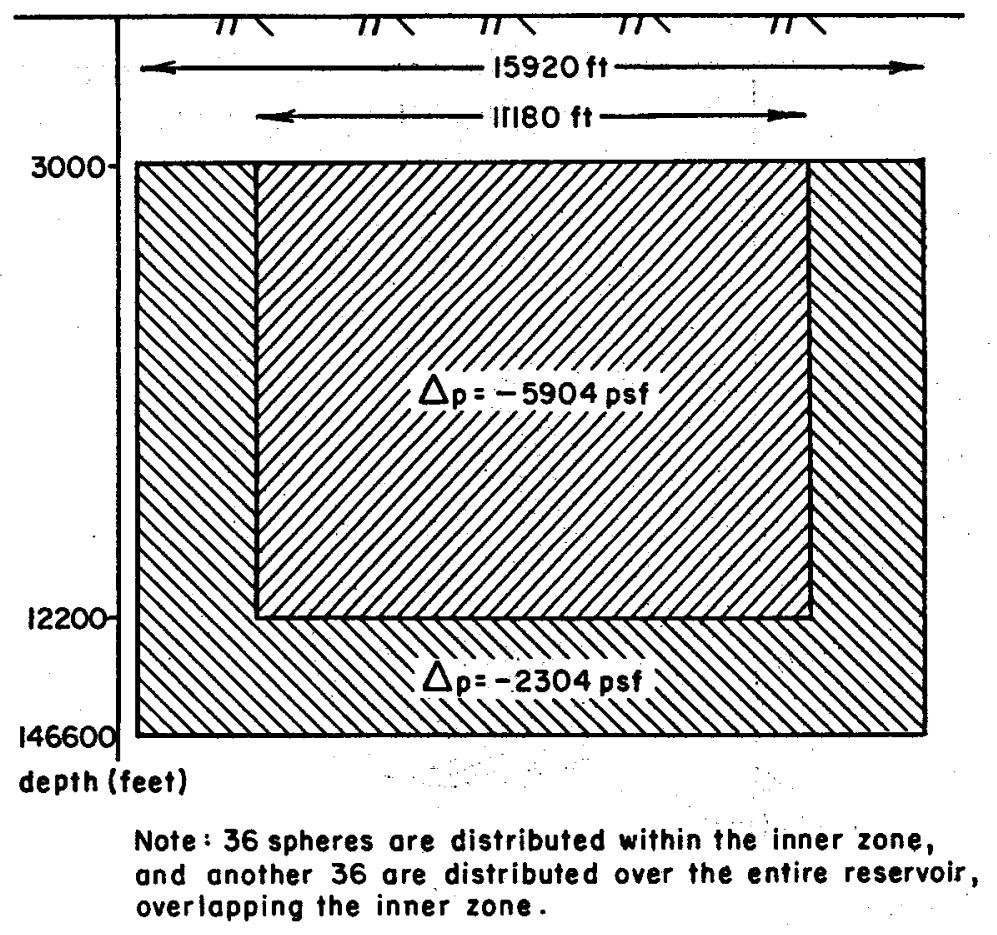

FIGURE 15

THE GEYSERS CASE STUDY

NUCLEUS-OF-STRAIN MODEL USING 72 SPHERES 




FIGURE 16

THE GEYSERS CASE STUDY

OBSERVED AND PREDICTED SUBSTDENCE PROFILES 
siltstones, and igneous intrusives. The field is clearly bounded hydrologically, but there is no evidence to indicate bounding of deformations.

Most hydrotheraal production is from faults. Production wells are generally 450 to 3000 feet in depth, though some extend to 4000 feet. Substantial pressure and temperature variations are found within the geothermal field.

A more detailed description can be found in Companion Report 3 (Miller et al. 1980c).

Models Used in Simulation

One-, two-, and three-dimensional simulations of Wairakel were attempted using hand calculations, Lewis' CONSOL3 model, and nucleusof-strain method SUBSID. Models were studied only for subsidence, so no flow models of Wairakei were attempted.

One-dimensional hand calculations have the advantage of simplicity and the ability to handle thermal effects and variations in material properties. CONSOL3 allows two-dimensional plane-strain finite-element analysis of stresses and deformations with multiple materials. It cannot, however, model thermal effects. The reservoir geometry at Wairakel is complex and may play an important role in subsidence. It cannot be represented adequately by either one- or two-dimensional models. The three-dimensional nucleus-of-strain model sUBSID allows a sophisticated representation of the geometry but requires the material in the half-space to be homogeneous.

Readers interested in hydrogeologic modeling of the Walrakei reservoir are referred to Pritchett et al. (1976) and to Mercer and Faust (1979). 
Resume of Model Simulations

One-Dimensional Hand Calculations

One-dimensional hand calculations for Wairakel ut1lized the same thermo-poro-elastic theory as was used in The Geysers case study. Due to the large lateral extent and the shallow depth of the Walrakel system, it was assumed that reservolr compaction would be fully reflected at the ground surface. The time period over which pressure information is avallable at Watrake is 1955-1976, and that is the period used in this study. Subsidence data were obtained from Pritchett et al. (1978) for the period 1956-1971.

For hand calculations, the following one-dimensional information was required:

- Material-property profile

- Pressure-change profile

- Temperature-change profile

Material Properties had to be specified for two formations at Wairake1, since significant changes in stress and temperature occur in both formations. The aquifer at Walrakel consists primarily of the Walora Formation. Overlying the Walora Formation is the Huka Falls aquitard. Values for thermoelastic properties of the Walora Formation and Huka Falls were obtained from Hendrickson (1976).

$\begin{array}{llll} & \begin{array}{c}\lambda \\ \text { (psf) }\end{array} & \begin{array}{c}G \\ (\text { psf) }\end{array} & \begin{array}{c}\alpha \\ \left({ }^{\circ} \mathrm{C}^{-1}\right)\end{array} \\ \text { Huka Fal1s } & 2.09 \times 10^{6} & 3.13 \times 10^{6} & 8.2 \times 10^{-6} \\ \text { Waiora Fm. } & 2.09 \times 10^{7} & 3.13 \times 10^{7} & 8.2 \times 10^{-6}\end{array}$

The stratigraphic profile of Wairakel varles over the entire cross section (figures 17 and 18). For the purpose of one-dimensional 


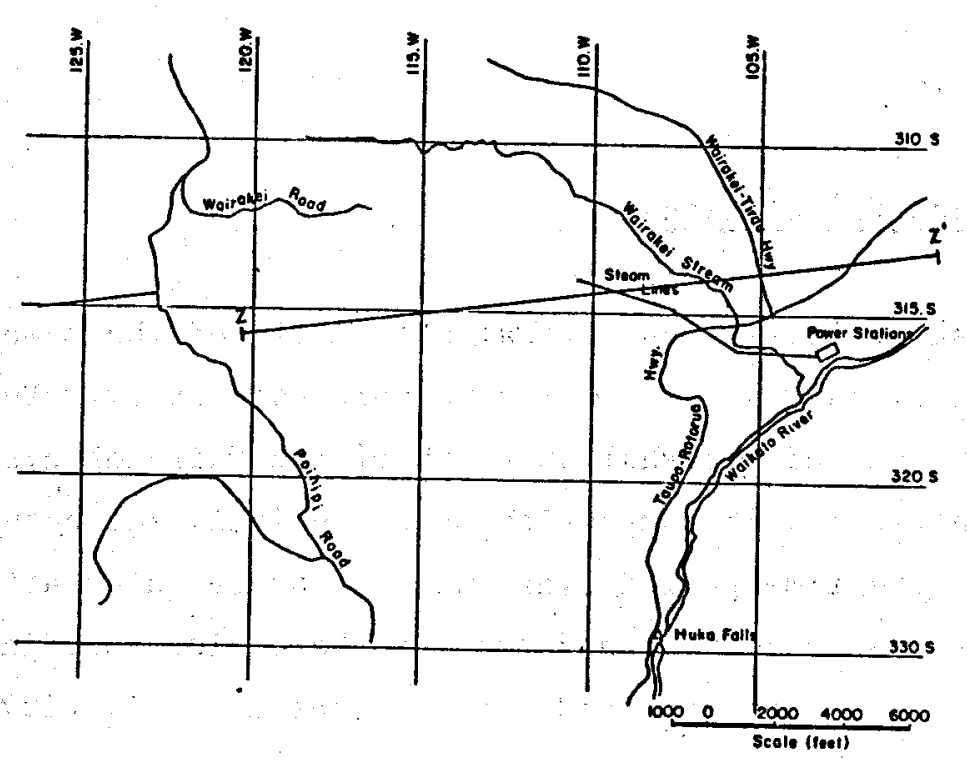

FIGURE 17

WAIRAKEI CASE STUDY

PLAN OF GEOTHERMAL FIELD

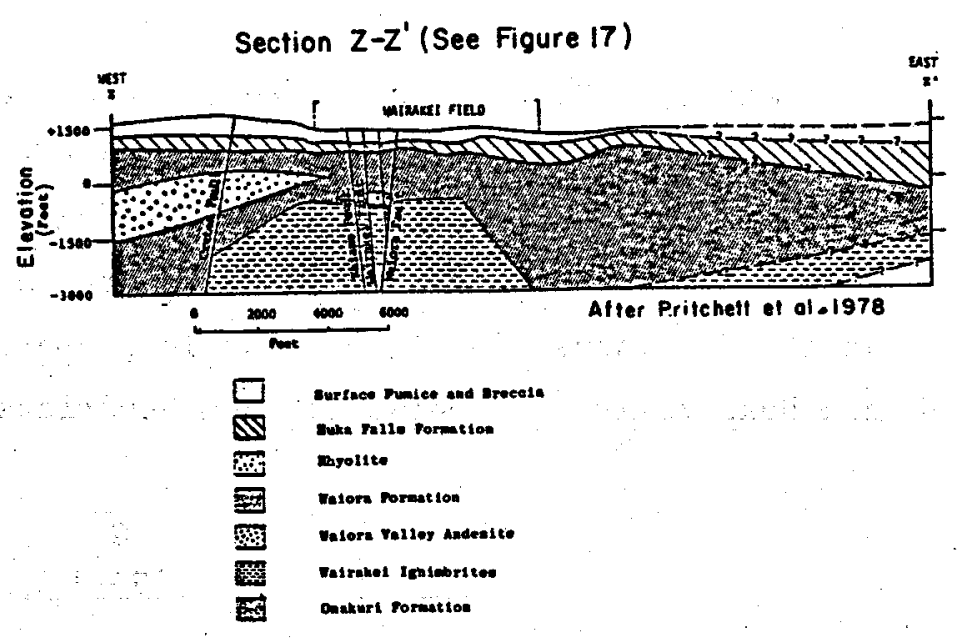

FIGURE 18

WAIRAKEI CASE STUDY

CROSS SECTION OF GEOTHERMAL FIELD 
analysis, a cross section with a maximum of the Waiora Formation (borehole 59) was selected (Figure 19).

Scant data are available for establishing vertical pressure change profiles in either the Waiora Formation or the Huka Falls Formation. In the Waiora, the on $1 y$ avallable pressure change information is a pressure drop of $4.75 \times 10^{4}$ psf from 1955 to 1976 recorded by Pritchett et al. (1978) at an elevation of 500 feet below sea level. . This pressure change was assumed to represent the entire Walora Formation. It is 11 kely that pressures do vary within the formation, especially considerIng the presence of steam in the upper part of the aquifer. However, no data are avallable to substantiate that.

In the Huka Falls Formation, monitoring wells recorded pressure drops of approximately $3.89 \times 10^{4}$ psf near the boundary with the Waiora. It was assumed that the average pressure drop for the entire Huka Falls Formation was one-third this value, or $1.30 \times 10^{4} \mathrm{psf}$. Pressure drops assumed for the Huka Falls and Walora formations are shown in Figure 19.

Temperature change profiles were based on Bolton (1970). Below an elevation of -1000 feet, Bolton found no temperature change. At +600 feet, a drop of 29 degrees centigrade occurred between 1956 and 1969. Using a linear interpolation between those two points, the temperaturechange profile shown in Figure 19 was developed. It was assumed that additional temperature drops from period 1969-1976 were not significant.

Using the expression for linear elastic compaction,

$$
C=\frac{H}{\lambda+2 G} \Delta P+3 K \propto \Delta T
$$

the compaction of the Waiora and Huka Falls formations due to the assumed pressure and temperature change profiles was calculated for the 




FIGURE 19

WAIRAKEI CASE STUDY

1-D MODEL ASSUMED TEMPERATURE

AND PRESSURE CHANGES 
Watora Formation as $C=1.138+0.249$ feet and for the Huka Falls Formation as

$$
c=0.776+0.001 \text { feet }
$$

The total compaction is 2.16 feet, with 1.91 feet due to the pressure drop in the two formations and .25 feet due to the temperature drop. As the reservoir is shallow and has a large lateral extent, this compaction is assumed to directly result in unform subsidence of 2.16 feet at the surface.

\section{Two-Dimensional CoNSOL3 Finite Element Mode1}

The variability in geologic cross section cannot be adequately modeled in one dimension, where uniformly thlck layers must be assumed. The two-dimensional finite element model CONSOL 3 was intended to allow the modeling of a cross section with varying thicknesses of material for the Huka Falls and Waiora formations.

Figure 20 shows the cross section and finite element grid used in the CONSOL3 model for Wairake1. The cross section is based on that shown in Figure 18 and on further information contained in Companion Report 3 (Miller et al. 1980c). Materlal propertles for the Huka Falls and Walora formations are the same as those assumed in one-dimensional hand calculations. Material elastic properties for the surface pumice and breccla, rhyolite, and Wairakel Ignimbrites are as follows:

\begin{tabular}{|c|c|c|}
\hline Surface pumice and breccla & $3.99 \times 10^{5}$ & $1.60 \times 10^{6}$ \\
\hline Rhyolite & $5.22 \times 10^{7}$ & $7.87 \times 10^{7}$ \\
\hline Wairakei ignimbrites & $5.22 \times 10^{7}$ & $7.87 \times 10^{7}$ \\
\hline
\end{tabular}





FIGURE 20

WAIRAREI CASE STUDY

CROSS SECTION USED IN 2-D FINITE-ELEMENT MODEL 
These values were assumed such that surface pumice and breccia would be considerably more deformable than the Huka Falls or Walora formations while the Wairakel Ignimbrite and rhyolite intrusive would be less deformable.

Pressure-change values assumed were the same as those for the onedimensional hand calculations: $1.30 \times 10^{4}$ psf in the Huka Falls Formation and $4.75, x 10^{4} \mathrm{psf}$ in the Waiora Formation. This pressure change was limited to the central 18,000 feet of the cross section.

CONSOL3 does not perform thermoelastic deformation calculations, so temperature change data were not used.

The CONSOL 3 model falled to solve the system. The computed ground surface deformations were erratic and not bellevable. Even when no pressure drops were spectfled, there were substantial deformations.

Presumably, the reason for this fallure is an unresolved bug in the code-a relatively common occurrence. Unfortunately, with the program authors overseas, it was not possible to resolve the problem in time for this report.

Three-Dimensional Nucleus-of-Strain Model SUBSID

The advantage of the nucleus-of-strain model is that it can represent the spatial varlability of the Wairakel Geothermal Field in three dimensions. It is limited, however, to an isotropic homogeneous elastic half-space.

The nucleus-of-strain model requires as input the specification of material properties for the half-space, and the pressure drops in the nuclei of strain which represent the Huka Falls and Walora formations. Because this method requires a homogeneous material, the material 
properties of the Walora Formation were used for the entire half-space and the actual variation in material properties was approximated by increasing the pressure drops in the Huka Falls Formation by a factor of 10 , the ratio of the elastic moduli.

The distribution of nuclei of strain was determined using the three-dimensional description of the field developed by Bolton (1970) and structural contour maps by Grindley (1965) and Mercer and Faust (1979).

Figure 21 shows the plan of the pressure-drop region modeled by SUBSID. Part of the neighboring Tauhara Field was included because a significant hydrological connection apparently exists between the two fields (Pritchett et al. 1978). Temperature changes were not incorporated into this model, but could easily have been added as the equivalent pressure drops, $\Delta \mathrm{P}=3 \mathrm{~K} \alpha \Delta \mathrm{T}$.

Contours of surface subsidence predicted by the three-dimensional nucleus-of-strain model are shown in Figure 22. The maximum subsidence is about 2 feet. Based on results from the one-dimensional hand calculations, the inclusion of temperature changes in the model could be expected to increase the predicted subsidence by 13 percent.

\section{Wairake1 Summary}

While the computed deformations agree reasonably well with the average of the observed values (Figure 22), the observed values are much less regular than the model predicts. The source of this heterogeneity is not clear, but presumably it lies in one or more of three areas:

- Inhomogeneity in reservolr pressure drops

- Inhomogeneity in geology (local thickening of beds, facles changes) 


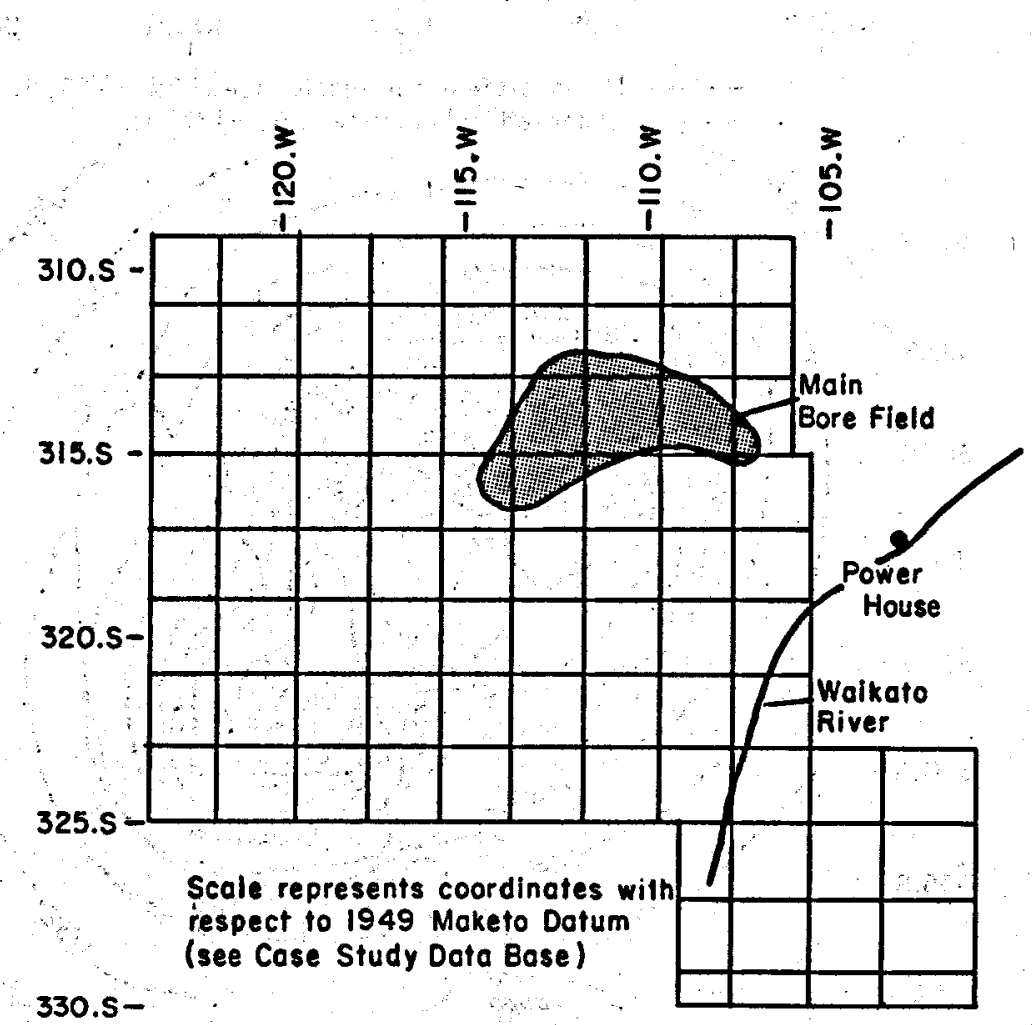

FIGURE 21

WAIRAKEI CASE STUDY

PLAN OF GRID FOR NUCLEUS-OF-STRAIN MODEL 


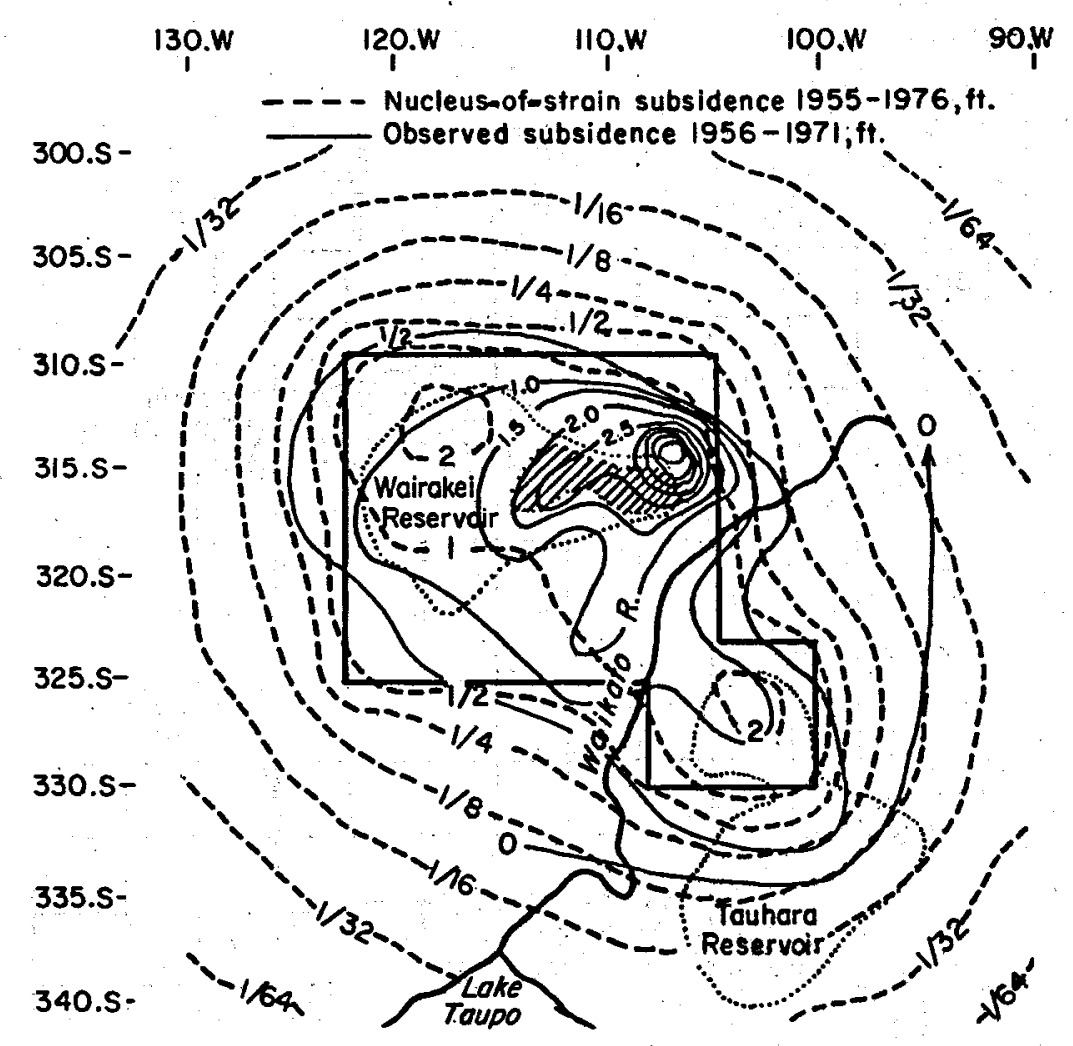

FIGURE $22^{\circ}$

WAIRAKEI CASE STUDY

OBSERVED AND PREDICTED SUBSIDENCE CONTOURS 
- Inhomogenelty in material properties such as compaction coefficlents or maximum previous loading.

The data that were available were much too limited to define the Inhomogenelties In the real system, and as a result the more complex models did not perform appreclably better than the simple hand calculations.

Pore pressure drops are the dominant source of compaction at Wa1rakel, but temperature effects are st111 significant.

\section{DISCUSSION OF REAL-CASE STUDIES}

In this section we shall discuss the result of model simulations of the real-case studies. The results of the sfmulations are summarized in figures 16 and 22 .

The real-case studies provided answers to several important questions.

- How accurately do current models and available Information approximate real behavior?

- How can the appropriate modeling approach be determined for a particular real case?

- What type of Information is necessary for different modeling approaches?

- How applicable are the various models and their underlying assumptions?

Each of the above questions is discussed below. 
Accuracy of Model Predictions

Considering the questionable method by which temperature and pressure-drop data were obtained, simulations of The Geysers fit overall observed behavior surprisingly well (Figure 16). It should be noted that different assumptions for pressure or temperature changes from 1973 to 1977 would produce markedly different model predictions which could be in error by a substantial factor. Temperature effects, for example, may be lower than assumed due to the amount of time required for steam temperature changes to be reflected in rock temperature changes throughout the reservolr. As should be expected from the geometry of The Geysers, two- and three-dimensional results are considerably better than one-dimensional results. It should be noted, however, that while twodimensional model predictions are substantially better than onedimensional predictions, the difference between two- and threedimensional results is small. None of the models, however, predicted the details of the subsidence bowl with any precision.

For Wairake1 the modeling was not so successful. Although the models predict the median behavior reasonably well, they are totally incapable of matching the areas of local subsidence which dominate the response at Wairakei (Figure 22). It is our opinion that this modeling fallure lies in the data rather than in the models.

\section{Relationship Between Real Case and Choice of Model}

A model will never be able to accurately describe all aspects of a geothermal reservoir. However, the selection of the best model for a given reservolr requires matching of the following:

- Model and real-case dimensionality

- Model information requirement and available information

- Mode1 constitutive relations and real behavior. 


\section{Model and Real-Case Dimensionality}

The geometry of a real case can be used to determine the appropriate dimensionality for modeling. If vertical extent is insignificant with respect to lateral extent in both length and width, one-dimensional modeling may be suffictent. If all dimensions are comparable, threedimensional modeling is probably necessary. This is the case at The Geysers, where depth, length, width, and thickness are of comparable scale." Results from The Geysers one-, two-; and three-dimenstonal simulations verify the fact that three-dimensional (axisymmetric) results are superior to elther one- or two-dimensional results. However, the improvement from one to two dimensions is substantially greater than from two to three dimensions. At Walrakel, depth is small relative to lateral extent, and there is little difference between maximum subsidence predicted by one- and three-dimensional simulations.

\section{Mode1 Information Requirements and Available Information}

It is a waste of effort to use a model which is substantially more sophisticated than avallable information. At The Geysers, no information is avallable on the flow regime, so it would have been fruitless to implement a sophisticated flow model such as CCC. At the same time, results from one-dimensional models which cannot utilize information avatlable about the two-dimenstonal nature of the pore pressure changes are inferior to two-dimensional models which utilize that information. At Wairake1, spatial variability data which were avallable could only be used completely by the three-dimensional model.

\section{Model Constitutive Relations and Behavior}

Ideally, model constitutive relations should provide a reasonable representation for behavior. At The Geysers, where 80 percent of deformation is attributable to temperature changes, a model which ignored 
thermal deformations would be inappropriate. On the other hand, only 13 percent of deformation at Walrakel is due to temperature change, so its inclusion is not essential. It is important for model constitutive relations to represent all important factors affecting behavior. However, the sophistication of that representation must be tempered by avallable information. In the case of The Geysers, where information quality is so low, assumptions made about temperature and pressure changes are more critical than assumptions of constitutive relations. Use of constitutive relations which were more complex than elastic relations would therefore be unjustified.

\section{Information Requirements of Modeling Approaches}

The models used for The Geysers were all homogeneous, isotropic, Iinear thermoelastic. Therefore, they all required the same type of information: thermoelastic and elastic properties, pressure changes, and temperature changes within the modeled region. The three models used different solution techniques, but the only real difference between the models was that of dimensionality.

None of the modeling approaches used at Wairakel applied truly homogeneous material properties. Two-dimensional finite elements required a complete two-dimensional description of the variation of material properties in a cross section. The three-dimensional model assumed homogeneous materlal properties for the elastic half-space, but material properties for both Huka Falls and Walora had to be known to calculate equivalent pressure drops used to represent variations in material properties. Other than spatial variation of properties, however, Wairakel models required the same information on thermoelastic parameters, pressure changes, and temperature changes as for The Geysers. 


\section{Applicability of Model Assumptions}

Constitutive relations were the same in all models, so the applicability of all models depended upon the same assumption of isotropic Inear thermo-poro-elasticity. This assumption is approximately true for some geologic materials, but is not valid for most. Geological materials tend to be Inhomogeneous, anisotropic, nonlinear, and inelastic. However, the magnitude of error due to the approximation of elastic properties may be small relative to uncertainties in model parameters. In the case of The Geysers, model constitutive relations appear to be adequate. Note, however, that 1sotropic, homogeneous properties and symmetric pressure-change profiles could not predict the asymmetric behavior actually observed (Figure 16). 
100 
INTRODUCTION

The use of an 1dealized-case study allows us to avold the problems Introduced Into rea1-case studies by Insufficient or inaccurate data. In the Idealfzed-case study, the site 1 s assumed to be known and is represented by conceptual model. This allows the study of many important aspects of subsidence modeling which could not be properly studied otherwise.

AUSTIN BAYOU PROSPECT

Austin Bayou Prospect is the 1dealized-case study. It is more generalized and hypothetical than elther The Geysers or the Watrakel case studies. The data used in this site model is based on actual data from Austin Bayou and Chocolate Bayou; however, there has been no production of geothermal fluids at Austin Bayou and therefore no subsidence. For the purposes of this case study, where material or fluid properties were unknown, reasonable assumptions were made so that computer models of the site could be generated. This case study served to determine the effects of different modeling assumptions on subsidence prediction for a geopressured site.

\section{Brief S1te Description}

Austin Bayou Prospect is a geothermal exploration site in the Brazorla Fairway, a 200-square-mile strip of land on the Texas Gulf Coast Identified as an area of potential geothermal development. The geology of the area is characterized by thick"sequences of Interbedded deltaic shales and sandstones with a complex system of faults dividing the sediments into blocks and wedges. The pay sands at depth have abnormally high fluid pressures due to the hydrologlc barriers provided by the faulting and the bedding of impermeable material. 
A more detailed site description is presented in Companion Report 3 (Miller et al. 1980c).

Conceptual Mode1

Using the available information on geology, material properties, and pore fluid pressures and temperatures, a conceptual model of Austin Bayou Prospect was developed. A cross section of the model, parallel to the bounding faults, is presented in Figure 23 and indicates the assumed geology and pore-fluid pressure variation. A plan view of the reservoir interval at a depth of 15,045 feet is presented in Figure 24. Figure 25 shows the assumed repetitive pattern of sandstone and shale in the vertical within the reservoir interval. Overburden material properties and the properties of the sandstone and shale layers are presented in tables 8 and 9 , respectively. A vertical thermal gradient of $.01^{\circ} \mathrm{C} / \mathrm{ft}$ was assumed.

Clearly, the model presented in figures 23 through 25 does not represent the real geology of the Austin Bayou Prospect. There are no data avallable describing the extent and interconnection of individual sand and shale layers. Our model has assumed that the sands are several kilometers in extent and have no direct interconnection. If we had assumed that they were less extensive or better connected, our results might be different. This emphasizes the hypothetical nature of the Austin Bayou case study. Its purpose is to study modeling, not to study the Austin Bayou. We have tried to make the model realistic only to the extent that it is similar to a real Gulf Coast geopressured system.

The pay sands in the reservoir Interval were assumed to be produced by three wells whose positions relative to the bounding faults are shown in Figure 24. The rate of production out of the sandstone was held constant at $8.87 \times 10^{-11} \mathrm{ft} / \mathrm{sec}$ per cubic foot of sandstone. Each well was assumed to be completed in each of two 60-foot-thick sandstone 


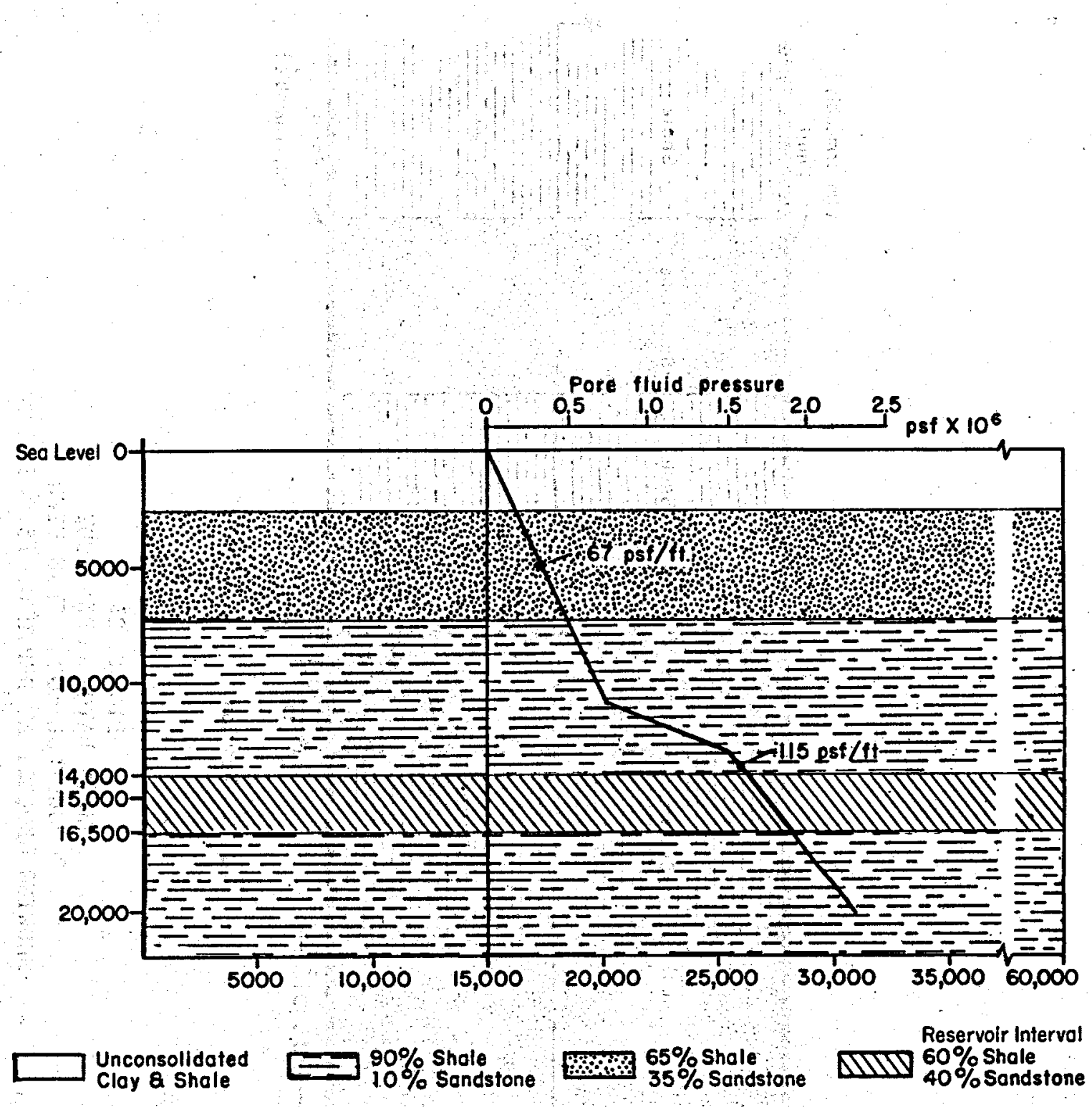

FIGURE 23

AUSTIN BAYOU CASE STUDY

CONCEPTUAL-MODEL CROSS SECTION

PARALLEL TO BOUNDARY FAULTS 


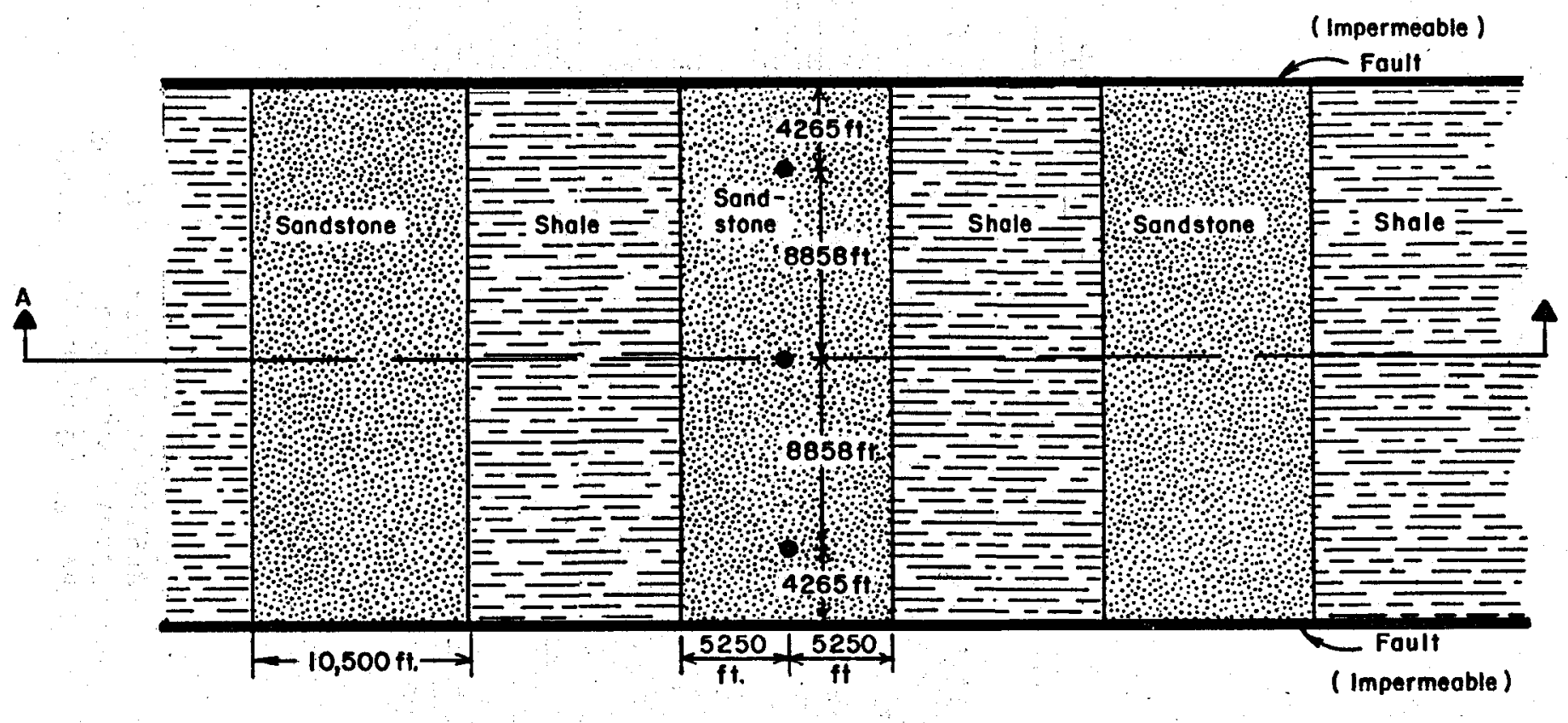

FIGURE 24

AUSTIN BAYOU CASE STUDY

CONCEPTUAL MODEL PLAN VIEW

SHOWING GEOLOGY AT DEPTH OF 15,045 FEET 


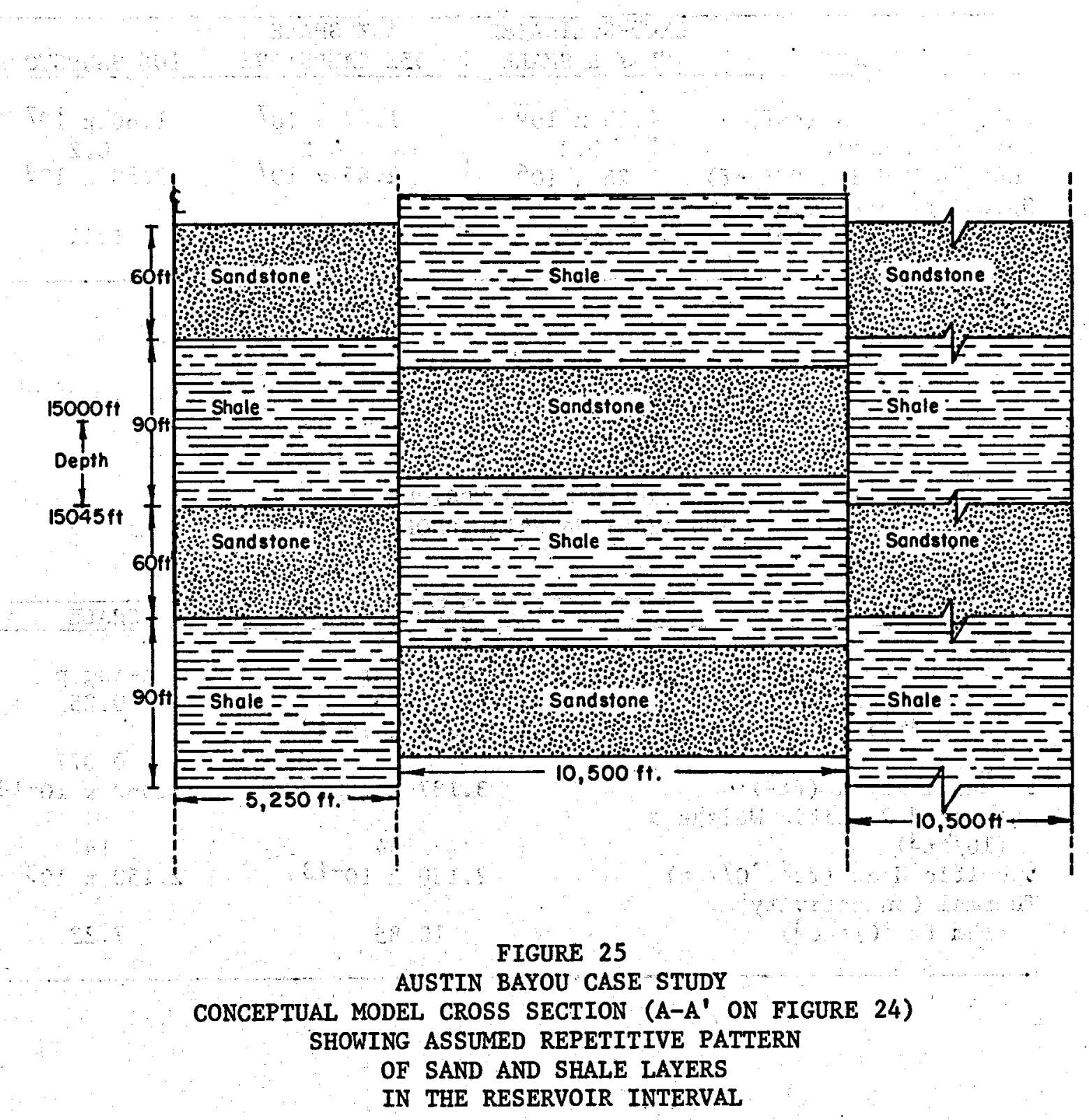


TABLE 8

OVERBURDEN MATERIAL PROPERTIES

\begin{tabular}{|c|c|c|c|}
\hline PROPERTY & $\begin{array}{l}\text { UNCONSOLIDATED } \\
\text { CLAY \& SHALE }\end{array}$ & $\begin{array}{c}65 \% \text { SHALE } \\
35 \% \text { SANDSTONE }\end{array}$ & $10 \%$ SANDSTONE \\
\hline $\begin{array}{l}\text { Bulk Modulus K (psf) } \\
\text { Poisson's Ratio U } \\
\text { Young's Modulus E (psf) } \\
\text { Saturated Specific } \\
\text { Weight } \alpha \text { (lb/ft3) }\end{array}$ & $\begin{array}{c}4.18 \times 10^{6} \\
0.2 \\
7.25 \times 10^{6} \\
1.44\end{array}$ & $\begin{array}{c}1.47 \times 10^{7} \\
0.2 \\
2.65 \times 10^{7} \\
1.44\end{array}$ & $\begin{array}{c}1.60 \times 10^{7} \\
0.2 \\
2.88 \times 108 \\
1.44\end{array}$ \\
\hline
\end{tabular}

TABLE 9

RESERVOIR SANDSTONE

AND SHALE MATERIAL PROPERTIES

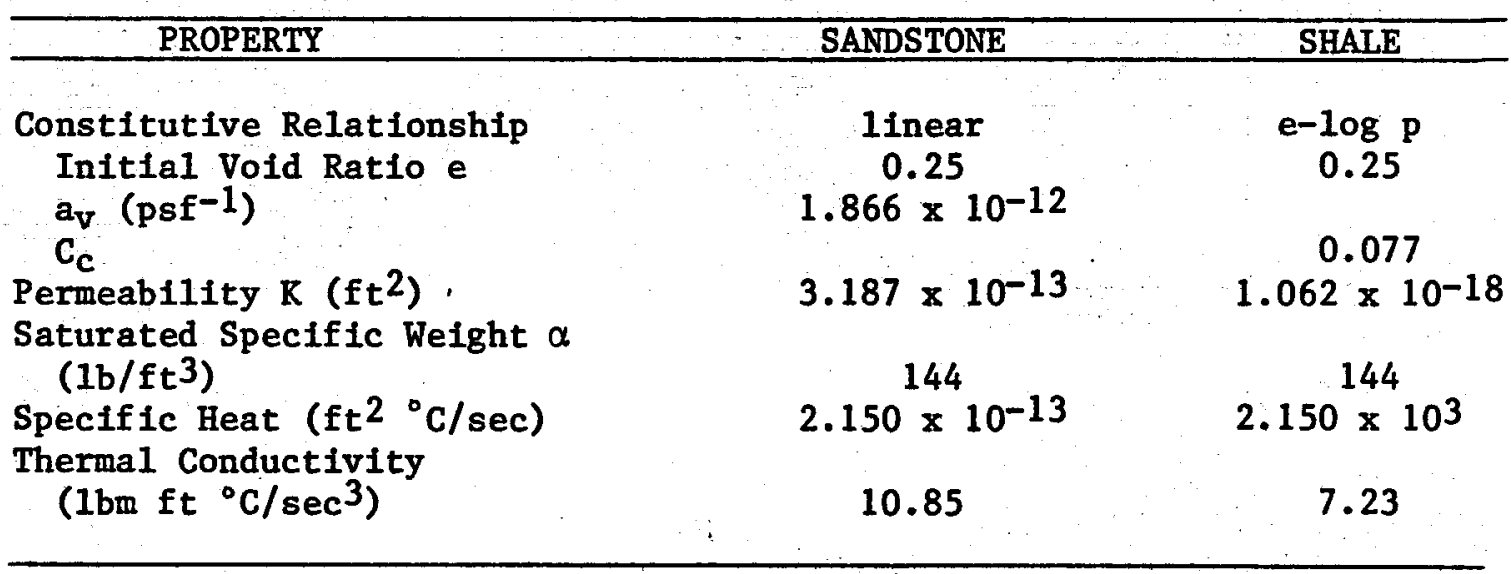


1ayers. The total production was $2.93 \mathrm{ft}^{3} / \mathrm{sec}=45,000 \mathrm{bb} 1 / \mathrm{day}$ ( 2 layers $\times$ 60-foot thickness $\times 10,500$-foot width $\times 26,246$-foot length $x$ $8.87 \times 10^{-11}$ ).

\section{Investigation P1an}

The Idealized Austin Bayou case study allowed the investigation of several important issues. Th1s study focused on modeling assumptions. The reglonal geology, material properties, and geothermal production were all assumed to be known.

The Issues addressed in the Aust In Bayou case study were as follows:

- The applications of different flow models for the geothermal reservoirs

- The importance of flow/deformation coupling

- A comparison of different types of constitutive relationships

- The importance of dimensionality

- The implementation and accuracy of models incorporating only a portion of the total system

- The effects of faults in reglons of geothermal production

- The sensitivity of surface subsidence to variations of material elastic propertles

- The effects of geothermal waste-water reinjection.

Computer models of Austin Bayou Prospect were developed to study these topics. Reservolr compaction computed by CCC served as input to NFOLD and BIEM2D, which were used to calculate the resulting surface subsidence based on average overburden properties. The program CoNSOL 3 was used to model the entire system, including the reservoir interval and the overburden. 
In addition to the computer model, a simple hand-calculation model was used which represented the reservoir as a disk and computed surface subsidence based on the quantity of fluid removed.

\section{Resume of Model Simulations}

The conceptual Austin Bayou model was the basis for generating computer models of Austin Bayou which were one-dimensional, twodimensional planar and axisymmetric, and three-dimensional. Material properties were adjusted to conform to the 1imitations and input requirements of each program. Portions of the Austin Bayou conceptual model were extracted and modeled, with appropriate boundary conditions, to determine the usefulness of such partial models.

\section{Hand Calculations}

The compaction of the reservoir interval and the resulting surface subsidence were calculated by hand using the methods presented in Section 2.0 of Companion Report 2 (M11ler et al. 1980b).

To compute one-dimensional compaction, elastic material properties for both sandstone and shale were assumed. It was also assumed that the pore pressure decrease in the shale was equal to that in the sandstone. As the reservolr interval was 60 percent shale and 40 percent sandstone, an equivalent compressibility for that heterogeneous interval was calculated as

$$
\begin{aligned}
c_{m_{e q}} & =0.6 C_{m_{s h}}+0.4 c_{m_{s s}} \\
& =2.19 \times 10^{-8} \mathrm{psf}
\end{aligned}
$$

The total volume outflow of water after 1000 weeks of pumping was

$$
\Delta V_{w}=6.437 \mathrm{~A} \mathrm{ft}^{3}
$$


where the volume of the sandstone is $120 \mathrm{~A} \mathrm{ft}^{3}$ and $\mathrm{A}$ is the area of the aquifer. Calculating compaction from equation [5] of Companion Report 2 (Miller et al. 1980b), ignoring temperature effects, gives:

$$
c=5.31 \mathrm{ft}
$$

The surface subsidence was calculated using Geertsma's (1973) formulation and modeling the rectangular reservoir as a disk of equivalent area. The disk radius was:

$$
\operatorname{Req}=9366 \mathrm{ft}
$$

With Polsson's ratio equal to 0.2 and the reservoir at a depth of 15,000 feet, the subsidence was calculated and is plotted in Figure 26 . The maximum subsidence predicted by this method is 1.29 feet.

$$
\text { CCC, NFOLD, BIEM2D }
$$

The portions of Austin Bayou Prospect modeled in one, two, and three dimensions by CCC are shown in plan and cross section in Figure 27. Due to program-size limitations, the region modeled in three dimenslons was considerably smaller than that included in either of the twodimensional models. In the axisymmetric model, pumping at the central wa11 was found to produce a nearly uniform pressure drop throughout the sandstone layer. Th1s demonstrated that the fluid production for the planar flow and one-dimensional formulations could be modeled as being evenly distributed across the aquifer.

The reservoir Interval compaction calculated by CCC was used as input to the plane strain BIEM2D and the three-dimensional NFOLD programs.

As both programs required the overburden to be homogeneous and Isotroplc, an average value of Young's modulus, based on a composition 


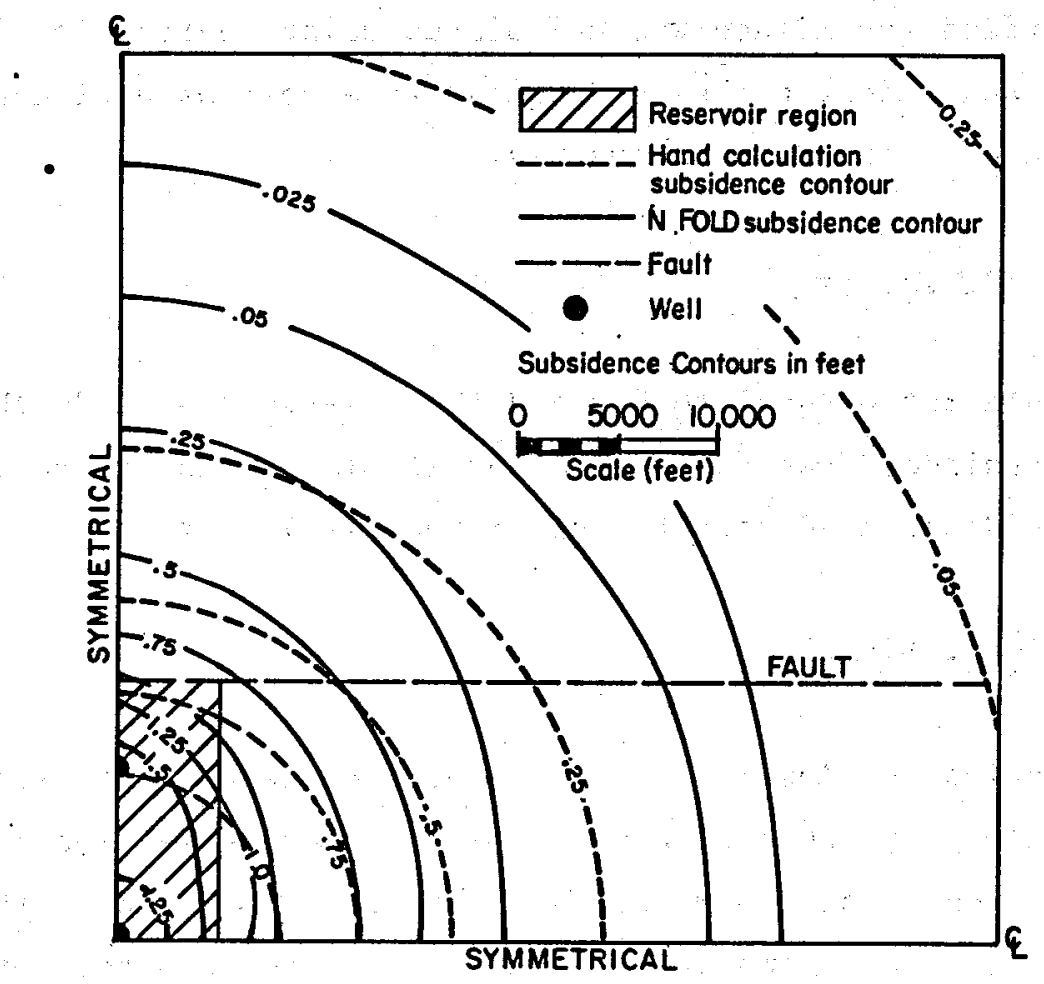

FIGURE 26

AUSTIN BAYOU CASE STUDY

SUBSIDENCE CONTOUR FROM HAND CALCULATIONS AND NFOLD 


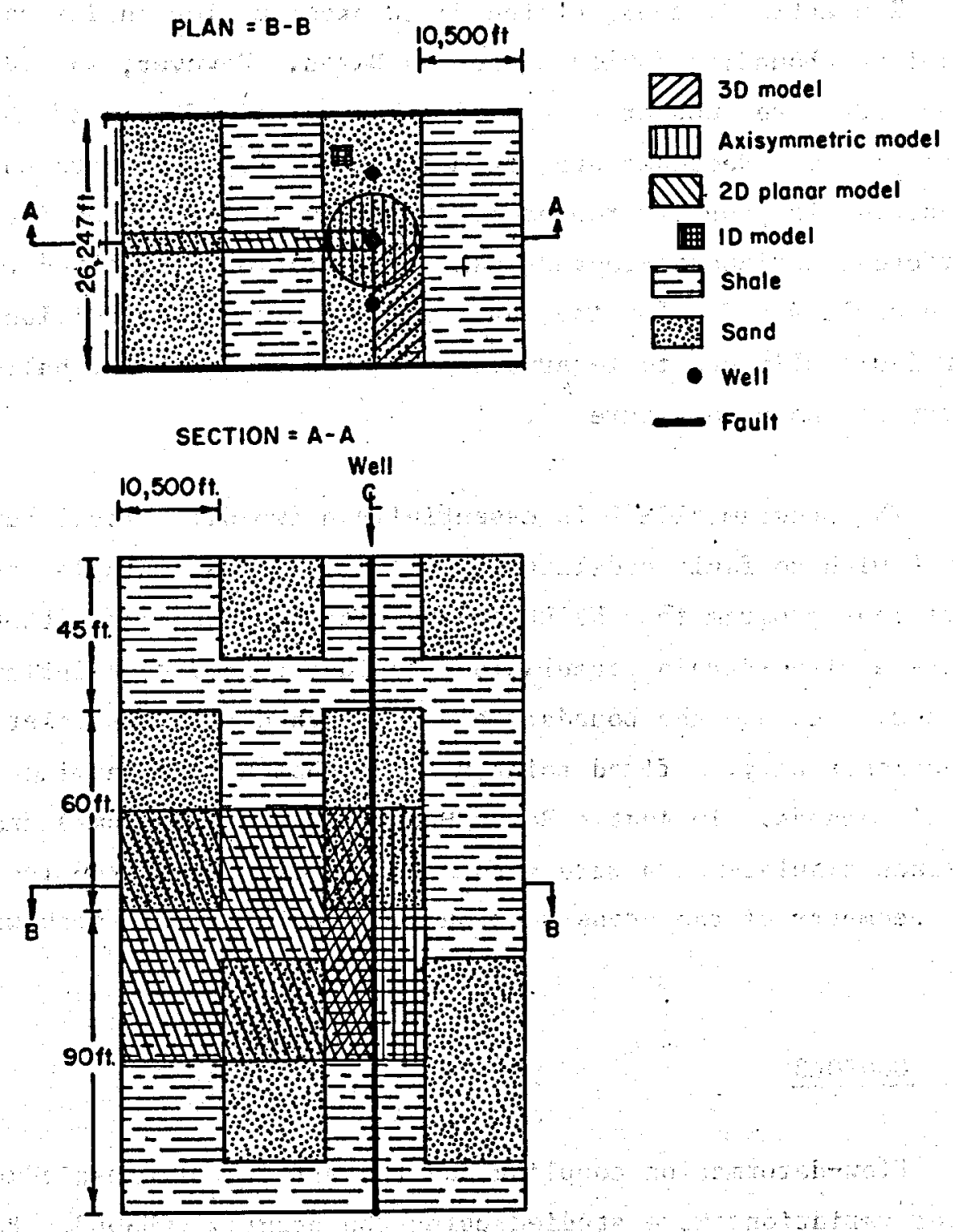

FIGURE 27

AUSTIN BAYOU CASE STUDY

CCC MODELS FOR AUSTIN BAYOU RESERVOIR

IN ONE, TWO, AND THREE DIMENSIONS 
of 20-percent sandstone, 80-percent shale, was determined as $3.20 \mathrm{x}$ $10^{7}$ psf. Polsson's ratio was taken as 0.2 .

The attractiveness of the NFOLD program lies in its ability to model the bounding faults at Austin Bayou. However, subsidence results from NFOLD are suspect because (1) horizontal effects of the reservoir pore pressure decrease are not modeled and (2) there are unresolved difficulties in properly representing a free surface in an infinite space. Different horizontal-to-vertical stress ratios were tried with a friction angle $\emptyset=25^{\circ}$ for the fault to determine the conditions necessary for fault slip due to reservoir compaction. The NFOLD half-space geometry is shown in Figure 28.

The program BIEM2D is essentially a two-dimensional version of NFOLD with no fault modeling capability. It is a simpler and more efficient program than NFOLD and is useful in regions without faults where a plane-strain formulation provides a good description of the system. Because the boundary element method predicts relative displacements only, a fixed point must be chosen to determine absolute displacements. In Austin Bayou Prospect, it was assumed that the ground surface displacements were zero at large distances from the reservoir. The geometry of the cross section modeled by BIEM2D is shown in Figure 29.

\section{CONSOL3}

Flow-deformation coupling and the effects of elastic material parameter variations were studied using the program CONSOL3. Both plane strain and axisymmetric formulations of the Austin Bayou conceptual model were developed. All materials were taken to be linear elastic.

The importance of flow-deformation coupling was determined by comparing the "extended" Austin Bayou model with the "limited" Austin 


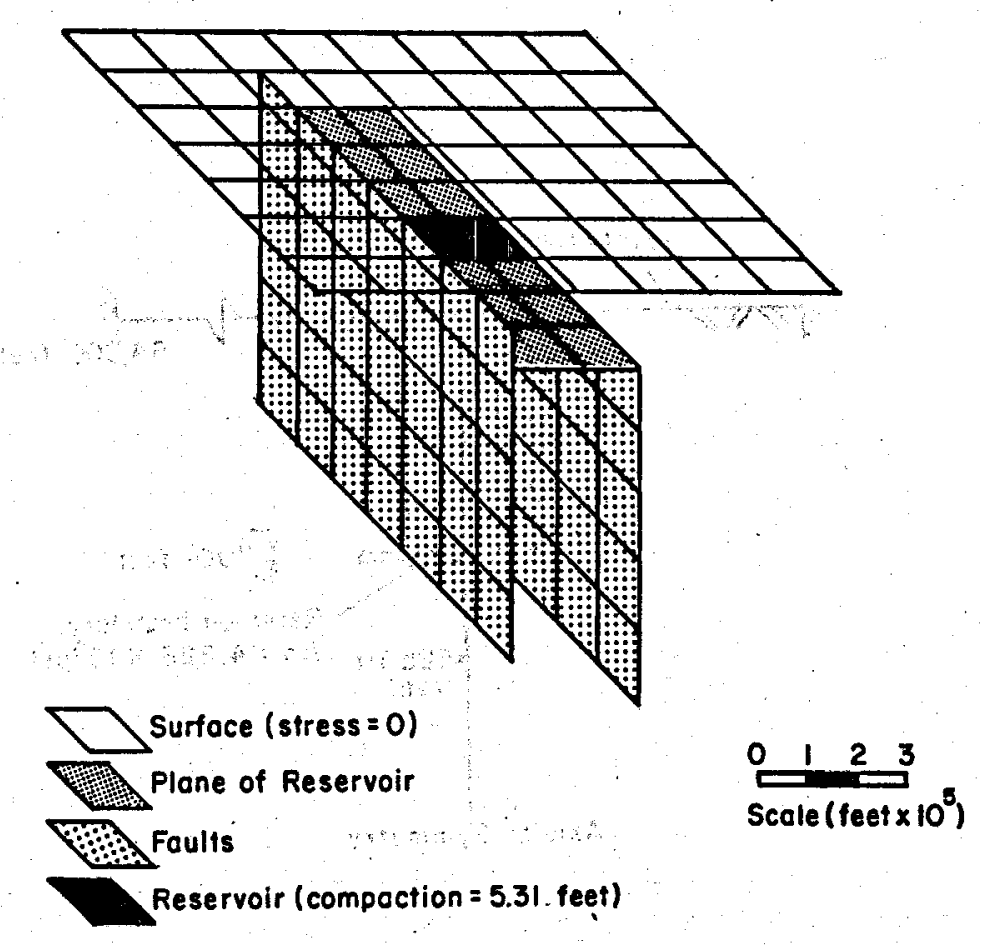

FIGURE 28

AUSTIN BAYOU CASE STUDY NFOLD 3-D MODEL 


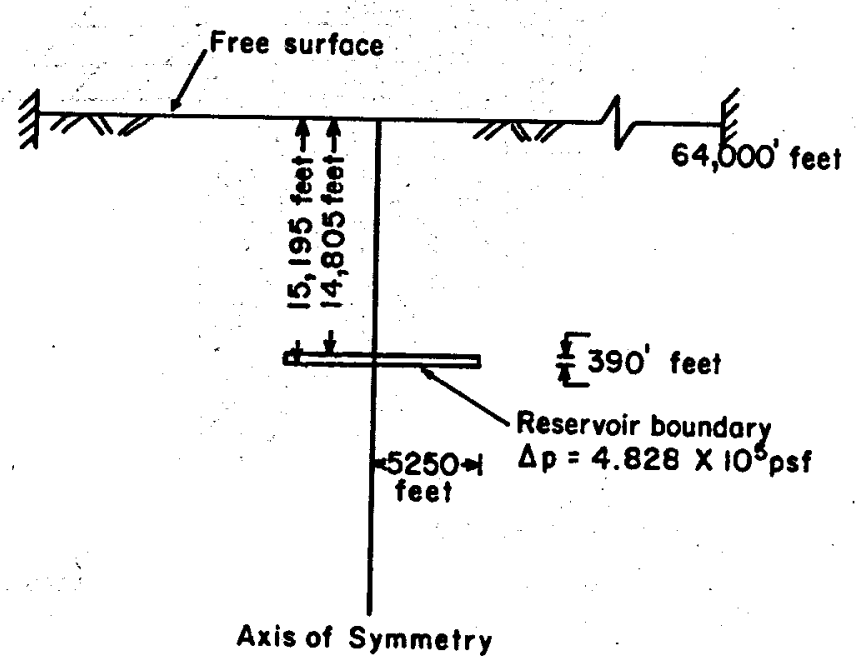

FIGURE 29

AUSTIN BAYOU CASE STUDY

BIEM2D 2-D MODEL 
Bayou model. The "extended" Austin Bayou was made of two 65-foot-thick sandstone layers separated by shale, as shown in Figure 30. This system was sandwiched by layers of impermeable material and layers of composite 40-percent sandstone, 60-percent shale and was embedded in the halfspace described in Figure 23. The equivalent "limited" model consisted of half of a sandstone layer and half of a shale layer, with constantstress, impermeable boundaries. The Austin Bayou reservoir interval for the "limited" model boundaries are indicated by dashed Iines in Figure 30. Plane strain conditions were assumed for both models, and fluid outflow occurred from the sandstone layers at a centerline well.

For the purposes of the elastic parameter varlation study, a full half-space axisymmetric Austin Bayou model was developed with the reservoir Interval geometry, as shown in Figure 31. Away from the producing aquifers, the sandstone and shale blocks were modeled as composite 40percent sandstone, 60-percent shale. Limitations of the axisymetric version of CONSOL 3 required that outflow be distributed horizontally within the sandstone layers and not simply removed from the well at radius zero. The half-space geometry and material properties outside the reservoir interval are as shown In Figure 23 and Table 8.

DISCUSSION OF IDEALIZED-CASE STUDY

The Austin Bayou conceptual model and the derivative computer models described in the previous section were used to answer the questions posed in the Investigation plan.

\section{Flow Modeling}

The use of flow models allows the prediction of reservoir compaction and reservolr pore-pressure decrease due to the removal of geothermal fluids. Flow at Austin Bayou was modeled with the integrated 


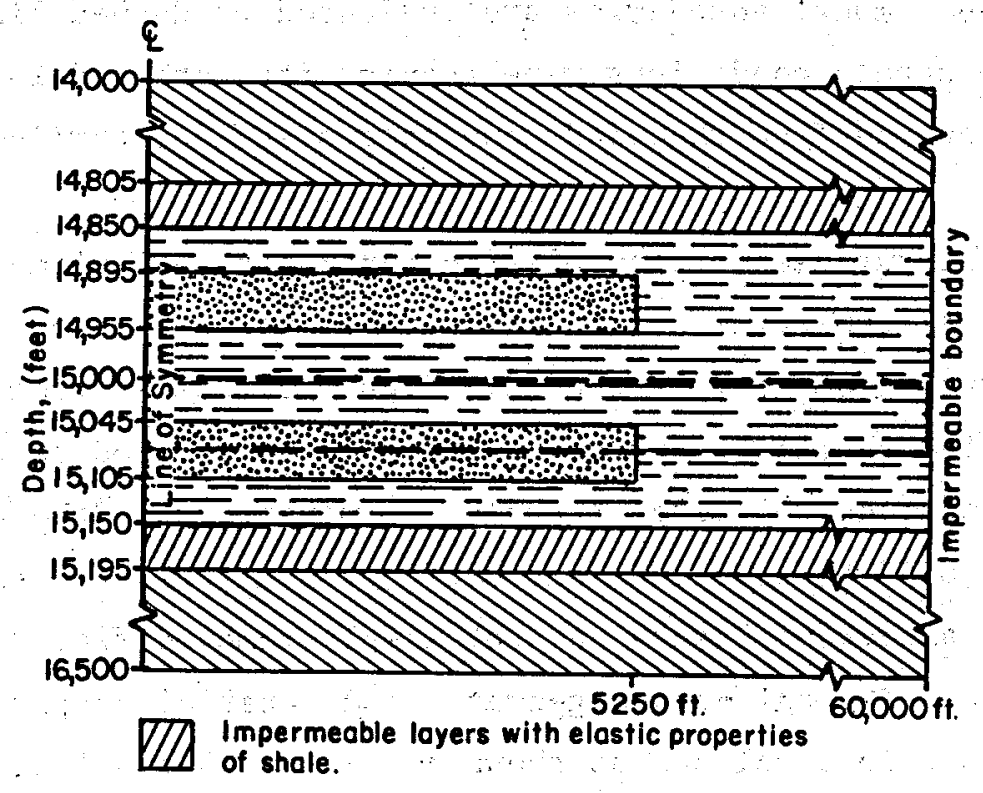

D $40 \%$ sondstone. $-60 \%$ shale composite moterial.

Sandstone

E shale

FIGURE 30

AUSTIN BAYOU CASE STUDY

CONSOL3 "EXTENDED" MODEL RESERVOIR INTERVAL

WITH "LIMITED" MODEL INTERVAL SHOWN BY DASHED LINE 


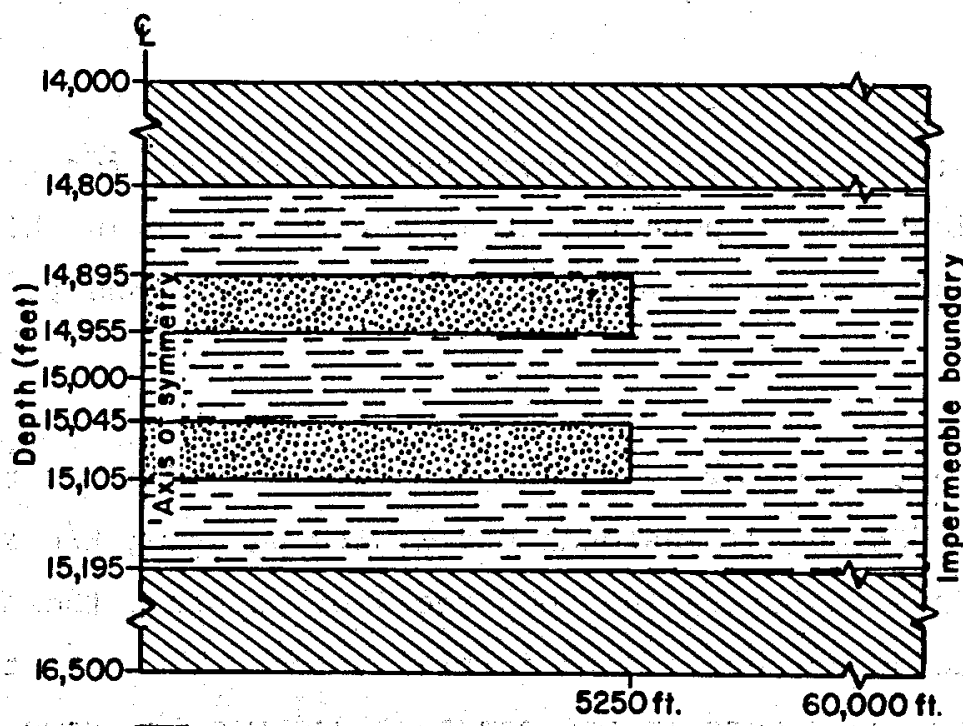

A $40 \%$ sandstone $-60 \%$ shale composite material.

Sandstone

E] shale

FIGURE 31

AUSTIN BAYOU CASE STUDY

CONSOL3 MODEL OF RESERVOIR INTERVAL

USED IN ELASTIC PARAMETER STUDY 
finite difference program CCC and the finite element program CONSOL3. In CCC the viscosity and density of the fluid varied with temperature and pressure, while constant fluid parameters were assumed by CONSOL3.

The predicted pore pressure in the aquifer at 1000 weeks was 940,200 psf in the Consol3 "Iimited" Austin Bayou model and was 920,500 psf in the equivalent CCC planar flow model. The respective compactions for the 75-foot-thick sandstone-shale layer were 1.36 feet and 1.33 feet.

Since the pore pressure drops and compactions for the two cases differ by less than 3 percent, it is apparent that in this case fluid viscosity and density variations with temperature and pressure were not important.

The effect of allowing permeability to vary was determined by running the CCC one-dimensional model with an $e-\log \mathrm{k} / \mathrm{c}$ relationship in the shale layer. During the 1000 weeks of pumping, the shale void ratio decreased to 50 percent of its intial value. The rate that water was removed from the reservoir was constant and was the same in both cases. In the variable permeability model, a somewhat smaller proportion of that water came from the shale and a larger proportion came from the sandstone. The increased sandstone compaction almost balanced the decreased shale compaction so that the total compaction at any time was only 1 percent less than in the case of constant shale permeability. In reality, it would be difficult to maintain a constant pumping rate as the reservoir permeability decreased.

Because the Austin Bayou reserves are at great depth and high pressure, single-phase flow was maintained within the reservoir. Extrapolation of the CCC results indicates that, after about 30 years of pumping, pressure would be reduced sufficiently to induce some phase change. Nelther CCC nor CONSOL3 is capable of handling multiphase flow, 
and computer models which can do this are quite complicated. However, this study shows that even in cases where single-phase flow models are appropriate initially, phase change may occur after pressures have been reduced. Such a case would require that further study be conducted with a multiphase model.

\section{Flow-Deformation Coupling}

The case studies at The Geysers and Walkrakel attempted to predict the observed surface subsidence by representing the results of reservoir fluid extraction as pore-pressure changes or as reservolr interval compactions. In the Austin Bayou case study, we addressed the question of the appropriateness of this separation of flow with deformation. Both CCC and CONSOL 3 couple flow with deformation; however, simplifying assumptions are made in CCC when calculating the Induced deformations. CCC assumes that horizontal displacements are negligible and that the upper boundary of the reservolr is a constant stress boundary. The validity of these assumptions was tested by comparing the "extended" CONSOL3 Austin Bayou model with 1ts "limited" model (which is equivalent to the CCC planar flow model). In the "extended" model the total vertical stress at the 15,000 -foot level could vary from its inital value as fluid was removed from the reservolr and the system deformed. In the "limited" model the overburden is not explicitly included and the total vertical stress at that level remains constant and equal to the overburden weight. The stiffness of the overburden in the "extended" model could be expected to restrain the compaction of the shale-sandstone layers, while in the "limited" model only the stiffness of the layers themselves affects compaction.

In Figure 32, the resulting "extended" Austin Bayou total stress profile at 15,000 feet is compared to the constant stress boundary assumption. Note that the maximum difference between the two analyses is less than 5 percent while the average difference is only 1 percent. 


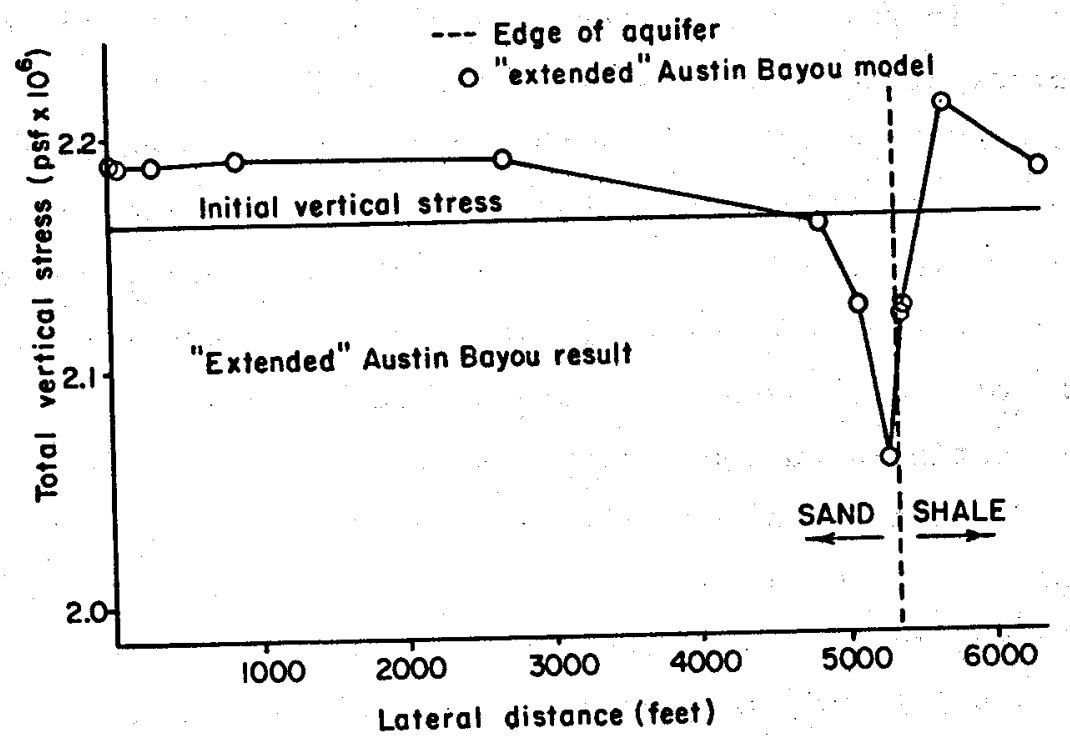

FIGURE 32

AUSTIN BAYOU CASE STUDY

TOTAL VERTICAL STRESS PROFILE

TIME 1000 WEEKS, ELEVATION 15,000 FEET 
Comparative plots of vertical compaction for the 75-foot shale-sandstone layer are presented in Figure 33. Some horizontal compaction occurred in the "extended" model, while horizontal displacements in the "limited" model were constrained to be zero. The difference in total volume change of the reservoir interval for the two cases was 2 percent.

The "1imited" Austin Bayou model, which apparently does a very good job of representing the reservolr portion of the Austin Bayou system, validates the assumptions made by CCC. The plane-strain version of CONSOL3 and the combination of planar flow CCC and BIEM2D, with appropriately chosen homogeneous material properties for the overburden, should supply equally good models of the ent1re Aust in Bayou Prospect. The cost to run the CCC-BIEM2D combination model was 208 CPU seconds ( 206 for CCC and 2 for BIEM2D), while the cost to run the CONSOL 3 mode1 was $318 \mathrm{CPU}$ seconds.

Constitutive Relationships

Two types of constitutive stress-strain relations were used in the Aust In Bayou case study. In the CONSOL3, NFOLD, and BIEM2D mode1s, all materials were linearly elastic, while in CCC models an e-log p law was usually used for shale layers. The elastic material parameters were derived from the e-log p parameters using secant values. The shale compaction was quite nonlinear, with the instantaneous compaction coefficient at the end of 20 years being only about 35 percent of the initial value. The effect on subsidence is only about 10 percent, due to the fact that we specifled the quantity of fluid produced from the reservolr. Had we specified the pore pressure drop, the compaction (and the amount of fluid produced) would have decreased.

\section{Dimensionality}

As one-dimensional models are much simpler than two- or threedimensional models, it is important to understand when higher 




FIGURE 33

AUSTIN BAYOU CASE STUDY

VERTICAL COMPACTION OF 75-FOOT AQUIFER-AQUITARD LAYER

"LIMITED" AND "EXTENDED" AUSTIN BAYOU MODELS 
dimensional models are required to adequately describe a system. Significant factors that must be considered are boundary conditions and the relative magnitudes of reservolr depth, width, thickness, and length. These factors were studied by modeling one-, two-, and three-dimensional portions of the Austin Bayou conceptual model with CCC combined with either BIEM2D or NFOLD for propagating deformations to the surface.

Fluid extraction from Austin Bayou occurred from wells within the sandstone layers. If flow to the wells were radial, a three-dimensional flow model would be necessary because each radial path would be through different amounts of sandstone and shale (Figure 34 ). However, in the Austin Bayou mode1, pumping from a central well (a three-dimensional boundary condition) was functionally equivalent to extracting fluid unfformly across the sandstone layer (a one-dimensional boundary, condition). This is because the high sandstone permeability causes pressure draps in the pumped layer to equalize rapidly (Figure 35) so that flow in the shale aquitard is essentially one-dimensional, toward the sandstone (F1gure 36).

The reservoir depth, width, and length in the Austin Bayou conceptual model $(15,000 \mathrm{ft}, 10,500 \mathrm{ft}$, and $26,500 \mathrm{ft}$, respectively) require that a two- or three-dimensional model be used to predict surface subsidence. (In the Walrakel case study, the reservolr depth was substantially less than the lateral extent and a one-dimensional model was more reasonable.) A one-dimensional Austin Bayou model would predict a surface subsidence of 5.31 feet, equal to the compaction of the reservoir interval. The plane-strain BIEM2D program takes lateral strains into account. For the same reservolr compaction, BIEM2D predicted surface subsidence ranging from 1.67 feet over the center of the reservolr to 1.45 feet at the edge of the reservolr (Figure 37 ). The maximum subsidence predicted by the three-dimensional NFOLD program is 1.73 feet. A contour plot of NFOLD surface subsidence is presented in Figure 26. 




Each poth involves different lengths through sand and through shale.

FIGURE 34 - AUSTIN BAYOU CASE STUDY THREE-DIMENSIONAL NATURE OF FLOW

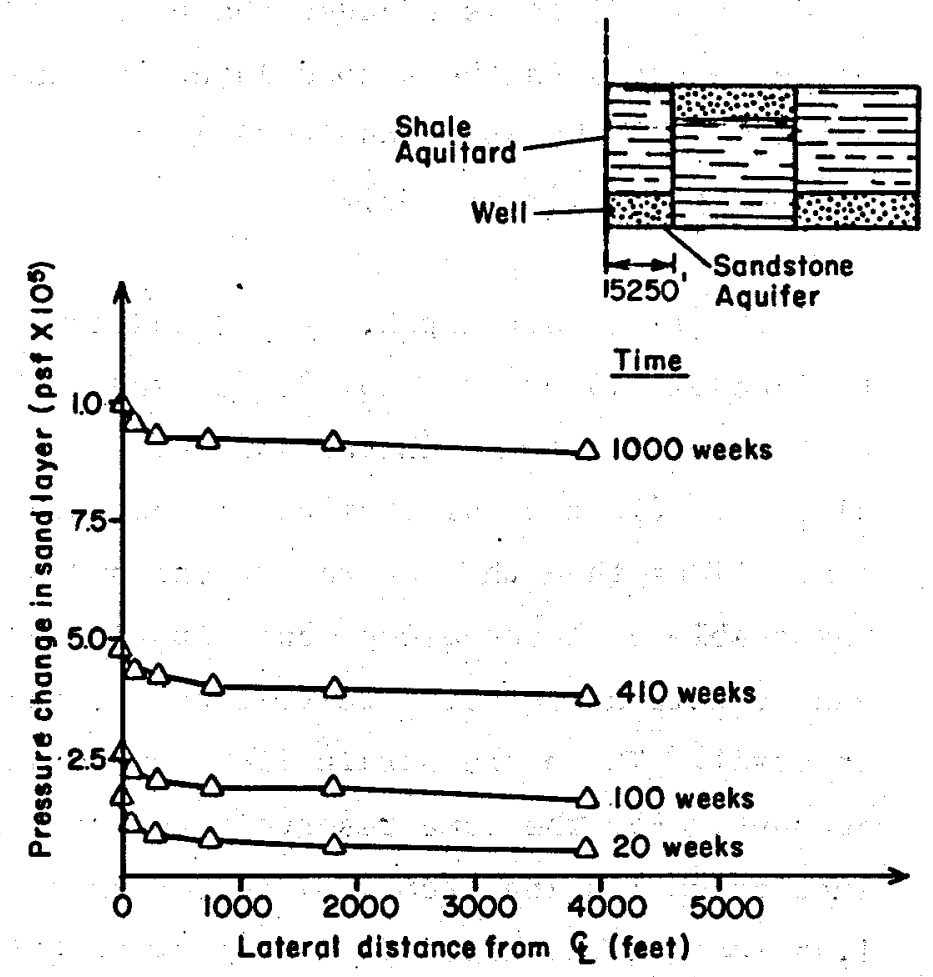

FIGURE 35 - AUSTIN BAYOU CASE STUDY CHANGE IN PORE PRESSURE IN AQUIFER WITH DISTANCE FROM WELL (AXISYMMETRIC CASE) 


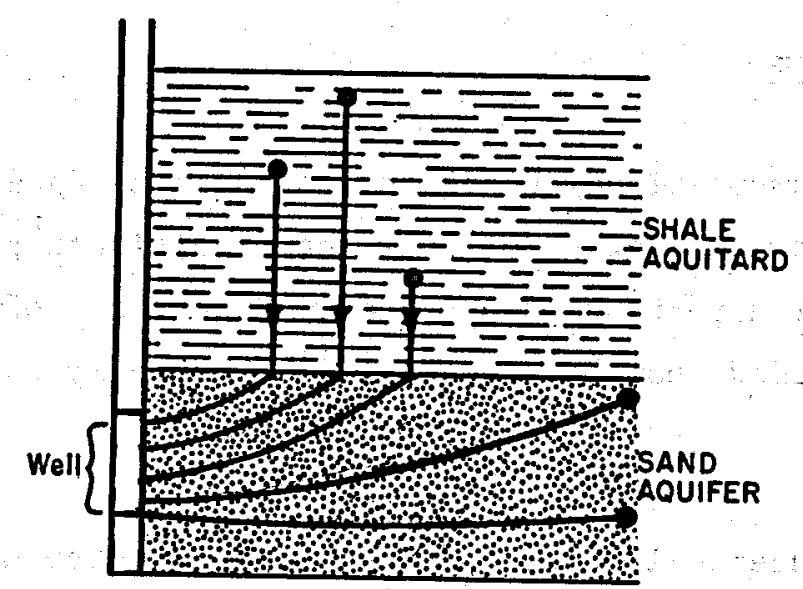

Sand acts as equipotential, causing

flow in shole to occur one dimensionally.

FIGURE 36 - AUSTIN BAYOU CASE STUDY

ONE-DIMENSIONAL FLOW IN AQUITARD DUE TO RAPID EQUALIZATION OF : PORE PRESSURE IN SANDSTONE

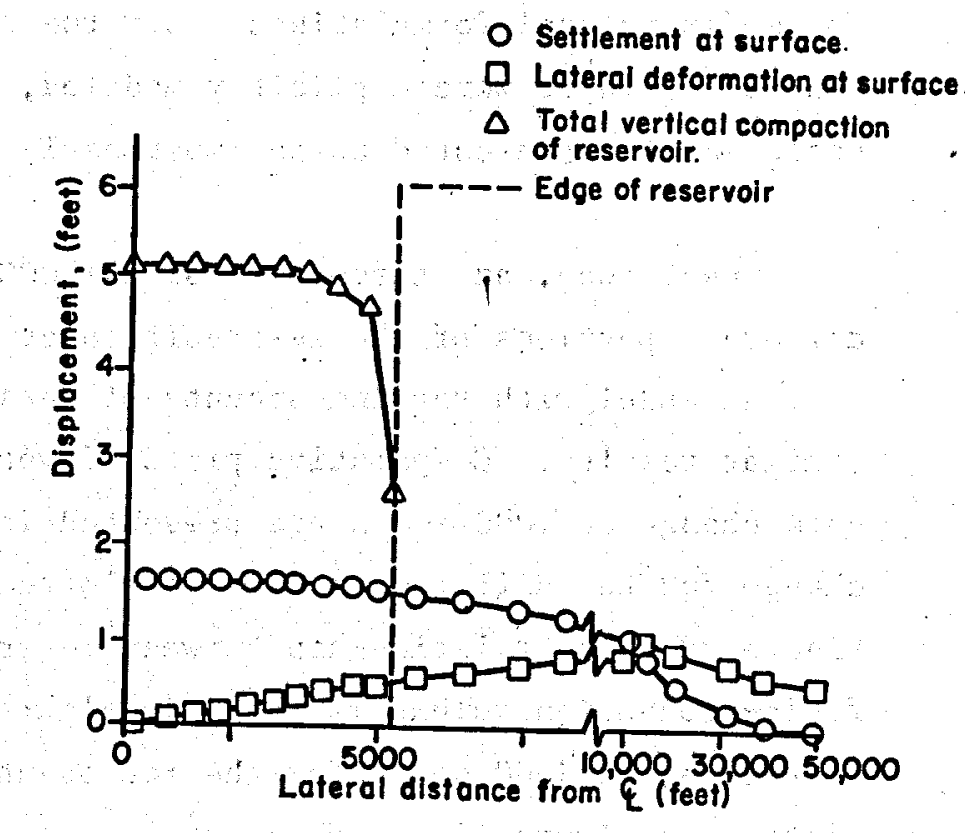

FIGURE 37 - AUSTIN BAYOU CASE STUDY

SURFACE DISPLACEMENT PREDICTED BY BIEM2D 
Modeling Portions of a System

In order to minimize computational costs and to maximize detail, it is desirable to include in a computer model only the significant portions of a system. To model a portion of a system, the effects of the regions not explicitly included must be represented as boundary conditions on the partial model.

In the Austin Bayou conceptual model, a repetitive geometry within the 2500-foot-thick reservoir interval was assumed (Figure 25). This allowed that portion of the system to be represented by a single 75foot-thick sandstone-shale unit with impermeable horizontal boundaries. From the planar flow CCC model it was found that the shale laterally adjacent to the sandstone aquifer acted essentially as an impermeable barrier. Therefore, in the CCC one-dimensional, axisymmetric, and three-dimensional formulations, only the sandstone and vertically adjacent shale layer were explicitly modeled, with the laterally adjacent shale layer represented as an impermeable vertical boundary.

One-, two-, and three-dimensional CCC models, which represented different portions of the reservolr interval of the Austin Bayou conceptual model with varying amounts of detail, were found to produce similar results. Comparative plots of vertical profiles of pore pressure change at 1000 weeks are presented in Figure 38. Pore-pressure change for the different models is plotted as a function of time in Figure 39. The relationship between reservoir interval compaction and fluid-production volume is shown in Figure 40. Horizontal profiles of compaction at 1000 weeks for the representative 75-foot-thick layer are plotted in Figure 41.

This study indicates that a simple, one-dimensional 75-foot-thick sandstone-shale layer provides a good model for the 2500-foot-thick 


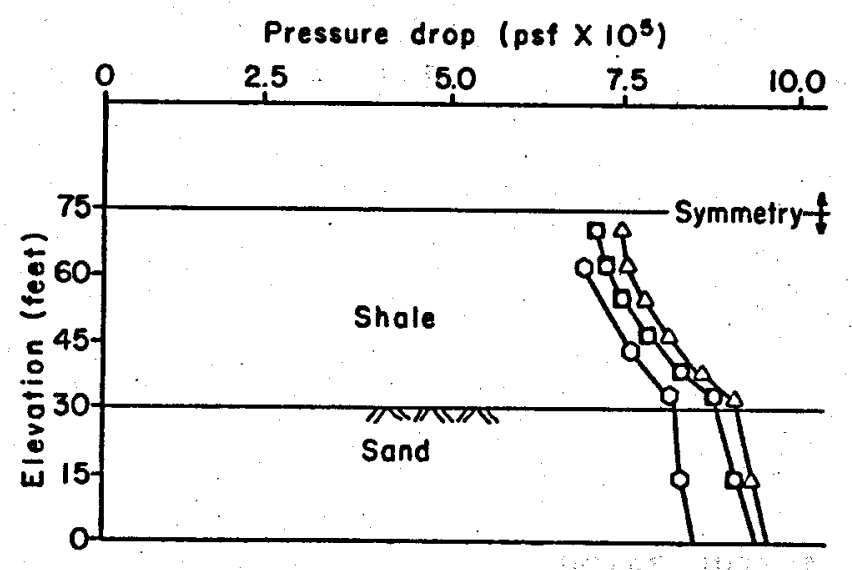

FIGURE 38 - AUSTIN BAYOU CASE STUDY PORE-PRESSURE PROFILE FOR CCC MODELS OF VARIOUS PORTIONS OF AUSTIN BAYOU SYSTEM AT 1000 WEEKS
- One dimensional
- Planar flow
$\Delta$ Axisymmetric
- Three dimensional
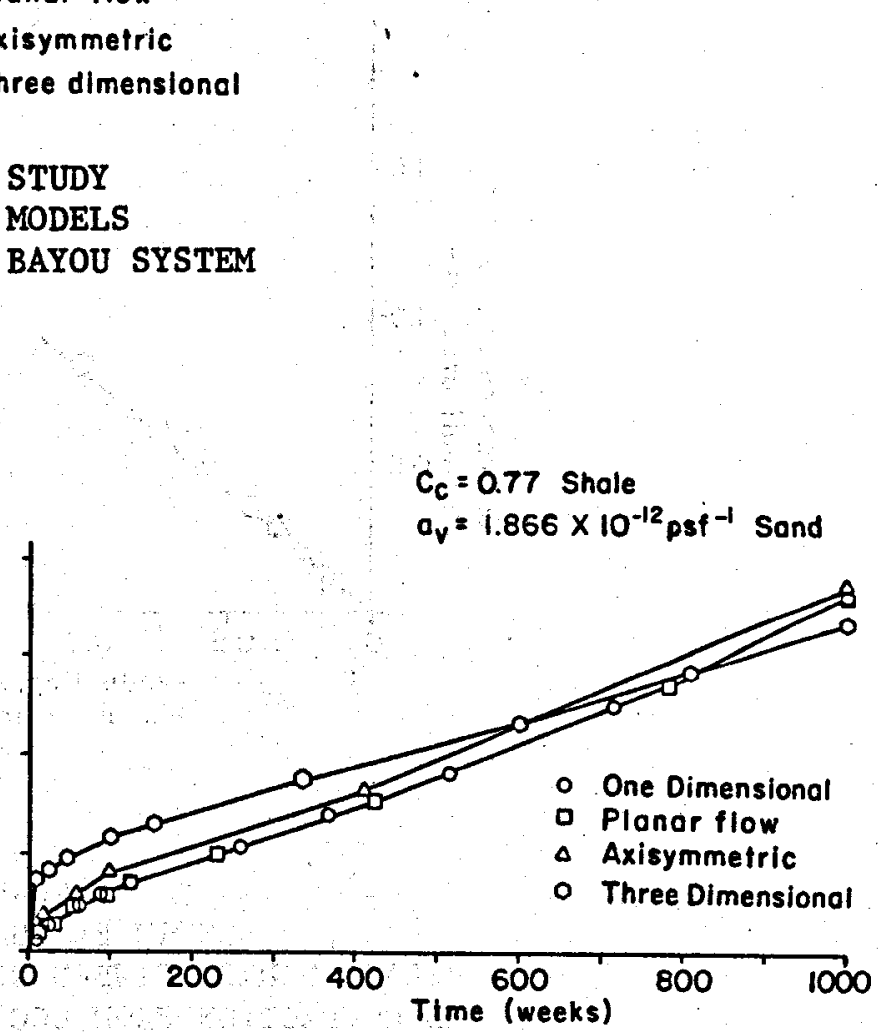

FIGURE 39 - AUSTIN BAYOU CASE STUDY PORE-PRESSURE CHANGE WITH TIME CCC MODELS OF VARIOUS PORTION OF AUSTIN BAYOU SYSTEM AT 1000 WEERS CENTER OF SAND NEAREST EDGE 


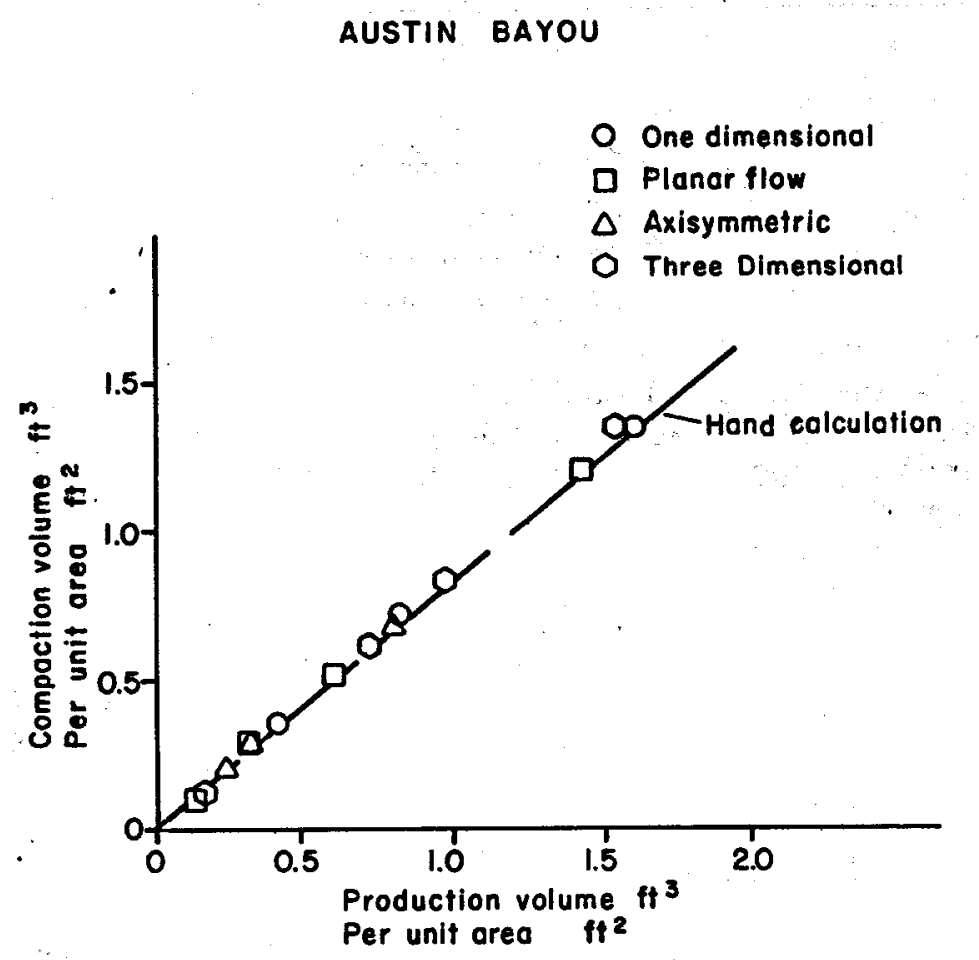

FIGURE 40

AUSTIN BAYOU CASE STUDY

RELATIONSHIP BETWEEN GEOTHERMAL PRODUCTION

AND COMPACTION FROM CCC AND HAND CALCULATIONS

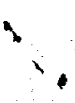




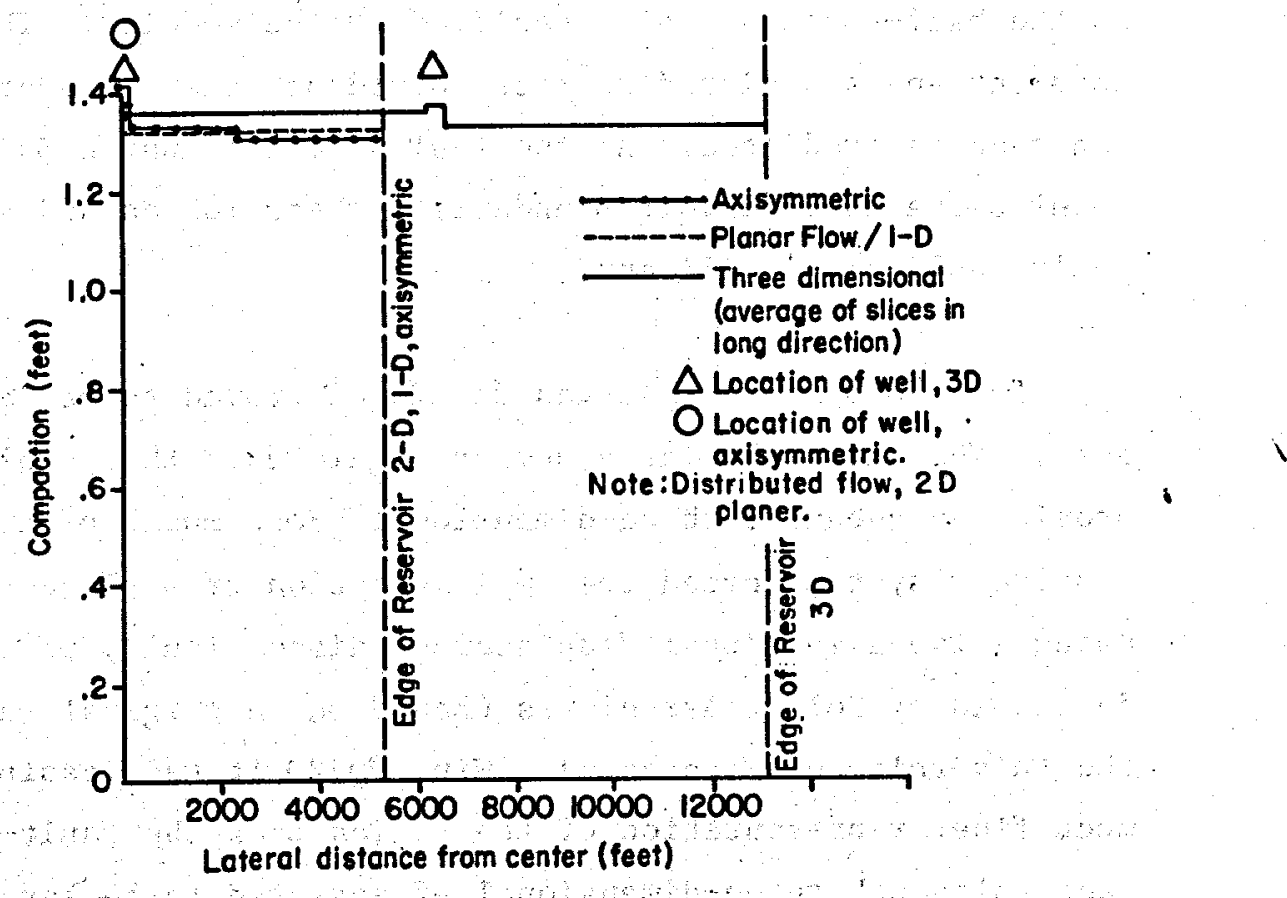

FIGURE 41

AUSTIN BAYOU CASE STUDY

COMPACTION PROFILE FROM CCC AT 1000 WEEKS

AXISYMMETRIC AND 3-D GEOMETRIES 
reservoir interval. Regions not explicitly included are well represented by boundary conditions. The use of more costly and complex models for the reservoir interval is unwarranted.

Faults

The role of faults in geothermal subsidence was explored by use of the program NFOLD. The fault position, the friction angle, the shear and normal stiffness of the fault material, and the initial stress field in the half-space are all specified by the modeler. The induced fault movement and associated surface subsidence due to reservoir compaction can then be predicted. As the faults in the Austin Bayou conceptual model serve as reservolr boundaries, shear forces and slip along the fault could be significant.

The NFOLD model that was developed proved to be inadequate, however. The extremely large number of elements that would be required to provide an adequate three-dimensional NFOLD model of the fault and reservolr system forced the implementation of a plane-strain model using a two-dimensional displacement-discontinuity program, DDJ2D, developed by Golder Assoclates (based on an original version produced at the University of Minnesota). With DDJ2D it was feasible to develop a much finer representation of the region near the fault-reservoir interface, although three-dimensional effects had to be ignored.

The DDJ2D representation of Austin Bayou is 11lustrated in Figure 42. The system was modeled with two different initial stress fields. In one case the ratio of horizontal-to-vertical total stress was 1.0 , while in the other it was taken as .94 , which corresponds to the lowest physically realizable ratio of horizontal-to-vertical effective stress. S1ip along the fault occurred in both cases. For the horizonta1-tovertical stress ratio of 1.0 , the fault slipped 2.1 feet downward above the reservolr and 2.1 feet upward below the reservoir. However, the 
region of slip extended only 120 feet vertically in each direction. For smaller normal stresses on the fault (horizontal-to-vertical stress ratio of 0.94 ), the slip was 2.3 feet at the reservoir and propogated 320 feet. In neither case did the fault slip affect surface subsidence.

The faults in the Austin Bayou conceptual model proved to be relatively unimportant. This result should not, however, be generalized to other reservolr systems. Each case must be considered separately with initial stress and fault parameters chosen to best represent the actual system.

\section{Elastic Parameter Study}

The sensitivity of the dependence of surface subsidence on elastic material properties was studied using an axisymmetric CONSOL 3 model of the entire Austin Bayou system.

The effect of varying the (drained) bulk modulus of the materials while holding the ratio of bulk to shear modulus constant at 0.75 was first determined. This amounted to changing the overall stiffness of the system while holding the drained Poisson's ratio constant at 0.2. The material properties of the surface unconsolidated layer were not varied. Material elastic properties for the three cases considered are 1isted in Table 10, and the resulting surface subsidences at 1000 weeks are shown in Figure 43. Over the center of the reservoir, the abrupt decrease in subsidence is not real, but is an artifact of the axisymmetric formulation. Although the small peak in subsidence over the edge of the reservoir may be associated with the modeling, the cause is not known. Note that for the drained bulk modulus increased by a factor of 10, the surface subsidence only decreases to 70 percent of the original value. This can be explained by the fact that the overburden materials do not drain appreciably as the reservoir is pumped and that their 
TABLE 10

PARAMETER STUDY, $K$ VARIED WITH $G / K=0.75$

\begin{tabular}{|c|c|c|c|c|c|c|}
\hline \multirow[b]{2}{*}{ MATERIAL } & \multicolumn{3}{|c|}{$\begin{array}{c}\text { BULK MODULUS } K \\
(\text { psf } \times 108) \\
\text { Case }\end{array}$} & \multicolumn{3}{|c|}{$\begin{array}{l}\text { SHEAR MODULUS } G \\
\left(\text { psf } \times 10^{8}\right) \\
\text { Case }\end{array}$} \\
\hline & 1 & 2 & 3 & 1 & 2 & 3 \\
\hline Unconsolidated Layer & & .418 & & . & .314 & \\
\hline $\begin{array}{l}65 \% \text { Shale } \\
35 \% \text { Sandstone }\end{array}$ & .267 & 1.45 & 2.62 & .200 & 1.090 & 1.97 \\
\hline $\begin{array}{l}90 \% \text { Shale } \\
10 \% \text { Sandstone }\end{array}$ & .231 & 1.27 & 2.31 & .173 & .953 & 1.73 \\
\hline $\begin{array}{l}60 \% \text { Shale } \\
40 \% \text { Sandstone }\end{array}$ & .334 & 1.83 & 3.34 & .251 & 1.370 & 2.51 \\
\hline Shale & .209 & 1.04 & 2.09 & .157 & .780 & 1.57 \\
\hline Sandstone & 3.340 & 18.40 & 33.40 & 2.510 & 13.800 & 25.10 \\
\hline
\end{tabular}






FIGURE 43

AUSTIN BAYOU CASE STUDY

COMPARISON OF SURFACE SUBSIDENCE

OBTAINED BY CONSOL3 WITH DIFFERENT VALUES

OF ELASTIC PARAMETERS, CONSTANT $\mathrm{G} / \mathrm{K}=0.75$ 
elastic behavior is dominated by the pore-fluid stiffness. Varying the drained moduli therefore causes relatively small changes to the effective stiffness of the overburden.

Three cases were then considered in which the drained bulk modulus was held constant and the shear modulus to drained bulk modulus ratio varled. This corresponds to the varying of Polsson's ratio. Again, the effective bulk modulus of the undrained overburden is actually largely due to the presence of pore fluids. The shear modulus of the materials, however, 1s not affected. The effective Polsson's ratios for the overburden for specifled Polsson's ratios of $0.1,0.2$, and 0.45 were about $0.46,0.47$, and 0.5 , respectively. The drained material properties are listed in Table 11 and the surface subsidences at 1000 weeks are plotted in Figure 44. For material relatively weak in shear $(G / K=0.10)$ the surface subsidence is quite large; for higher shear strength material, however, the subsidence, 1 s only weakly dependent on the actual $\mathrm{G} / \mathrm{K}$ value.

ReInjection of Geothermal Fluid Wastes

Reinfection of geothermal waste-water has been proposed as a solution to subsidence problems and problems of waste-water disposal. The conceptual model for Austin Bayou can be used to study waste-water reinjection without recourse to mathematical or compute models.

Compaction of the Austin Bayou reservolr has been shown to be directly related to the extraction of geothermal fluids (FIgure 40). It is therefore $\log 1 \mathrm{cal}$ to assume that reinjection of fluid will produce heave sufficlent to largely neutralize subsidence. Reinjection of fluids can be performed at different levels of the stratigraphy (Figure 45). The level at which relnjection occurs can be expected to determine its effect upon geothermal energy recovery and on subsidence. Below, we sha1l discuss several possible reinjection schemes and the insight that can be gained from the conceptual model. 


\section{TABLE 11}

PARAMETER STUDY, $K$ CONSTANT, G/K VARYING

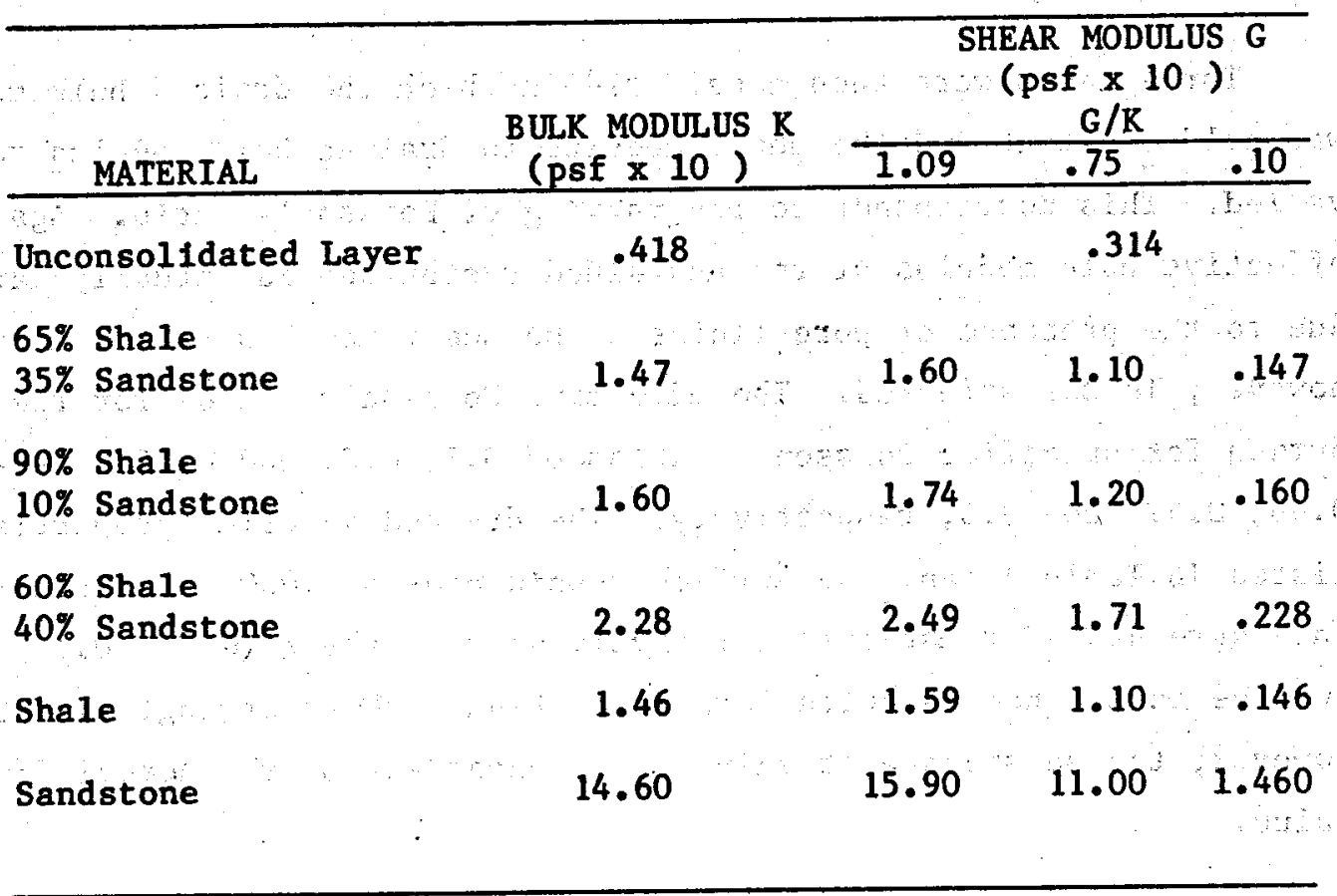




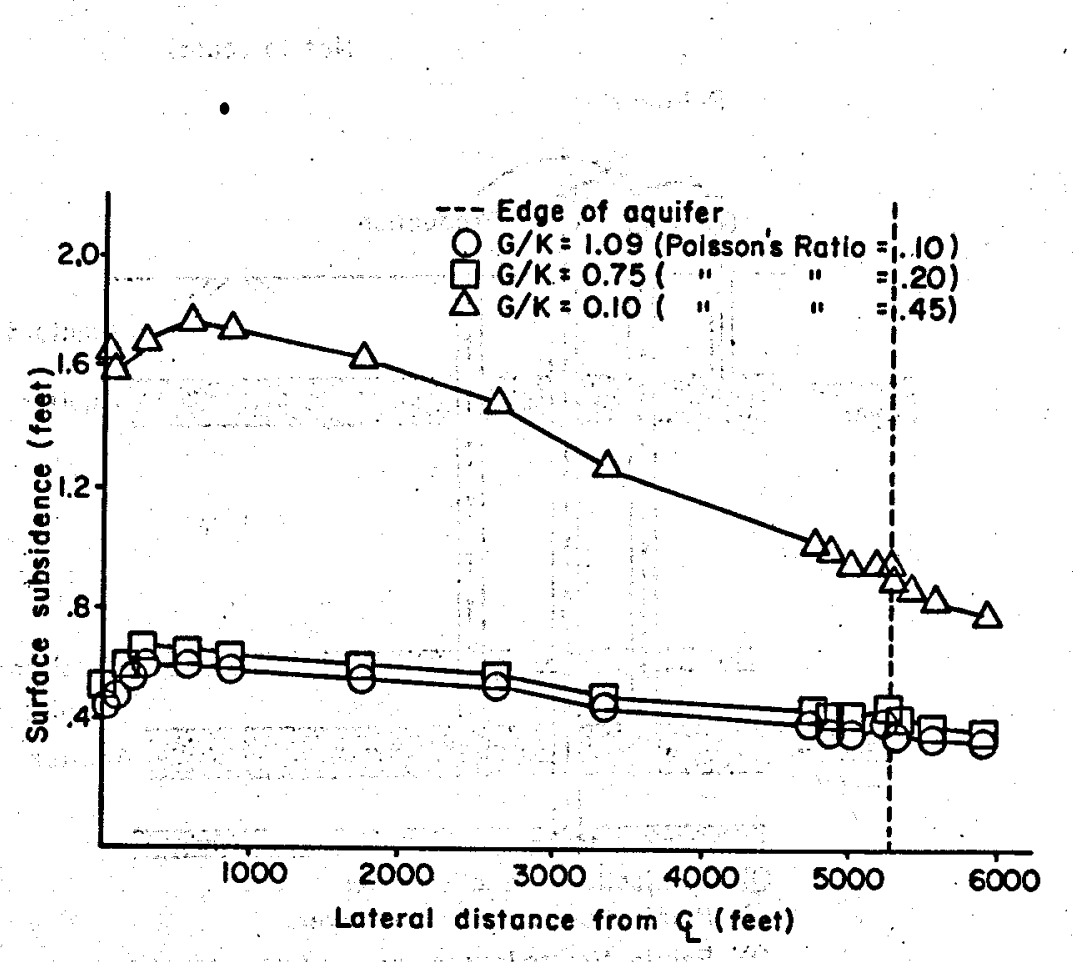

FIGURE 44

AUSTIN BAYOU CASE STUDY

COMPARISON OF SURFACE SUBSIDENCE OBTAINED WITH CONSOL3

WITH DIFFERENT VALUES OF ELASTIC PARAMETERS, $G / \mathrm{K}=1.09,0.75,0.10$ 
(Not to scole)

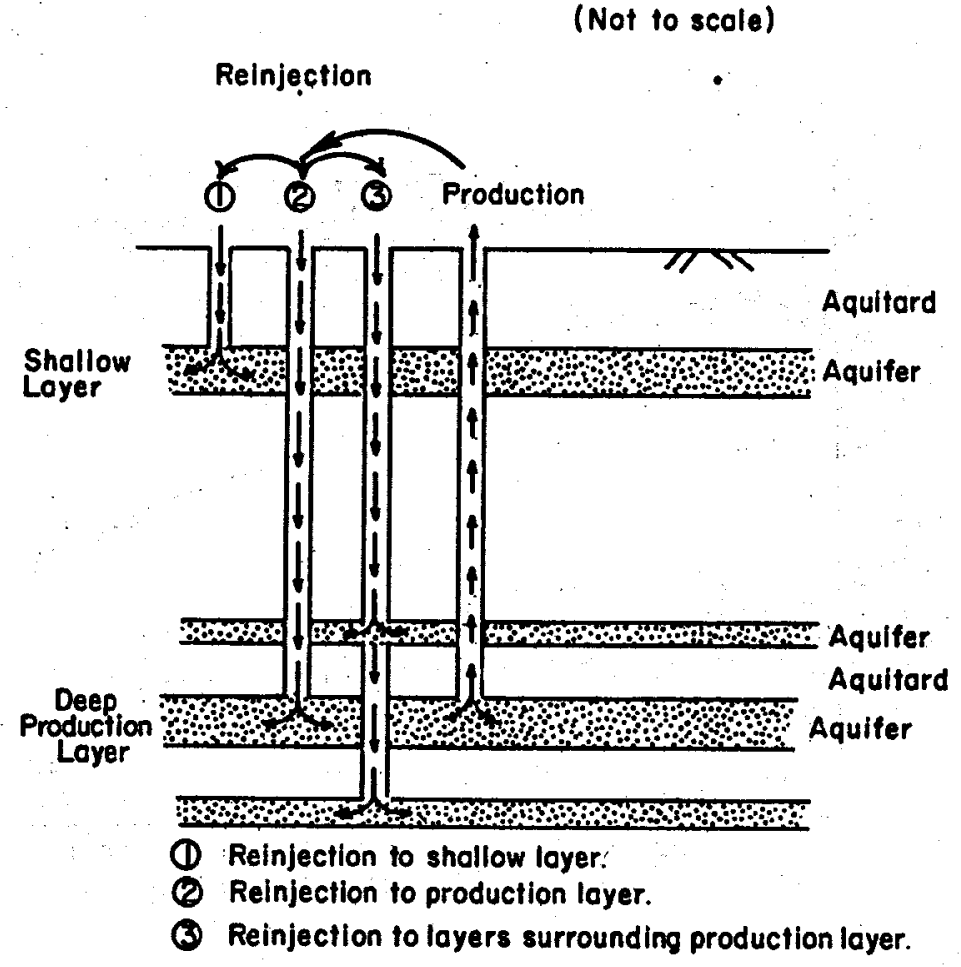

FIGURE 45

AUSTIN BAYOU CASE STUDY

REINJECTION SCHEMES FOR CONTROL

OF GEOTHERMAL SUBSIDENCE 
- Reinjection in Upper Layers

Recharge to an upper layer is attractive for several reasons. Recharge to shallow layers requires lower pumping pressure than recharge to deeper layers. In addition, the cooler recharge fluids do not decrease energy recovery because they are isolated from the production zone.

The value of recharge to shallow layers for reduction of subsidence is questionable due to the Inelastic stress-strain properties of the shale in which most deformation occurs. The production-reinjection stress-strain curve for shale is shown schematicaliy In Figure 46. Because initial reinjection volume equals production volume, subsidence is effectively neutralized by reinjection. However, as time passes, pore pressures return to their Initial values and the same net subsidence occurs as would have occurred without reinjection. In addition, the reinjection of fluids to a shallow layer may produce hydrofracturing if the pressure required to reinject exceeds the strength of the rock mass.

ReInjection In Producing Layer

Reinjection in the producing layer has the advantage that reinjected flulds can be used to force geothermal flulds out (FIgure 47). Some of the energy expended to pump in the recharge fluld is thereby recovered. In addition, recharge in the producing aquifer will completely eliminate subsidence, since no net pressure change w111 occur In the Inear elastic sandstone aquifer. However, reinjection in the sandstone aquifer will prevent extraction of fluid from the shale aquitard, as relnjected flulds will reach the well before the shales drain (Figure 36). According to our results, 90 percent of 


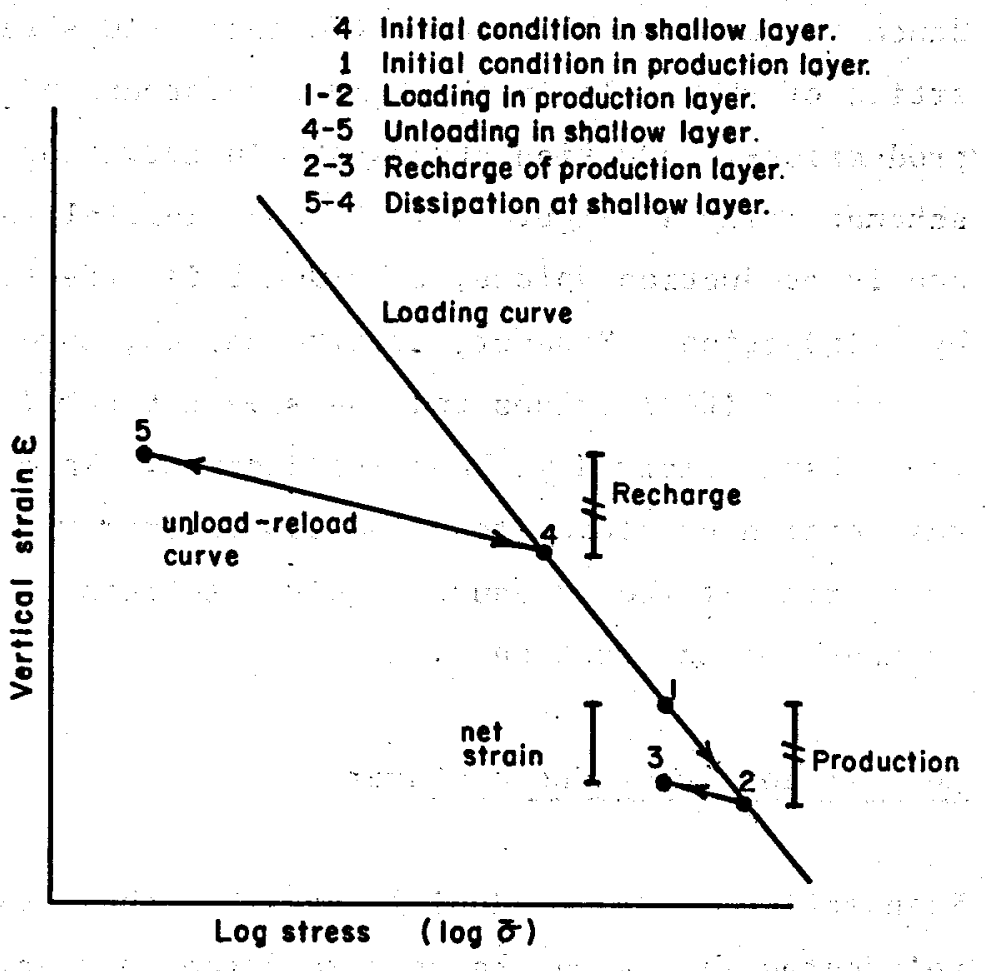

FIGURE 46

AUSTIN BAYOU CASE STUDY

NONLINEAR, INELASTIC STRESS CURVES

FOR REINJECTION INTO SHALLOW LAYERS 
the geothermal fluids at Austin Bayou are produced from the shales.

- Reinjection in Sands Above and Below the Producing Layer

Reinjection in layers above and below the producing aquifer (F1gure 48) could avoid the problems of both of the other schemes, provided there is, in fact, no high permeability connection between producing and reinjection layers. Although our conceptual model shows no connection, it is not known how well the Ideallzed geology approximates real conditions.

Provided no high permeability path exists, fluld flow can be expected to occur as diagramed in Figure 36 . No subsidence would occur. However, pressures necessary to pump into aquifers at depth may be too large ( $2 \times 10^{6} \mathrm{psf}$ ) for reinjection to be feasible.

CASE STUDY - CONCLUSIONS

- In every case, the lack of basic physical data was the limiting factor in the accuracy of the modeling.

- The basic physical processes of subsidence appear to be well understood and correctly modeled.

- The dimensionality of the model (one-dimensional, twodimensional, axisymmetric, three-dimensional) was an important factor in its suitability.

- Accurate knowledge of either the reservolr pressure and temperature drops or the rate of fluld extraction was important. 


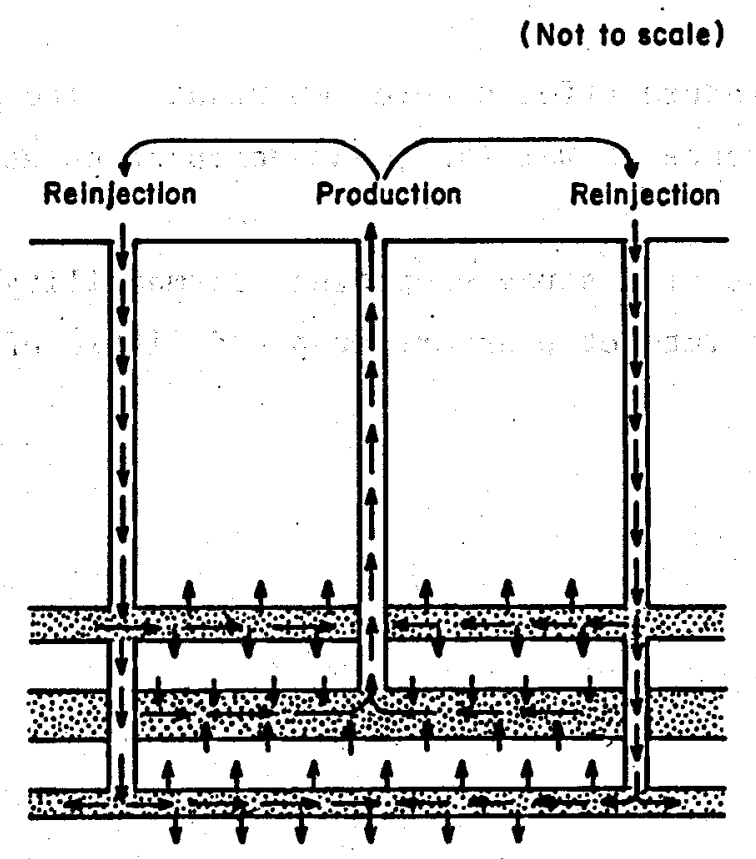

Reinjection to surrounding layers forces aquitard to drain to producing layer.

FIGURE 48

AUSTIN BAYOU CASE STUDY

REINJECTION INTO LAYERS

SURROUNDING PRODUCTION LAYERS 


\section{4}

- Accurate knowledge of stress-strain properties was of little importance at The Geysers, was somewhat important at Austin Bayou (due to nonlinearity of shale behavior), and was very Important at Walrakel.

- Depth of the reservolr compared to its extent is an important parameter in determining subsidence.

- Temperature effects were important at The Geysers, of minor Importance at Wairake1, and unimportant at Austin Bayou.

- The use of a stress-dependent permeability had a modest effect on the rate of pressure drop and little effect on compaction. 


\section{REVIEW AND RECOMMENDATIONS}

The research documented in this report attempted to find answers to the following questions:

- How adequate are existing models for estimation of land subsidence and lateral ground deformation?

- What additional development, if any, is desirable in geothermal modeling?

In the course of our research we have learned that, as discussed earlier, mathematical models cannot be evaluated without reference to the entire subsidence prediction process. The following is a review of what has been learned about subsidence models in the context of the overall prediction methodology.

OVERALL SUBSIDENCE PREDICTION PROCESS

The subsidence prediction process can be viewed as a three-stage process, as was discussed in the beginning of this report.

- Data collection and organization

- Development of conceptual model

- Implementation of mathematical flow and deformation models based on conceptual model

Error and uncertainty are introduced at each stage of the prediction process. It is important that the level of accuracy of each stage be compatible, as it is polntless to use precise models where data are only approximate. Figure 49 presents schematically our estimates of the sources of uncertainty in subsidence predictions. 


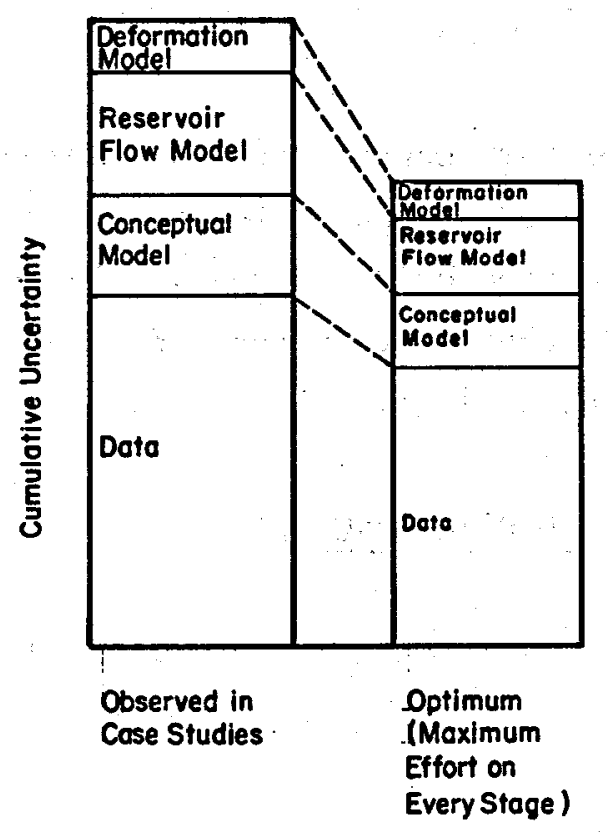

FIGURE 49

CONTRIBUTIONS TO UNCERTAINTY

OF GEOTHERMAL SUBSIDENCE PREDICTIONS 
Experience gained from the case studies Indicates that the level of error and uncertainty due to data insufficiency is considerably greater than that introduced by using even the most rudimentary of deformation models.

It is our opinion that, due to the physical impossibility of fully characterizing a subsidence system, subsidence models will never be able to predict subsidence with great precision. It is reasonable to expect to predict the general nature and magnitude of the deformations, but the prediction accuracy w11l never be great and there w111 of ten be "anomalles" such as those as Walrakel.

As a result, the sophistication of current deformation models appears to be adequate, as they do not significantly increase prediction error:

RECOMMENDATIONS

Overal1 Approach

- It appears that the development of highly sophisticated, coupled models for reservolr flow and deformation is not desirable at this time. Not only is the use of overly sophisticated models not justifled by available data, but, as was shown in the Austin Bayou case study, coupling of flow and deformations increases cost more than it does accuracy.

- Conceptual models should be developed to as great a level of sophistication as is permitted by available data. Mathematical models should be selected which are appropriate to the sophistication of the conceptual model. 
- In some cases, where production can be assumed known, reservoir flow modeling may not be necessary. This was the case at Austin Bayou.

- The level of sophistication of the model should sult the level of data available. Thus, simple hand calculations and onedimensional models are appropriate for feastibility-study computations, while more complex, multidimensional models would be justified for situations where a large body of data was avallable. It should be pointed out, however, that in all of the case studies we reviewed the data was much too limited to allow the complex models to perform measurably better than the simpler models.

- The type of model must suit the type of reservoir; onedimensional models are not suitable for irregular reservoirs, and nucleus-of-strain models are not good for shallow, extensive reservoirs.

\section{Reservolir Flow Models}

- Further theoretical development of reservoir flow models appears to be appropriate. At present, lack of adequate reservoir flow theory represents a significant limitation to prediction of the subsidence of geothermal reservoirs. Current theories have not, in general, been adequately tested. In addition, further theoretical work might be appropriate in the fields of multiphase and fracture/porous media flow. We anticipate a rapid evolution in the state-of-the-art of heat/fluid flow over the next few years. 
- Two types of mathematical models should be developed for reservolr flow:

- Models utilizing state-of-the-art theoretical developments

- Models utilizing simplifying assumptions so that they can be used by nonspecialists.

Possible simplifying assumptions include lower dimensionality, restricted physical processes, and Iimitation of calculation to static equilibrium conditions.

Deformation Models

- Current theory appears to be adequate for all practical deformation modeling problems. Although assumptions of homogeneity, 1sotropy, and Iinear elasticlty are frequently gross, they often appear to be adequate considering the level of inaccuracy introduced by lack of data.

- None of the models we reviewed considered the time-dependent nature of the material's stress-strain behavior. While this is a real phenomenon whose effects are often apparent in casehistory studies, we do not consider that its inclusion would have significantly improved our modeis.

- There is another time-dependent phenomenon which is more 1mportant. Th1s is the time-lag required for pore pressures in low-permeability/high-compressibility materlals to equilibrate. When clay beds are contained in or adjacent to a reservoir this effect could be significant. The capability to simulate this time-dependent behavior was avallable in two of the models we tested: UPDOWN and CONSOL3. 
- Somewhat to our surprise, we found that thermal contraction effects were of considerable Importance in one of the case studies (The Geysers). Fortunately, it is possible to do a simple modification of the isothermal poroelastic theory which w111 allow inclusion of thermal effects where necessary. This theory is described in Companion Repont 1 (Miller et al. 1980a).

- Much to our surprise, we found that for shallow reservoirs the surface subsidence was considerably greater than the compaction (by a factor of $2[1-v]$ ). Accordingly, it is important when doing hand calculations to use an analytical technique (such as Geertsma's disk solution) to propogate deformations to the surface.

- There is no single model which is superior to all others. We tested six different models and found that each was valuable in some situations and that none was good in all situations.

- The range of mathematical models now avallable (Table 12) is sufficient for most reservoir deformation problems. What is needed is not newer, more sophisticated mathematical models, but more usable versions of current models. Some criteria for models are as follows:

- To be avallable in the public domain

- To be well-documented both with regard to theory and to usage

- To have simplified input and automatic element generation

- To produce clear, comprehensive output and, where appropriate, feature plotting capabilities 
TABLE 12

MATHEMATICAL MODELS FOR DEFORMATION

\begin{tabular}{|c|c|c|}
\hline DIMENS IONALITY & TESTED VERSION & COMMENTS \\
\hline Hand Calculation Axisymmetric & Geertsma & $\begin{array}{l}\text {-Simple, easy to use } \\
\text {-Very useful } \\
\text {-Disk reservoir } \\
\text { solution needs } \\
\text { further development }\end{array}$ \\
\hline $\begin{array}{l}\text { Boundary Integral } \\
\text { Equation }\end{array}$ & BIEM2D & $\begin{array}{l}\text {-Simple, cheap, } \\
\text { powerful } \\
\text {-Axisymmetric } \\
\text { version would be } \\
\text { valuable } \\
\text {-BIEM2D worked well }\end{array}$ \\
\hline $\begin{array}{l}\text { Terzaghi } \quad \text { I-D } \\
\text { Consolidation }\end{array}$ & UPDOWN & $\begin{array}{l}\text {-Invaluable for } \\
\text { problems involv- } \\
\text { ing highly com- } \\
\text { pressible layers } \\
\text {-UPDOWN works well } \\
\text { for linear problems } \\
\text { poorly for non- } \\
\text { linear (e-log p) }\end{array}$ \\
\hline $\begin{array}{c}\text { Nucleus of Strain Axismmetric } \\
3-D\end{array}$ & SUBSID & $\begin{array}{l}\text {-Versatile colu- } \\
\text { tion for 3-D } \\
\text { problems } \\
\text {-Inexpensive, easy } \\
\text { to use } \\
\text {-SUBSID works well, } \\
\text { Input/output could } \\
\text { be improved }\end{array}$ \\
\hline $\begin{array}{l}\text { Displacement } \\
\text { Discontinuity }\end{array}$ & NFOLD & $\begin{array}{l}\text {-Only feasible } \\
\text { method for } \\
\text { modeling faults in } \\
\text { 3-D } \\
\text { - Less expensive } \\
\text { than 3-D finite, } \\
\text { but still expensive } \\
\text { - NFOLD needs fur- } \\
\text { ther development. }\end{array}$ \\
\hline
\end{tabular}


TABLE 12 (Cont.)

\begin{tabular}{|c|c|c|c|}
\hline TYPE OF MODEL & DIMENSIONALITY & TESTED VERSION & COMMENTS \\
\hline $\begin{array}{l}\text { Finite Element } \\
\text { (Nonlinear) }\end{array}$ & 3-D & None & $\begin{array}{l}\text {-Essentlal for } \\
\text { Inhomogeneous/ } \\
\text { nonilnear problems } \\
\text {-Moderately expen- } \\
\text { sive, difficult to } \\
\text { use } \\
\text {-CONSOL3 has many } \\
\text { drawbacks, improved } \\
\text { program suggested }\end{array}$ \\
\hline $\begin{array}{l}\text { Finite E1ement } \\
(3-D)\end{array}$ & 3-D & None & $\begin{array}{l}\text {-Method useful in } \\
\text { complex situations } \\
\text {-Expensive } \\
\text { - Usable version } \\
\text { needs to be } \\
\text { developed }\end{array}$ \\
\hline
\end{tabular}


- To have improved efficiency

- To allow Increased flexibility by incorporating a variety of current techniques in a single model.

Avallabllity in the public domain might be facilitated by development of a public library of well-documented mathematical models. 
154 


\section{REFERENCES}

Assens, G.E. (1976). "Derivation, by Averaging, of the Equations of Heat, Mass and Momentum Transfer in a Geothermal Reservoir," Summaries Second Workshop Geothermal Reservoir Engineering, Stanford University, Stanford, California, No. 5-7, December.

Atherton, R.W. et al. (1976). "The Analysis of Subsidence Associated With Geothermal Development" (3 vol.), Systems Control, Inc.

Bolton, R.S. (1970). "The Behavior of the Walrakel Geothermal Field During Exploitation," Proc. U.N. Symposium on the Development and Utilization of Geothermal Resources, Pisa, Geothermics Special Issue 2, pp. 1426-1449.

Borsetto, M., G. Carradori, and R. RAbacchi (1979a). "Thermal Effects in Well Testing for Geothermal Purpose," presented at the Int. Conf. on Num. Meth, In Thermal Problems, Swansea, Wales.

(1979b). "On the Coupling Between Heat and Mass Transfer and Stress Flelds in Rocks," presented at the Int. Conf. on Num. Meth. In Thermal Problems, Swansea, Wales.

Brigham, W.E., and W.B. Morrow (1974). "P/Z Behavior for Geothermal Steam Reservolrs," SPE 4899, presented at 44th Annual California Regional Meeting of SPE, San Franc1sco, California, Apr11.

Brownel1, D.H., Jr., S.K. Garg, and J.W. Pritchett (1975). "Computer Simulation of Geothermal Reservoirs," SPE 5381, presented at the 45 th Annual Calffornia Regional Meeting of the Soclety of Petrol. Engineers of AIME, Ventura; California.

Coats, K.H. (1974). "Simulation of Steamflooding with Distillation and Solution Gas," SPE 5015, presented at the 19th Annual Fall Meeting of Soc. Petrol. Engineers, Houston, Texas, October.

(1977). "Geothermal Reservoir Modelling," SPE 6892, presented at the 52nd Annual Fall Technical Conference and Exhibition of the Soc. of Petro1. Englneers, Denver, Colorado, October.

Crouch, S.L. (1976). Analysis of Stresses and Displacements Around Underground Excavations: An Application of the Displacement Discontinuity Method. Dept. of Civil and Mineral Engineering, University of Minnesota.

Crouch, S.L., and C. Fairhurst (1973). "The Mechanics of Coal Mine Bumps and the Interaction Between Coal Pillars, Mine Roof, and Floor," Final Report, USBM Research Contract H0101778. 
Faust, C.W. (1976). "Numerical Simulation of Fluid Flow and Energy Transport in Liquid- and Vapour-Dominated Hydrothermal Systems," Ph.D. dissertation, Pennsylvania State University, University Park, Pennsylvania.

Faust, C.R., and J.W. Mercer (1975). "Mathematical Modelling of Geothermal Systems," Proc. 2nd U.N. Sympostum on the Development and Use of Geothermal Resources, Vol. 3, P. 1633 .

(1977a). "Finite-Difference Model of Two-Dimensional Single- and Two-Phase Heat Transport in a Porous Medium - Version I," U.S. Geological Survey Open-File Report 77-234.

(1977b). "Theoretical Analysis of Fluid Flow and Energy Transport in Hydrothermal Systems," U.S. Geological Survey Open-File Report 77-60.

(1979a). "Geothermal Reservoir Simulation I: Mathematical Models for Liquid- and Vapour-Dominated Hydrothermal Systems," Water Resources Research, Vo1. 15, pp. 23-30.

(1979b). "Geothermal Reservoir Simulation II: Numerical Solution Techniques for Liquid- and Vapour-Dominated Hydrothermal Systems," Water Resources Research, Vol. 15, pp. 31-46.

Gambolati (1972). "A Three-Dimensional Model to Compute Land Subsidence," Bulletin of the Int. Assoc. of Hydrological Sclences, Vol. 17, No. 17, pp. 219-227.

Garg, S.K., J.W. Pritchett, and D.H. Browne11, Jr. (1975). "Transport of Mass Energy in Porous Media," Proc. 2nd U.N. Symposium on Development and Use of Geothermal Resources, Vol. 3, p. 1651.

Garg, S.K., J.W. Pritchett, M.H. Rice, and T.D. Riney (1977). U.S. Gulf Coast Geopressured Geothermal Reservoir Simulation, work performed under U.S. Energy Research and Dev. Adm. contract $E(40-1)-5040$ for the University of Texas, Austin.

Garrison (1972). "Geothermal Steam in The Geysers - Clear Lake Region, California," Geological Society of America Bulletin, Vol. 83, pp. 1449-1468.

Geertsma, J. (1973). "Land Subsidence Above Compacting 011 and Gas Reservoirs," SPE 3730, Journal of Petroleum Technology.

Goodier, J. (1937). "On the Integration of Thermal-Elastic Equations," Phil. Mag., Vol. 23, p. 1017. 
Grimsrud, P.G., B.C. Turner, and P.A. Frame (1978). Case Histories of Subsidence Areas Catagory 1, Project 1, prepared for Lawrence Berkeley Laboratory, University of California, Berkeley.

Grindley, G.W. (1965). The Geology, Structure and Exploitation of the Wairakel Geothermal Fleld, Taupo, New Zealand, DSIR Bull. n.s. 75.

Grover, M.K. et al. (1977). Evaluation of Geothermal Energy Exploration and Resource Evaluation - Final Report., Vol. 1: "A Review of Geothermal Subsidence Modeling," R\&D Assoclates (P.0. Box 9695, Marina De1 Rey, California).

He1m, D.C. (1975). "One-Dimensiona1 Simulation of Aquifer System Compacting Near Pixley, Calffornla: Constant Parameters," Water Resources Research, Vol. II, No. 3, June.

Hendrickson, R.R. (1976). "Tests of Cores from the Walrakel Geothermal "Project, Wairake1, New Zealand," Geohydrological Environmental Effects of Geothermal Power Production, Phase IIA, Systems Science and Software, La Jolla, Callfornia.

Hoek, E., and E.T. Brown (1980?). Underground Excavation Engineering. To be published by the Institution of Minfing and Metallurgy, London, England.

Huyakorn, P.S., and G.F. PInder (1977). "A Pressure-Enthalpy Finite Element Model for Simulating Hydrothermal Reservolrs," in Advances in Computer Methods for Partial Differential Equations II, R. Vichnevetsky (ed.), IMACS, p. 284 .

Lasseter, T.J. (1975). "SHAFT: A Computer Program for the Numerical Simulation of Heat and Mass Transfer in Multidimensional Two-Phase Geothermal Reservolrs," preliminary report by Geonuclear Nobel Paso, Geneva, Switzerland, to the Lawrence Berkeley Laboratory, University of California, Berkeley.

1.. Lasseter, T.J,, P.A. Witherspoon, and M.J. Lippmann (1975). "The Numertcal Simulation of Heat and Mass Transfer in Multidimensional -Two-Phase Geothermal Reservoirs," Proc. 2nd U.S. Symposium on Development and Use of Geothermal Resources, Vol. 3, p. 1715.

Lew1s, R.W., and B.A. Schrefler (1978). "A Fully Coupled Consolidation Model of the Substdence of Venice," Water Resources Research, Vo1. 14, No. 2, April.

- Lipman, S.C., C.J. Strobe1, and M.S. Gulat (1977). "Reservo1r Performance of The Geysers Field." Presented at Larderello Workshop on Geothermal Assessment, Larderello, Italy. 
Lippmann, M.J., T.N. Narasimhan, and P.A. Witherspoon (1977). "Modeling Subsidence due to Geothermal Fluid Production," ASCE Fall Convention, October.

Mercer, J.W., and C.R. Faust (1979). "Geothermal Resource Simulation: Application of Liquid and Vapor Dominated Hydrothermal Modeling Techniques to Wairakei, New Zealand," Water Resources Research, Vol. 15, No. 3, pp. 653-671.

Miller, I.W., W. Dershowitz, K. Jones, L. Meyer, K. Roman, and M. Schauer (1980a). "Companion Report 1, Physical Processes of Compaction." Companion report to "Simulation of Geothermal Subsidence" by I. Miller et al., prepared for Lawrence Berkeley Laboratory, University of California, Berkeley, LBID 182.

(1980b). "Companion Report 2, Detailed Report on Tested Models." Companion report to "Simulation of Geothermal Subsidence" by I. Miller et al., prepared for Lawrence Berkeley Laboratory, University of California, Berkeley, LBID 183.

(1980c). "Companion Report 3, Case Study Data Base." Companion report to "Simulation of Geothermal Subsidence" by I. Miller et al., prepared for Lawrence Berkeley Laboratory, University of California, Berkeley, LBID 184.

Mindlin, R., and D. Chen (1971). "Thermo-Elastic Stresses in the Semi-Infinite Solid," Journal of Applied Physics, p. 931.

0'Ne111, K. (1977)." "The Transient Three-Dimensional Transport of Liquid and Heat in Fractured Porous Media," Ph.D. dissertation, Dept. of Civil Engineering, Princeton University.

Pinder, G.F. (1979). "State-of-the-Art Review of Geothermal Reservoir Modelling," prepared for Lawrence Berkeley Laboratory, University of California, Berkeley, LBL 9093, Subsidence Series 5.

Pritchett, J.W. (1975). "Numerical Calculation of Multiphase Fluid and Heat Flow in Hydrothermal Reservoirs," Workshop on Geothermal Reservoir Engineering, P. Kruger and H. J. Ramey, Jr. (eds.), Geothermal Report SGP-TR-12, Stanford University, Stanford, California, p. 201.

Pritchett, J.W., S.K. Garg, D.H. Brownell, Jr., L.F. Rice, M.H. Rice, T.D. Riney, and R.R. Hendrickson (1976). Geohydrological Environmental Effects of Geothermal Power Production - Phase IIA, Systems, Science and Software, Report SSS-R-77-2998, La Jolla, California. 
Pritchett, J.W., L.F. Rice, and S.K. Garg (1978)." "Reservoir Eng1neering Data; Wairake1, Goethermal Field, New Zealand," Systems, Sclence and Software, Report SSS-R-78-3597-I (Draft), La Jolla, California.

Schrefler, B.A., R.W. Lewis, and V.A. Norris (1977). "A Case Study of the Subsurface Subsidence of the Palezone Area," Int. J. for Num. and Analytical Method In Geomechanics, Vol. 1, pp. 377-386.

Sinha, Krishna P. (1979). "Displacement Discontinuity Technique for Analyzing Stresses and Displacements Due to Mining in Seam Deposits," Ph.D. Thesis, University of Minnesota, Minneapolis.

Thomas, L.K., and R. Pierson (1976). "Three Dimensional Geothermal Reservoir Simulation," SPE 6104, presented at the 51st Annual Fall Technical Conference and Exhibition of the Society of Petroleum Engineers of AIME, New Orleans.

Toronyi, R.M. (1974). "Two-Phase, Two-Dimensional Simulation of a Geothermal Reservoir and the Wellbore System," Ph.D. Dissertation, Pennsylvania State University, Pennsylvania.

Toronyi, R.M., and S.M. Farouq-Al1 (1975). "Two-Phase, Two-Dimensional Simulation of a Geothermal Reservolr and the Wellbore System," SPE 5521, presented at the 50th Annual Fall Meeting of the Soc. Pet. Eng., AIME, Dallas, Texas.

Truesdale, A.H., and D.E. White (1973). "Production of Superheated Steam From Vapor Dominated Geothermal Reservoirs," Geothermics, Vol. 2, No. 2-4.

U.S. Bureau of Mines (1953). "Physical Properties of Some Typical Foundation Rocks," U.S. Bureau of Reclamation, Concrete Laboratory Report SP-39, Denver, Colorado.

Voss, C.I. (1978). "Finite Element Simulation of Multiphase Geothermal Reservolrs," Ph.D. Dissertation, Dept. of Clvil Engineering, Princeton University, Princeton, New Jersey.

Weinstein, H.G., J.A. Wheller, and E.G. Woods (1974). "Numerical Model for Steam Simulation," SPE 4759, presented at the Improved 011 Recovery Symposium of Soc. Petrol. Englneers, Tulsa, Oklahoma.

Whiting, R.L., and H.J. Ramey, Jr. (1969). "Application of Material and Energy Balances to Geothermal Steam Production," Jour. Petrol: Tech., p. 893. 
Wuerker, R.G. (1963). "Annotated Tables of Strength and Elastic Properties of Rocks," Society of Petroleum Engineers of AIME, Dallas, Texas. 